\title{
Expression of the Clifednamide Biosynthetic Pathway in Streptomyces Generates 27,28- seco-Derivatives
}

Yu-Jie Jiao, ${ }^{\dagger, \perp}$ Yan Liu,,$^{+, \perp}$ Hao-Xin Wang, ${ }^{\ddagger}$ De-Yu Zhu, ${ }^{\S}$ Yue-Mao Shen, ${ }^{\dagger}$ and YaoYao $\mathrm{Li}^{*},+$

†Key Laboratory of Chemical Biology of Ministry of Education, School of Pharmaceutical Sciences, Cheeloo College of Medicine, Shandong University, Jinan 250012, China

"State Key Laboratory of Microbial Technology, Shandong University, Qingdao 266237, China

${ }^{\S}$ School of Basic Medical Sciences, Cheeloo College of Medicine, Shandong University, Jinan 250012, China 
Table S1. Deduced functions of ORFs in the cfts023 gene cluster.

\begin{tabular}{|c|c|c|c|c|}
\hline ORF & $\begin{array}{l}\text { Amino } \\
\text { acids }\end{array}$ & Blastp Homologue & $\begin{array}{l}\text { \% Identity/ } \\
\text { similarity }\end{array}$ & Accession number \\
\hline Orf1 & 509 & MFS transporter & $99 / 99$ & WP 051755296.1 \\
\hline Orf2 & 345 & AsnC family transcriptional regulator & $100 / 100$ & WP_082558364.1 \\
\hline $\mathrm{CftE}$ & 292 & fatty acid hydroxylase family protein & $99 / 100$ & WP_082558363.1 \\
\hline CftB & 3180 & $\begin{array}{l}\text { hybrid non-ribosomal peptide synthetase/type I } \\
\text { polyketide synthase }\end{array}$ & $99 / 99$ & WP_078879927.1 \\
\hline CftA & 419 & cytochrome P450 & 99/99 & WP_030393627.1 \\
\hline $\mathrm{CftC}$ & 608 & NAD(P)/FAD-dependent oxidoreductase & 96/96 & WP_078896112.1 \\
\hline CftD & 352 & NADP-dependent oxidoreductase & 99/99 & WP- 043466673.1 \\
\hline Orf3 & 193 & TrmH family RNA methyltransferase & $99 / 100$ & WP_030393624.1 \\
\hline Orf4 & 214 & methyltransferase domain-containing protein & $100 / 100$ & WP_045937686.1 \\
\hline
\end{tabular}


Table S2. Plasmids and primers used in this study.

\begin{tabular}{|c|c|}
\hline \multicolumn{2}{|l|}{$\begin{array}{l}\text { Plasmids } \\
\text { Primers }\end{array}$} \\
\hline Plasmids & Description \\
\hline pSET5035 & $\begin{array}{l}\text { Derived from pSET152 by shortening the origin of transfer site (oriT) and the } \\
\text { multiple cloning site }\end{array}$ \\
\hline pUC-KT & Derived from pUC18 by insertion of two convergent promotes kasOp*/tcp830p \\
\hline pUC-EE & Derived from pUC18 by insertion of two convergent promotes ermEp*/erm21p \\
\hline Primers & Sequence of oligos $\left(5^{\prime}-3^{\prime}\right)$ \\
\hline \multicolumn{2}{|c|}{ For screening of fosmid library } \\
\hline S023LF: & CGCGGATCCCATATGACGGATTCCCGCTTCGT \\
\hline S023LR: & ATTACTAGTCCAGGCCACCTCCAGCAGTTT \\
\hline S023RF: & ATTAGATCTGGCTCGAACTGGGC \\
\hline S023RR: & CGCGAATTCAGACCTCGACCAGCACCTTG \\
\hline \multicolumn{2}{|c|}{ For construction of clifednamides expression constructs } \\
\hline capS02301-F: & GGGCAAGGTGCTGGTCGAGGTCTGAACTAGTAATGCATAACTGCAGGCG \\
\hline capS02301-R: & AGGTGACGAAGCGGGAATCCGTCATAACTCCCCCAGTCCTGCACG \\
\hline capS023SD-F: & GCGCTCCCCGACCGGCACCACCTGAACTAGTAATGCATAACTGCAGGCG \\
\hline capS023SD-R: & GCACGGTTCGAAGCCGCTTGCCCATATGTCCGCCTCCTTTGGTCG \\
\hline spect-cftD-F & $\begin{array}{l}\text { GAGGACAGCGAGAACGTGCAGACGGGAGCCCTGGCATGATGTAGGCTG } \\
\text { GAGCTGCTTC }\end{array}$ \\
\hline spect-cftD-R & $\begin{array}{l}\text { CAGTGAGCGAGGAAGCGGAAGAGCGCCTGCATTACTAGTATTCCGGGGA } \\
\text { TCCGTCGACC }\end{array}$ \\
\hline \multicolumn{2}{|c|}{ For verification of recombinant strains } \\
\hline 5035 -seqF & TCGATGTAGGAGGGCGTGGAT \\
\hline S023-verR & GGCCGCTGATGCCGAAGAA \\
\hline
\end{tabular}


a)

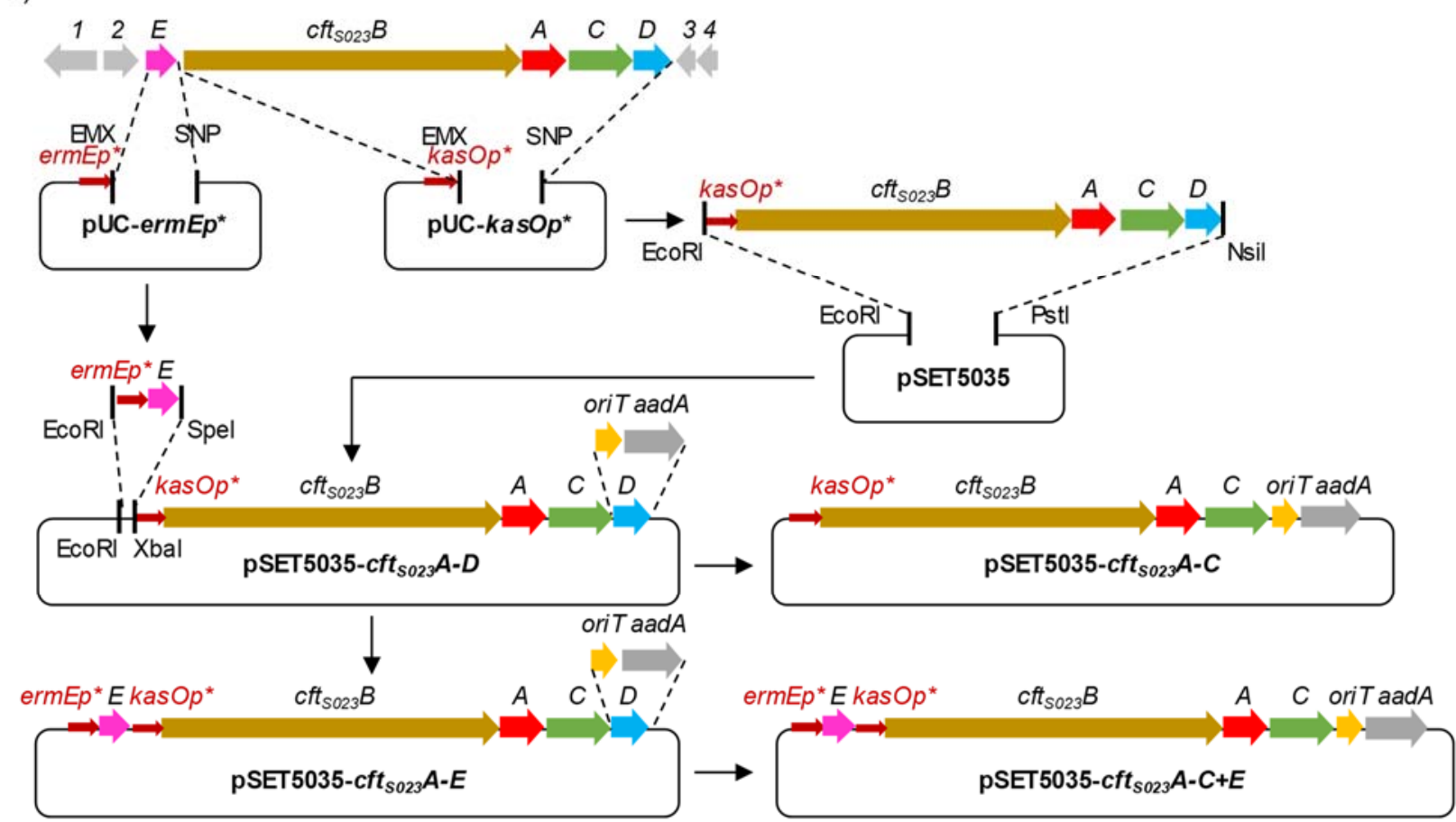

b)
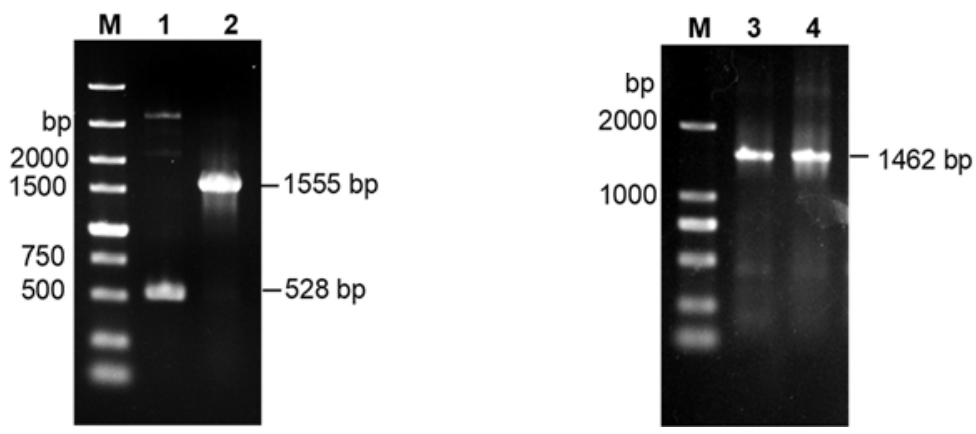

Figure S1. (a) Strategy for constructing the clifednamides expression vector for the production of clifednamides in Streptomyces sp. S001. EMX, EcoRI/Mfel/Xbal; SNP, Spel/Nsil/Pstl. (b) The verification of recombinant strains by PCR amplification. M, DNA marker (DL5000 or DL2000); 1, S001-cfts023A-D (528 bp expected); 2, S001-cftso23A-E (1555 bp expected); 3, S001-cftso23A-C (1462 bp expected); 4, S001cftso23A-C+E (1462 bp expected). 

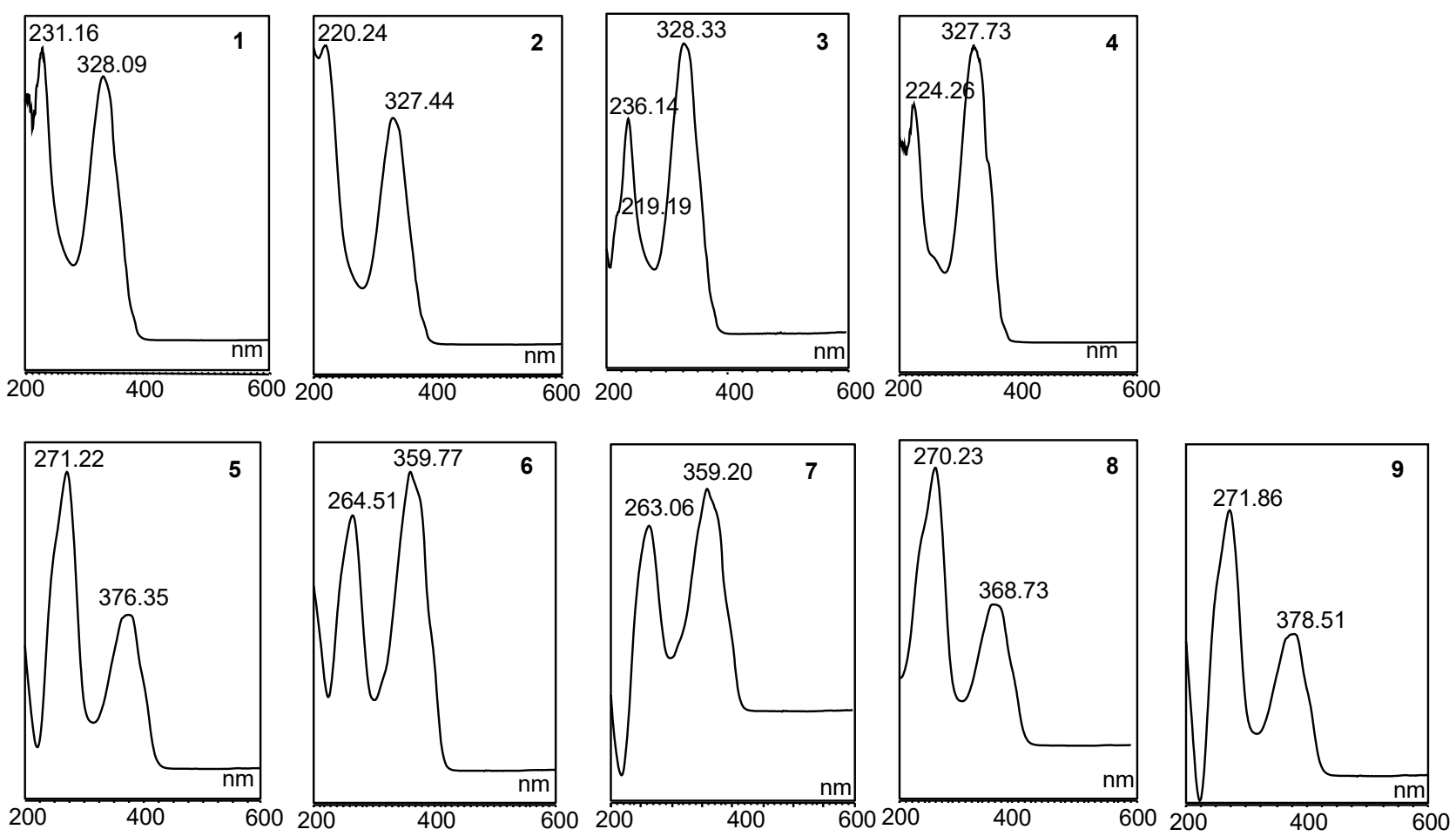

Figure S2. UV-Vis spectra of compounds 1-9. 

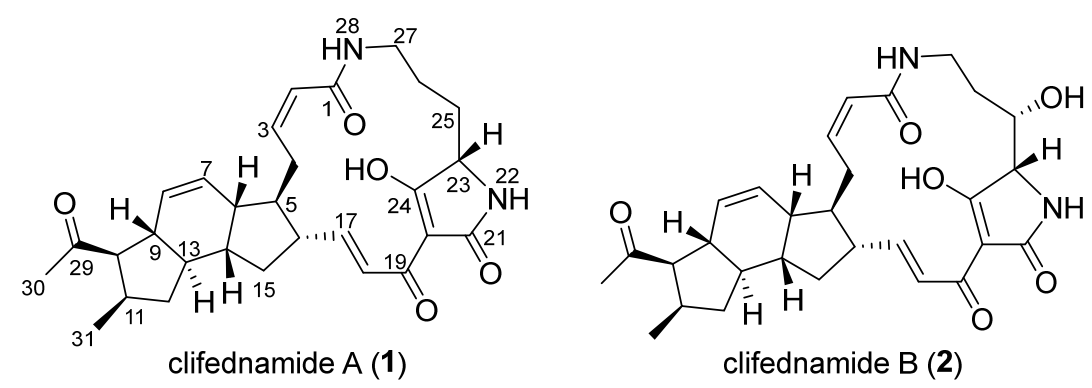

Figure S3. The chemical structures of $\mathbf{1}$ and 2.

Table S3. The NMR date of 1 and 2 in pyridine- $d_{5}$ (at $400 \mathrm{MHz}, \delta$ in ppm, $J$ in $\mathrm{Hz}$ ).

\begin{tabular}{|c|c|c|c|c|}
\hline \multirow[b]{2}{*}{ No. } & \multicolumn{2}{|l|}{1} & \multicolumn{2}{|l|}{2} \\
\hline & ${ }^{1} \mathrm{H}$ & ${ }^{13} \mathrm{C}$ & ${ }^{1} \mathrm{H}$ & ${ }^{13} \mathrm{C}$ \\
\hline 1 & & $166.8 \mathrm{~s}$ & & $166.6 \mathrm{~s}$ \\
\hline 2 & $6.27(\mathrm{~d}, 11.6)$ & $125.2 d$ & $6.23(\mathrm{~d}, 11.3)$ & $124.9 d$ \\
\hline 3 & $5.98(t, 11.1)$ & & $5.99(\mathrm{t}, 11.2)$ & $139.5 d$ \\
\hline \multirow[t]{2}{*}{4} & 4.18-4.07 (m) & $25.4 \mathrm{t}$ & $4.30-4.19(\mathrm{~m})$ & $25.2 \mathrm{t}$ \\
\hline & $2.55-2.46(\mathrm{~m})$ & & $2.53-2.43(\mathrm{~m})$ & \\
\hline 5 & $1.43-1.36(\mathrm{~m})$ & $48.7 d$ & $1.52-1.44(\mathrm{~m})$ & $48.7 d$ \\
\hline 6 & $2.46-2.38(\mathrm{~m})$ & $42.5 d$ & $2.48-2.42(\mathrm{~m})$ & $42.9 d$ \\
\hline 7 & $5.68(\mathrm{br} \mathrm{d}, 9.8)$ & $129.0 d$ & 5.69 (br d, 9.7) & $128.8 d$ \\
\hline 8 & $5.83(\mathrm{br} \mathrm{d}, 9.8)$ & $129.9 d$ & $5.86-5.80(\mathrm{~m})$ & $130.0 d$ \\
\hline 9 & $2.49-2.39(\mathrm{~m})$ & $43.0 \mathrm{~d}$ & $2.48-2.43(\mathrm{~m})$ & $42.9 \mathrm{~d}$ \\
\hline 10 & $2.69(\mathrm{t}, 11.0)$ & $58.7 d$ & $2.71(t, 10.8)$ & $58.6 \mathrm{~d}$ \\
\hline 11 & $2.57-2.49(\mathrm{~m})$ & $33.5 d$ & $2.59-2.52(\mathrm{~m})$ & $33.4 d$ \\
\hline \multirow[t]{2}{*}{12} & $2.5-1.96(\mathrm{~m})$ & $38.6 \mathrm{t}$ & $2.09-2.00(\mathrm{~m})$ & $38.5 \mathrm{t}$ \\
\hline & $0.66-0.59(\mathrm{~m})$ & & $0.70-0.61(\mathrm{~m})$ & \\
\hline 13 & $1.11-0.98(\mathrm{~m})$ & $47.5 d$ & $1.13-1.05(\mathrm{~m})$ & $47.4 d$ \\
\hline 14 & $1.97-1.89(\mathrm{~m})$ & $41.1 d$ & $2.00-1.94(\mathrm{~m})$ & $41.1 d$ \\
\hline \multirow[t]{2}{*}{15} & $1.96-1.90(\mathrm{~m})$ & $36.5 \mathrm{t}$ & $2.02-1.93(\mathrm{~m})$ & $36.4 \mathrm{t}$ \\
\hline & $1.02-0.95(\mathrm{~m})$ & & $1.12-103(m)$ & \\
\hline 16 & $2.36-2.29(\mathrm{~m})$ & $48.9 d$ & $2.35-2.27(\mathrm{~m})$ & $49.3 d$ \\
\hline 17 & $6.85(\mathrm{dd}, 15.1,10.0)$ & & $6.95(\mathrm{dd}, 15.3,10.1)$ & $149.8 d$ \\
\hline 18 & 7.97-7.95 (m) & & $7.68(d, 15.3)$ & $123.7 d$ \\
\hline 19 & & & & $174.3 \mathrm{~s}$ \\
\hline 20 & & & & $101.6 \mathrm{~s}$ \\
\hline 21 & & & & $177.4 \mathrm{~s}$ \\
\hline \multicolumn{5}{|l|}{22} \\
\hline 23 & 4.03 (br s) & $61.4 d$ & 4.55 (br s) & 69.8d \\
\hline 24 & & 196.7s & & $194.2 \mathrm{~s}$ \\
\hline \multirow[t]{2}{*}{25} & $2.25-2.14(\mathrm{~m})$ & $27.6 \mathrm{t}$ & $4.74(\mathrm{br} \mathrm{s})$ & $71.6 \mathrm{~d}$ \\
\hline & $2.03-1.93(\mathrm{~m})$ & & & \\
\hline \multirow[t]{2}{*}{26} & $1.83-1.73(\mathrm{~m})$ & $21.6 \mathrm{t}$ & $2.34-2.25(\mathrm{~m})$ & $32.4 \mathrm{t}$ \\
\hline & $1.55-1.45(\mathrm{~m})$ & & $1.94-1.86(\mathrm{~m})$ & \\
\hline \multirow[t]{2}{*}{27} & 3.92-3.86 (m) & $39.0 \mathrm{t}$ & $4.07-3.98(m)$ & $37.6 \mathrm{t}$ \\
\hline & $2.80-2.71(\mathrm{~m})$ & & $3.25-3.15(\mathrm{~m})$ & \\
\hline 28 & $8.82(\mathrm{~s})$ & & $9.20(t, 5.8)$ & \\
\hline 29 & & 209.0s & & $209.0 \mathrm{~s}$ \\
\hline 30 & $2.11(\mathrm{~s})$ & $31.0 q$ & $2.14(\mathrm{~s})$ & $31.0 q$ \\
\hline 31 & $0.82(d, 6.8)$ & $18.8 q$ & $0.84(d, 6.9)$ & $18.7 q$ \\
\hline
\end{tabular}

Clifednamide D (3) 


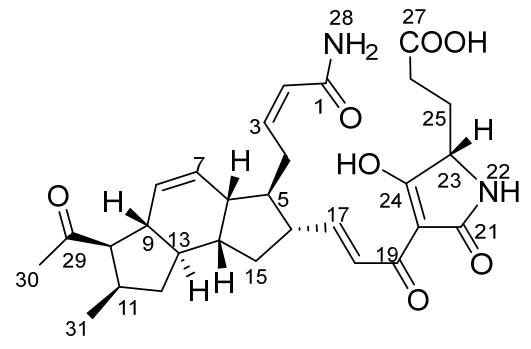

clifednamide D (3)

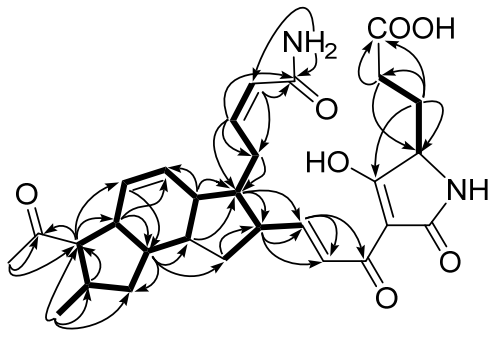

$\mathrm{HMBC}$

${ }^{1} \mathrm{H}-{ }^{1} \mathrm{H}$ COSY

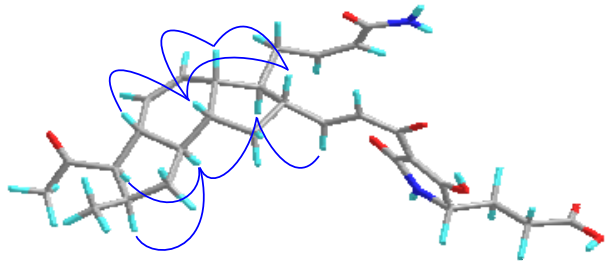

NOESY

Figure S4. The key HMBC, ${ }^{1} \mathrm{H}-{ }^{1} \mathrm{H}$ COSY and NOESY correlations of 3.

Table S4. The NMR date of 3 in DMSO- $d_{6}$ (at $600 \mathrm{MHz}, \delta$ in ppm, $J$ in $\mathrm{Hz}$ ).

\begin{tabular}{|c|c|c|c|c|}
\hline No. & ${ }^{1} \mathrm{H}$ & ${ }^{13} \mathrm{C}$ & ${ }^{1} \mathrm{H}-{ }^{1} \mathrm{H} \mathrm{COSY}$ & HMBC \\
\hline 1 & & $168.1 \mathrm{~s}$ & & \\
\hline 2 & $5.81(\mathrm{br} \mathrm{d}, 11.5)$ & $124.3 d$ & $\mathrm{H}-9$ & C-7, C-10, \\
\hline 3 & $5.98-5.93(\mathrm{~m})$ & $142.4 d$ & $\mathrm{H}-8, \mathrm{H}-10$, & C-7, C-8, C-10, C-11 \\
\hline 4 & $2.84-2.74(\mathrm{~m})$ & $29.5 \mathrm{t}$ & $\mathrm{H}-9, \mathrm{H}-11$ & C-8, C-9, C-11, C-12, C-22 \\
\hline 5 & $1.59-1.53(\mathrm{~m})$ & $50.6 \mathrm{~d}$ & $\mathrm{H}-10, \mathrm{H}-12, \mathrm{H}-22$ & C-9, C-10, C-12, C-13, C-22, C-23 \\
\hline 6 & $2.27-2.22(\mathrm{~m})$ & $47.1 \mathrm{~d}$ & $\mathrm{H}-11, \mathrm{H}-13, \mathrm{H}-20$ & C-11, C-13, C-14 \\
\hline 7 & 5.63 (br d, 9.9) & $129.7 d$ & $\mathrm{H}-12, \mathrm{H}-14$ & C-11, C-12, C-14, C-15, C-16, C-20 \\
\hline 8 & 5.75-5.72 (m) & $130.0 d$ & $\mathrm{H}-13, \mathrm{H}-15$ & C-12, C-13, C-15, C-19 \\
\hline 9 & $2.20-2.15(\mathrm{~m})$ & $42.9 \mathrm{~d}$ & $\mathrm{H}-14, \mathrm{H}-16, \mathrm{H}-19$ & $C-13, C-14, C-16, C-19, C-20$ \\
\hline 10 & $2.71(\mathrm{dd}, 11.9,10.1)$ & $58.3 d$ & $\mathrm{H}-15, \mathrm{H}-17$ & C-14, C-15, C-17, C-29, C-30 \\
\hline 11 & $2.63-2.57(\mathrm{~m})$ & $33.4 d$ & $\mathrm{H}-16, \mathrm{H}-18, \mathrm{H}-29$ & C-15, C-16, C-18, C-29 \\
\hline \multirow[t]{2}{*}{12} & $2.16-2.11(\mathrm{~m})$ & $38.7 t$ & $\mathrm{H}-17, \mathrm{H}-19$ & C-15, C-16, C-17, C-19, C-20, C-29 \\
\hline & $0.73-0.67(\mathrm{~m})$ & & & \\
\hline 13 & $1.22-1.15(\mathrm{~m})$ & $47.2 d$ & $\mathrm{H}-15, \mathrm{H}-18, \mathrm{H}-20$ & C-14, C-15, C-16, C-18, C-21 \\
\hline 14 & $2.05-2.01(\mathrm{~m})$ & $41.7 d$ & $\mathrm{H}-12, \mathrm{H}-19, \mathrm{H}-21$ & C-11, C-12, C-19 \\
\hline 15 & $\begin{array}{l}1.28-1.22(\mathrm{~m}) \\
2.11-2.06(\mathrm{~m})\end{array}$ & $36.9 \mathrm{t}$ & $\mathrm{H}-20, \mathrm{H}-22$ & C-12, C-19, C-20, C-22, C-23 \\
\hline 16 & $2.56-2.50(\mathrm{~m})$ & $49.0 d$ & $\mathrm{H}-11, \mathrm{H}-21, \mathrm{H}-23$ & C-11, C-23, C-24 \\
\hline 17 & $7.00(\mathrm{br} \mathrm{s})^{*}$ & $152.9 d$ & $\mathrm{H}-22$ & C-24, C-25 \\
\hline 18 & $7.00(\mathrm{br} \mathrm{s})^{*}$ & $121.3 d$ & & \\
\hline 19 & & $173.8 \mathrm{~s}$ & & \\
\hline \multicolumn{5}{|l|}{20} \\
\hline \multicolumn{5}{|l|}{21} \\
\hline \multicolumn{5}{|l|}{22} \\
\hline 23 & 3.89-3.80 (m) & $60.8 d$ & $\mathrm{H}-3$ & C-3, C-4 \\
\hline 24 & & $195.6 s$ & & \\
\hline \multirow[t]{2}{*}{25} & $1.96-1.89(\mathrm{~m})$ & $27.4 \mathrm{t}$ & $\mathrm{H}-2, \mathrm{H}-4$ & C-1, C-2, C-4, C-5 \\
\hline & $1.70-1.64(\mathrm{~m})$ & & & \\
\hline 26 & $2.34(\mathrm{t}, 7.5)$ & $29.7 \mathrm{t}$ & $\mathrm{H}-3$ & C-2, C-3, C-5 \\
\hline 27 & & $174.3 \mathrm{~s}$ & & \\
\hline \multirow[t]{2}{*}{28} & $7.31(\mathrm{~s})$ & & & C-7, C-8 \\
\hline & $6.81(\mathrm{~s})$ & & & \\
\hline 29 & & 209.9s & & \\
\hline 30 & $2.11(\mathrm{~s})$ & $31.5 q$ & & C-30 \\
\hline 31 & $0.76(d, 7.0)$ & $19.1 q$ & $\mathrm{H}-17$ & C-16, C-17, C-18 \\
\hline
\end{tabular}

“*” Overlapped signals. 


\section{Clifednamide E (4)}

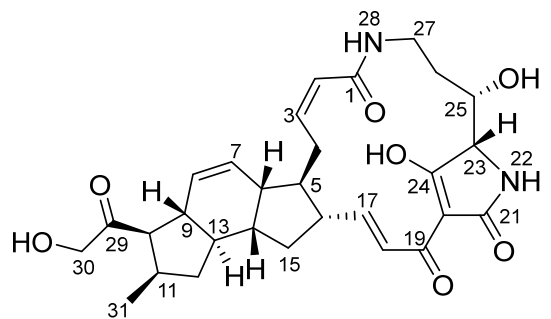

clifednamide E (4)

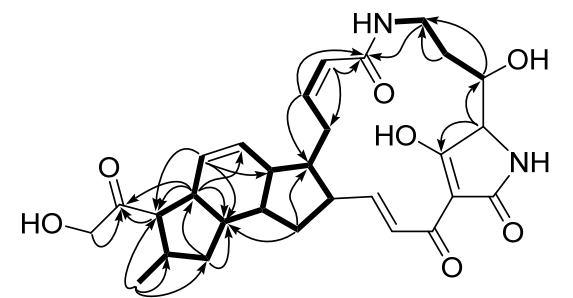

$\frown \mathrm{HMBC}$

$\longrightarrow{ }^{1} \mathrm{H}-{ }^{1} \mathrm{HCOSY}$

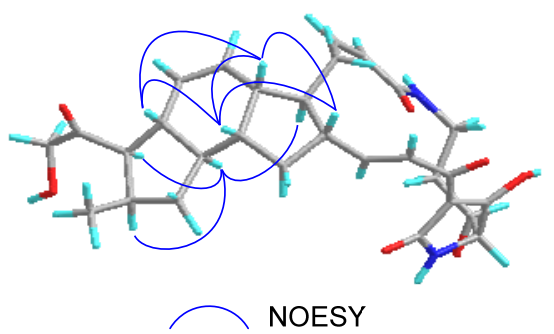

Figure S5. The key HMBC, ${ }^{1} \mathrm{H}-{ }^{1} \mathrm{H}$ COSY and NOESY correlations of 4.

Table S5. The NMR date of 4 in DMSO-d $d_{6}$ (at $600 \mathrm{MHz}, \delta$ in ppm, $J$ in $\mathrm{Hz}$ ).

\begin{tabular}{|c|c|c|c|c|}
\hline No. & ${ }^{1} \mathrm{H}$ & ${ }^{13} \mathrm{C}$ & ${ }^{1} \mathrm{H}-{ }^{1} \mathrm{H} \mathrm{COSY}$ & HMBC \\
\hline 1 & & $165.9 \mathrm{~s}$ & & \\
\hline 2 & $5.78(d, 11.7)$ & $124.9 d$ & $\mathrm{H}-9$ & C-7, C-10 \\
\hline 3 & $6.02(\mathrm{td}, 11.5,2.8)$ & $139.2 d$ & $\mathrm{H}-8, \mathrm{H}-10$ & C-7, C-11 \\
\hline \multirow[t]{2}{*}{4} & $3.66-3.55(\mathrm{~m})$ & $24.7 \mathrm{t}$ & $\mathrm{H}-9$ & C-11, C-12 \\
\hline & $2.12-2.01(\mathrm{~m})$ & & & \\
\hline 5 & $1.49-1.41(\mathrm{~m})$ & $48.6 \mathrm{~d}$ & $\mathrm{H}-12, \mathrm{H}-22$ & \\
\hline 6 & $2.59-2.52(\mathrm{~m})$ & $42.1 d$ & $\mathrm{H}-11, \mathrm{H}-20$ & C-13, C-14 \\
\hline 7 & $5.72(\mathrm{dt}, 9.9,2.8)$ & $129.6 d$ & $\mathrm{H}-12$ & C-15, \\
\hline 8 & $5.65(\mathrm{br} \mathrm{d}, 9.8)$ & $129.9 d$ & $\mathrm{H}-15$ & C-12, C-16, C-19 \\
\hline 9 & $2.30(\mathrm{t}, 11.3)^{*}$ & $43.4 d$ & $\mathrm{H}-16, \mathrm{H}-19$ & C-13, C-14, C-16, C-19, C-30 \\
\hline 10 & $2.82(\mathrm{dd}, 12.1,10.3)$ & $53.2 d$ & $\mathrm{H}-15, \mathrm{H}-17$ & C- $14, \mathrm{C}-15, \mathrm{C}-17, \mathrm{C}-29, \mathrm{C}-30$ \\
\hline 11 & $2.62-2.54(\mathrm{~m})$ & $34.1 \mathrm{~d}$ & $\mathrm{H}-18, \mathrm{H}-29$ & C-16, C-29 \\
\hline 12 & $\begin{array}{l}2.13-2.08(\mathrm{~m}) \\
0.74-0.69(\mathrm{~m})\end{array}$ & $39.2 t$ & $\mathrm{H}-17, \mathrm{H}-19$ & C-15, C-19, C-29 \\
\hline 13 & $1.26-1.18(\mathrm{~m})$ & $47.7 d$ & $\mathrm{H}-18, \mathrm{H}-20$ & \\
\hline 14 & $2.10-2.03(\mathrm{~m})$ & $41.1 \mathrm{~d}$ & $\mathrm{H}-12, \mathrm{H}-19, \mathrm{H}-21$ & C-11, C-19 \\
\hline 15 & $\begin{array}{l}2.08-2.01(\mathrm{~m}) \\
1.22-1.19(\mathrm{~m})\end{array}$ & $36.6 \mathrm{t}$ & $\mathrm{H}-20, \mathrm{H}-22$ & C-11, C-19 \\
\hline 16 & $2.30(t, 11.3)^{*}$ & $48.1 d$ & $\mathrm{H}-11$ & \\
\hline \multicolumn{5}{|l|}{17} \\
\hline \multicolumn{5}{|l|}{18} \\
\hline \multicolumn{5}{|l|}{19} \\
\hline \multicolumn{5}{|l|}{20} \\
\hline \multicolumn{5}{|l|}{21} \\
\hline \multicolumn{5}{|l|}{22} \\
\hline 23 & $3.57-3.54(\mathrm{~m})$ & $67.2 d$ & & C-1, C-3 \\
\hline 24 & & $193.5 \mathrm{~s}$ & & \\
\hline 25 & $3.79(\mathrm{~d}, 6.7)$ & $71.0 \mathrm{~d}$ & $\mathrm{H}-4$ & C-5 \\
\hline \multirow[t]{2}{*}{26} & $1.41-1.35(\mathrm{~m})$ & $31.6 \mathrm{t}$ & $\mathrm{H}-3, \mathrm{H}-5$ & C-5 \\
\hline & $1.20-1.12(\mathrm{~m})$ & & & \\
\hline \multirow[t]{2}{*}{27} & $3.33-3.28(\mathrm{~m})$ & $36.6 \mathrm{t}$ & $\mathrm{H}-4, \mathrm{H}-6$ & C-7 \\
\hline & $2.62-2.56(\mathrm{~m})$ & & & \\
\hline 28 & $7.98(\mathrm{t}, 6.1)$ & & $\mathrm{H}-5$ & \\
\hline 29 & & $212.7 \mathrm{~s}$ & & \\
\hline \multirow[t]{2}{*}{30} & $4.13(d, 18.5)$ & $69.3 t$ & & C-30 \\
\hline & $4.04(d, 18.5)$ & & & \\
\hline 31 & $0.76(d, 7.0)$ & $19.3 q$ & $\mathrm{H}-17$ & C-16, C-17, C-18 \\
\hline
\end{tabular}

“*” Overlapped signals. 


\section{Clifednamide F (5)}

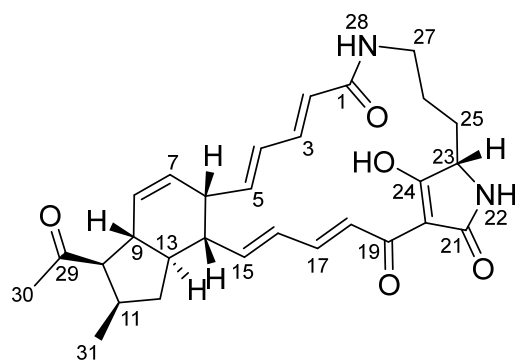

clifednamide F (5)

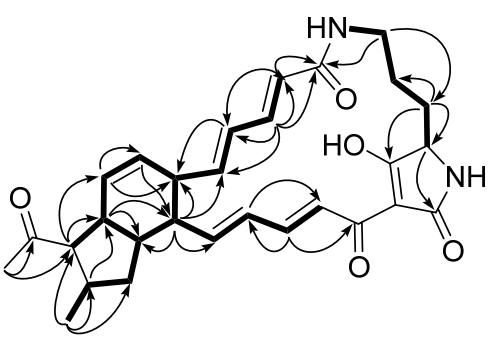

$\curvearrowright \mathrm{HMBC}$

$\longrightarrow{ }^{1} \mathrm{H}-{ }^{1} \mathrm{HCOSY}$

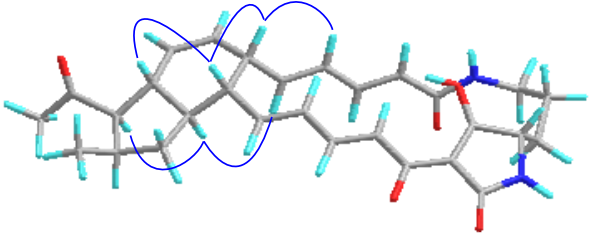

NOESY

Figure S6. The key HMBC, ${ }^{1} \mathrm{H}-{ }^{1} \mathrm{H}$ COSY and NOESY correlations of 5.

Table S6. The NMR date of 5 in DMSO-d $($ at $600 \mathrm{MHz}, \delta$ in ppm, $J$ in $\mathrm{Hz}$ ).

\begin{tabular}{|c|c|c|c|c|}
\hline No. & ${ }^{1} \mathrm{H}$ & ${ }^{13} \mathrm{C}$ & ${ }^{1} \mathrm{H}-{ }^{1} \mathrm{H}$ COSY & HMBC \\
\hline 1 & & $165.4 \mathrm{~s}$ & & \\
\hline 2 & $5.87(d, 15.0)$ & $125.1 d$ & $\mathrm{H}-9$ & C-7, C-10 \\
\hline 3 & $6.82(d d, 15.1,11.1)$ & $138.7 d$ & $\mathrm{H}-8, \mathrm{H}-10$ & C-7, C-8, C-10, C-11, \\
\hline 4 & $6.27(\mathrm{dd}, 15.4,10.2)$ & $131.5 d$ & $\mathrm{H}-9, \mathrm{H}-11$ & C-8, C-9, C-12, \\
\hline 5 & $5.43(\mathrm{dd}, 15.2,10.6)$ & $141.4 d$ & $\mathrm{H}-10, \mathrm{H}-12$ & C-9, C-13 \\
\hline 6 & $3.47(\mathrm{br} \mathrm{s})$ & $45.2 d$ & $\mathrm{H}-11, \mathrm{H}-20$ & C-11, C-13, C-14 \\
\hline 7 & $5.46(d t, 9.7,3.5)$ & $129.8 d$ & $\mathrm{H}-12, \mathrm{H}-14$ & C-20 \\
\hline 8 & $5.70(\mathrm{br} \mathrm{d}, 9.6)$ & $129.5 d$ & $\mathrm{H}-13$ & C-12, C-13, C-16, C-19 \\
\hline 9 & $2.37-2.30(\mathrm{~m})$ & $43.8 \mathrm{~d}$ & $\mathrm{H}-16, \mathrm{H}-19$ & C-13, C-14, C-16, C-20, C-30 \\
\hline 10 & $2.80(\mathrm{dd}, 12.2,10.1)$ & $58.1 \mathrm{~d}$ & $\mathrm{H}-15$ & C-14, C-15, C-17, C-29, C-30 \\
\hline 11 & $2.70-2.63(\mathrm{~m})$ & $33.1 \mathrm{~d}$ & $\mathrm{H}-18, \mathrm{H}-29$ & C-15, C-16, C-18, C-29 \\
\hline 12 & $\begin{array}{l}2.34-2.28(\mathrm{~m}) \\
0.87-0.81(\mathrm{~m})\end{array}$ & $38.2 t$ & $\mathrm{H}-17, \mathrm{H}-19$ & C-15, C-17, C-19, C-20, C-29 \\
\hline 13 & $1.61-1.53(\mathrm{~m})$ & $41.8 d$ & $\mathrm{H}-15, \mathrm{H}-18, \mathrm{H}-20$ & C-18, C-20 \\
\hline 14 & $2.77-2.72(\mathrm{~m})$ & $44.2 d$ & $\mathrm{H}-12, \mathrm{H}-19, \mathrm{H}-21$ & C-11, C-12, C-19, C-21 \\
\hline 15 & $6.15(\mathrm{dd}, 15.4,6.8)$ & $145.2 d$ & $\mathrm{H}-22$ & C-22 \\
\hline 16 & 6.97-6.89 (m) & $120.4 d$ & $\mathrm{H}-23$ & C-24 \\
\hline 17 & $7.38-7.30(\mathrm{~m})$ & 144.0d & $\mathrm{H}-22, \mathrm{H}-24$ & C-22, C-25 \\
\hline 18 & $6.24(d, 15.4)$ & $134.8 d$ & & \\
\hline 19 & & $173.3 \mathrm{~s}$ & & \\
\hline 20 & & 101.0s & & \\
\hline 21 & & $175.6 s$ & & \\
\hline \multicolumn{5}{|l|}{22} \\
\hline 23 & 3.87 (br s) & $61.5 d$ & $\mathrm{H}-3$ & $C-1, C-4$ \\
\hline 24 & & 195.9s & & \\
\hline 25 & $1.86-1.80(\mathrm{~m})$ & $26.7 \mathrm{t}$ & $\mathrm{H}-2, \mathrm{H}-4$ & C-1, C-2, C-4 \\
\hline \multirow[t]{2}{*}{26} & $1.45-1.38(\mathrm{~m})$ & $23.1 \mathrm{t}$ & $\mathrm{H}-3, \mathrm{H}-5$ & C-3 \\
\hline & $0.74-0.64(\mathrm{~m})$ & & & \\
\hline \multirow[t]{2}{*}{27} & $3.60-3.54(\mathrm{~m})$ & $38.2 \mathrm{t}$ & $\mathrm{H}-4, \mathrm{H}-6$ & C-3, C-7 \\
\hline & $2.34-2.28(\mathrm{~m})$ & & & \\
\hline 28 & $7.79(\mathrm{~m})$ & & $\mathrm{H}-5$ & C-7 \\
\hline 29 & & 209.7s & & \\
\hline 30 & $2.14(\mathrm{~s})$ & $31.6 q$ & & C-16, C-30 \\
\hline 31 & $0.79(d, 7.0)$ & $19.1 q$ & $\mathrm{H}-17$ & C-16, C-17, C-18 \\
\hline
\end{tabular}




\section{Clifednamide G (6)}
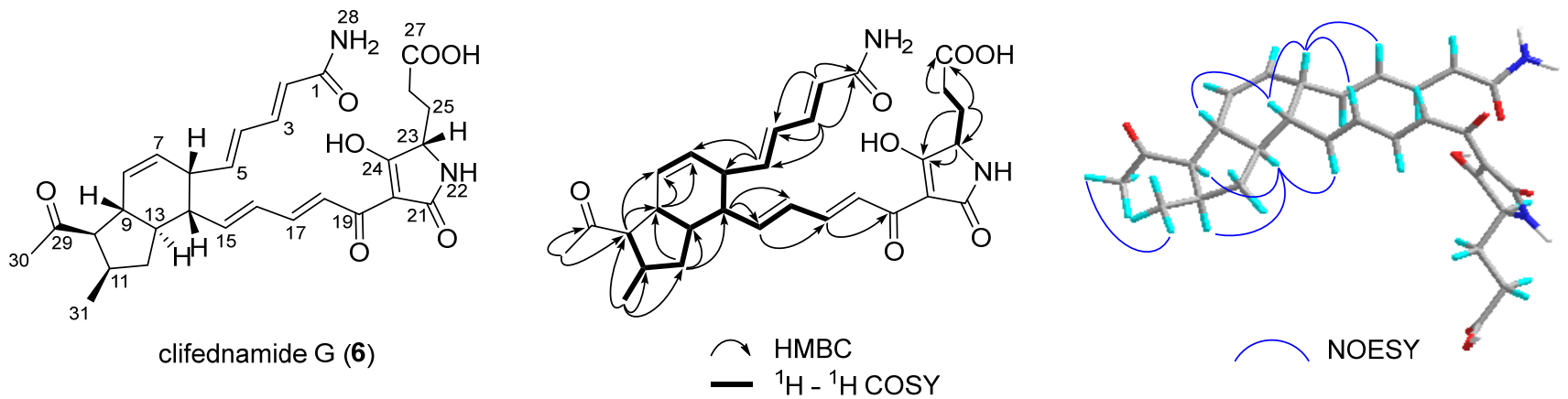

Figure S7. The key HMBC, ${ }^{1} \mathrm{H}-{ }^{1} \mathrm{H}$ COSY and NOESY correlations of 6.

Table S7. The NMR date of 6 in pyridine- $d_{5}$ (at $600 \mathrm{MHz}, \delta$ in ppm, $J$ in $\mathrm{Hz}$ ).

\begin{tabular}{|c|c|c|c|c|}
\hline No. & ${ }^{1} \mathrm{H}$ & ${ }^{13} \mathrm{C}$ & ${ }^{1} \mathrm{H}-{ }^{1} \mathrm{H}$ COSY & HMBC \\
\hline 1 & & $168.3 \mathrm{~s}$ & & \\
\hline 2 & $6.49(d, 15.2)$ & $124.7 d$ & $\mathrm{H}-9$ & C-7, C-10 \\
\hline 3 & $7.80(\mathrm{dd}, 15.1,11.5)$ & $140.6 \mathrm{~d}$ & $\mathrm{H}-8, \mathrm{H}-10$ & C-7, C-10, C-11 \\
\hline 4 & $6.34-6.30(\mathrm{~m})$ & $130.6 d$ & $\mathrm{H}-9, \mathrm{H}-11$ & C-8, C-9, C-12 \\
\hline 5 & $6.12(\mathrm{dd}, 15.2,8.3)$ & $141.2 d$ & $\mathrm{H}-10, \mathrm{H}-12$ & C-9, C-13, C-12 \\
\hline 6 & $3.10(\mathrm{br} \mathrm{s})$ & $45.3 d$ & $\mathrm{H}-11, \mathrm{H}-13, \mathrm{H}-20$ & $C-11, C-13, C-14, C-19, C-20$ \\
\hline 7 & $5.49-5.47(\mathrm{~m})$ & $129.4 d$ & $\mathrm{H}-12, \mathrm{H}-14$ & C-15, C-20 \\
\hline 8 & $5.91(d, 10.0)$ & $129.6 d$ & $\mathrm{H}-13$ & C-12, C-16, C-19 \\
\hline 9 & $2.56-2.51(\mathrm{~m})$ & $44.3 d$ & $\mathrm{H}-19$ & C-13, C-14, C-16, C-19, C-30 \\
\hline 10 & $2.69(\mathrm{brt}, 12.6)$ & $58.2 d$ & $\mathrm{H}-17$ & C-14, C-15, C-17, C-29, C-30 \\
\hline 11 & $2.51-2.49(\mathrm{~m})$ & $33.2 d$ & $\mathrm{H}-18, \mathrm{H}-29$ & C-15, C-29 \\
\hline 12 & $\begin{array}{l}1.90-1.86(\mathrm{~m}) \\
0.73-0.68(\mathrm{~m})\end{array}$ & $37.9 \mathrm{t}$ & $\mathrm{H}-17, \mathrm{H}-19$ & C-15, C-16, C-17, C-19, C-20, C-29 \\
\hline 13 & $1.60-1.53(\mathrm{~m})$ & $41.2 d$ & $\mathrm{H}-15, \mathrm{H}-18, \mathrm{H}-20$ & C-15, C-18, C-20 \\
\hline 14 & $2.51-2.49(\mathrm{~m})$ & $48.4 d$ & $\mathrm{H}-12, \mathrm{H}-19, \mathrm{H}-21$ & C-11, C-21, C-22 \\
\hline 15 & $6.08-6.05(\mathrm{~m})$ & $146.4 d$ & $\mathrm{H}-20, \mathrm{H}-22$ & C-19, C-23 \\
\hline 16 & $6.38-6.34(\mathrm{~m})$ & $130.6 d$ & $\mathrm{H}-21, \mathrm{H}-23$ & C-20, C-23 \\
\hline 17 & $7.70(\mathrm{dd}, 15.3,10.0)$ & $142.8 d$ & $\mathrm{H}-22$ & C-21, C-22, C-25 \\
\hline \multicolumn{5}{|c|}{ (1) } \\
\hline 19 & & 176.1s & & \\
\hline \multicolumn{5}{|l|}{20} \\
\hline \multicolumn{5}{|l|}{21} \\
\hline \multicolumn{5}{|l|}{22} \\
\hline 23 & 4.28 (br s) & $61.1 \mathrm{~d}$ & $\mathrm{H}-3$ & C-1, C-3, C-4 \\
\hline 24 & & $196.5 \mathrm{~s}$ & & \\
\hline 25 & $\begin{array}{l}2.63-2.59(\mathrm{~m}) \\
2.31-2.24(\mathrm{~m})\end{array}$ & $28.3 \mathrm{t}$ & $\mathrm{H}-2, \mathrm{H}-4$ & C-1, C-2, C-4, C-5 \\
\hline 26 & $2.88-2.86(\mathrm{~m})$ & $30.5 \mathrm{t}$ & $\mathrm{H}-3$ & $\mathrm{C}-2, \mathrm{C}-3, \mathrm{C}-5$ \\
\hline 27 & & $175.2 \mathrm{~s}$ & & \\
\hline \multicolumn{5}{|l|}{28} \\
\hline 29 & & $209.6 s$ & & \\
\hline 30 & $2.14(\mathrm{~s})$ & $30.9 q$ & & C-16, C-30 \\
\hline 31 & $0.86(d, 7.1)$ & $18.6 q$ & $\mathrm{H}-17$ & C-16, C-17, C-18 \\
\hline
\end{tabular}




\section{Clifednamide H (7)}
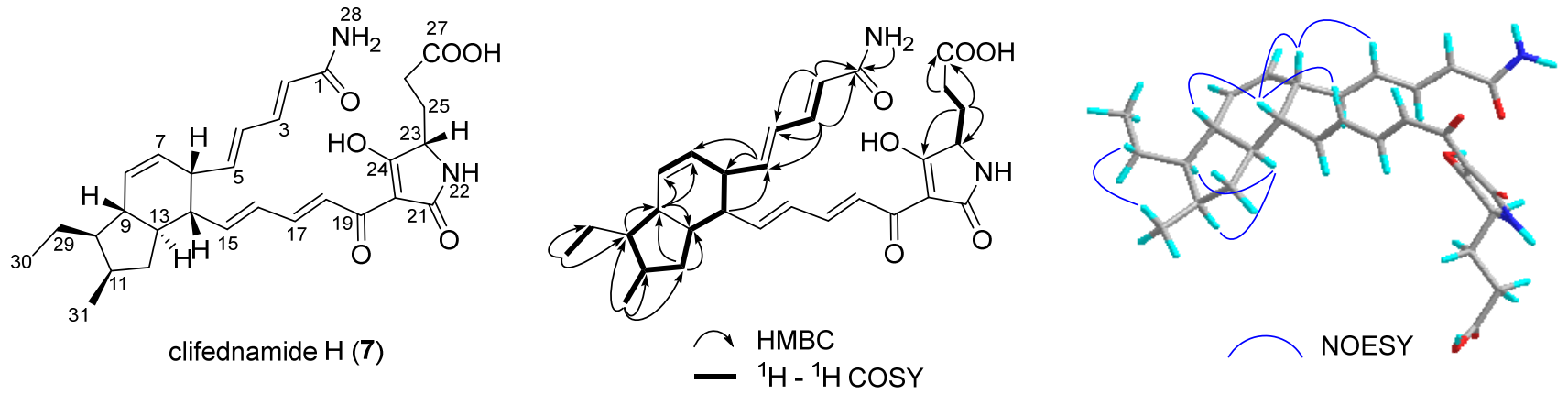

Figure S8. The key HMBC, ${ }^{1} \mathrm{H}-{ }^{1} \mathrm{H}$ COSY and NOESY correlations of 7.

Table S8. The NMR date of 7 in DMSO- $d_{6}$ (at $600 \mathrm{MHz}, \delta$ in ppm, $J$ in Hz).

\begin{tabular}{|c|c|c|c|c|}
\hline No. & ${ }^{1} \mathrm{H}$ & ${ }^{13} \mathrm{C}$ & ${ }^{1} \mathrm{H}-{ }^{1} \mathrm{H}$ COSY & HMBC \\
\hline 1 & & $167.4 \mathrm{~s}$ & & \\
\hline 2 & $5.92(d, 15.2)$ & $124.7 d$ & $\mathrm{H}-9$ & C-7, C-10 \\
\hline 3 & $7.02(\mathrm{dd}, 15.110 .4)$ & $139.8 d$ & $\mathrm{H}-8, \mathrm{H}-10$ & C-7, C-8, C-10, C-11 \\
\hline 4 & $6.13(\mathrm{dd}, 15.110 .6)$ & $130.2 d$ & $\mathrm{H}-9$ & C-8, C-9, C-11, C-12 \\
\hline 5 & $6.06(\mathrm{dd}, 15.18 .1)$ & $141.6 \mathrm{~d}$ & $\mathrm{H}-12$ & C-9, C-10, C-12, C-13 \\
\hline 6 & $3.16-3.08(\mathrm{~m})$ & $45.5 d$ & $\mathrm{H}-11$ & C-10, C-11, C-14, C-19 \\
\hline 7 & $5.47-5.44(d d d, 10.8,4.1,2.8)$ & $129.7 d$ & $\mathrm{H}-12, \mathrm{C}-14$ & C-15 \\
\hline 8 & $5.96(d, 9.9)$ & $130.3 d$ & $\mathrm{H}-13$ & C-12, C-15, C-16, C-19 \\
\hline 9 & $1.66-1.58(\mathrm{~m})$ & $48.2 d$ & $\mathrm{H}-16$ & $\mathrm{C}-13, \mathrm{C}-14, \mathrm{C}-16, \mathrm{C}-19, \mathrm{C}-30$ \\
\hline 10 & $1.41-1.36(\mathrm{~m})$ & $46.9 d$ & $\mathrm{H}-17, \mathrm{H}-15$ & C-15, C-17, C-29, C-30, C-31 \\
\hline 11 & $2.25-2.20(\mathrm{~m})$ & $32.6 \mathrm{~d}$ & $\mathrm{H}-16, \mathrm{H}-18, \mathrm{H}-29$ & C-15, C-18, C-29 \\
\hline 12 & $\begin{array}{l}1.94-1.86(\mathrm{~m}) \\
0.67-0.62(\mathrm{~m})\end{array}$ & $37.8 \mathrm{t}$ & $\mathrm{H}-17, \mathrm{H}-19$ & C-15, C-17, C-19, C-29 \\
\hline 13 & $1.55-1.50(\mathrm{~m})$ & $42.3 d$ & $\mathrm{H}-18, \mathrm{H}-20$ & C-15, C-16, C-18 \\
\hline 14 & $2.55-2.53(\mathrm{~m})$ & $48.2 d$ & $\mathrm{H}-19$ & C-11, C-22 \\
\hline \multicolumn{5}{|c|}{$-60-500$ (1) } \\
\hline 16 & 6.44-6.37 (m) & $130.3 d$ & & \\
\hline \multicolumn{5}{|c|}{ e.e. } \\
\hline \multicolumn{5}{|l|}{18} \\
\hline \multicolumn{5}{|l|}{19} \\
\hline \multicolumn{5}{|l|}{20} \\
\hline \multicolumn{5}{|l|}{21} \\
\hline \multicolumn{5}{|l|}{22} \\
\hline 23 & 3.72 (br s) & $60.3 d$ & $\mathrm{H}-3$ & \\
\hline 24 & & $195.6 \mathrm{~s}$ & & \\
\hline \multirow[t]{2}{*}{25} & $1.93-1.83(\mathrm{~m})$ & $27.7 \mathrm{t}$ & $\mathrm{H}-4$ & $C-1, C-2, C-4, C-5$ \\
\hline & $\begin{array}{l}1.6 /-1.56(\mathrm{~m}) \\
230-228(\mathrm{~m})\end{array}$ & $207 t>1$ & $\mathrm{H}-3$ & \\
\hline 26 & 2.30-2.28 (m) & $29.1 \mathrm{t}$ & $\mathrm{H}-3$ & C-2, C-3, C-5 \\
\hline \multirow{2}{*}{28} & 720 (a) & $1 / 4.45$ & & \\
\hline & $7.38(\mathrm{~s})$ & & & C-7, C-8 \\
\hline \multirow{2}{*}{29} & $151,17(\mathrm{~m})$ & $211+$ & & \\
\hline & $\begin{array}{l}1.51-1.47(\mathrm{~m}) \\
133-129(\mathrm{~m})\end{array}$ & $21 . \pi \mathrm{t}$ & $\mathrm{H}-31$ & $C-15, C-16, C-17, C-31$ \\
\hline 30 & $0.93(\mathrm{t}, 7.3)$ & $13.6 q$ & $\mathrm{H}-30$ & C-16, C-30 \\
\hline 31 & $0.86(d, 7.1)$ & $18.0 q$ & $\mathrm{H}-17$ & C-16, C-17, C-18 \\
\hline
\end{tabular}




\section{Clifednamide I (8)}

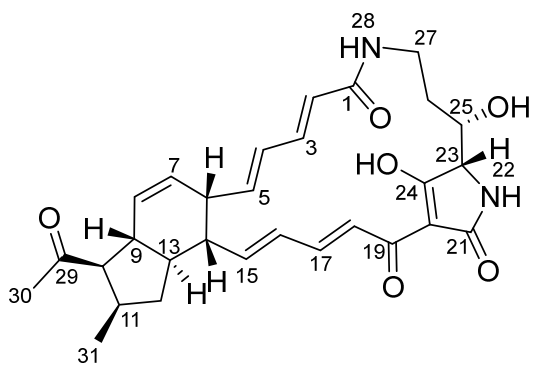

clifednamide I (8)

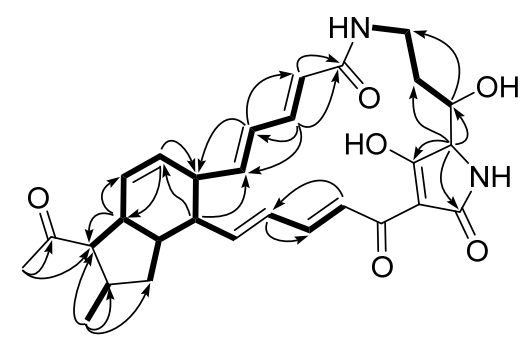

$\curvearrowright \mathrm{HMBC}$

$-{ }^{1} \mathrm{H}-{ }^{1} \mathrm{H} \operatorname{COSY}$

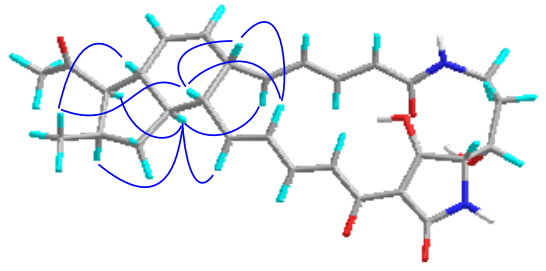

NOESY

Figure S9. The key HMBC, ${ }^{1} \mathrm{H}-{ }^{1} \mathrm{H}$ COSY and NOESY correlations of 8.

Table S9. The NMR date of 8 in DMSO- $d_{6}$ (at $400 \mathrm{MHz}, \delta$ in ppm, $J$ in Hz).

\begin{tabular}{|c|c|c|c|c|}
\hline No. & ${ }^{1} \mathrm{H}$ & ${ }^{13} \mathrm{C}$ & ${ }^{1} \mathrm{H}-{ }^{1} \mathrm{H}$ COSY & HMBC \\
\hline 1 & & $165.6 s$ & & \\
\hline 2 & $5.83(d, 15.0)$ & $124.8 \mathrm{~d}$ & $\mathrm{H}-9$ & C-7, C-10 \\
\hline 3 & $6.82(\mathrm{dd}, 15.0,11.1)$ & $138.9 d$ & $\mathrm{H}-8, \mathrm{H}-10$ & C-7, C-8, C-10, C-11 \\
\hline 4 & $6.23-6.13(\mathrm{~m})$ & $131.1 \mathrm{~d}$ & $\mathrm{H}-9, \mathrm{H}-11$ & C- $8, C-9, C-12$ \\
\hline 5 & $5.42-5.37(\mathrm{~m})$ & $141.9 d$ & $\mathrm{H}-10, \mathrm{H}-12$ & C-9, C-12 \\
\hline 6 & $3.50-3.42(\mathrm{~m})$ & $45.3 d$ & $\mathrm{H}-11, \mathrm{H}-13, \mathrm{H}-20$ & C-13, C-14 \\
\hline 7 & $5.44-5.40(\mathrm{~m})$ & $129.8 d$ & $\mathrm{H}-14, \mathrm{H}-12$ & C-12, C-14, C-15, C-20 \\
\hline 8 & $5.70(\mathrm{br} \mathrm{d}, 9.8)$ & $129.6 d$ & $\mathrm{H}-13$ & C-12, C-15, C-16, C-19 \\
\hline 9 & $2.37-2.29(\mathrm{~m})$ & $43.7 d$ & $\mathrm{H}-16, \mathrm{H}-19$ & C-13, C-14, C-16, C-19, C-20 \\
\hline 10 & $2.83-2.73(\mathrm{~m})$ & $58.1 d$ & $\mathrm{H}-15$ & C-14, C-15, C-17, C-29, C-30 \\
\hline 11 & $2.71-2.62(\mathrm{~m})$ & $33.1 \mathrm{~d}$ & $\mathrm{H}-29$ & C-16, C-29 \\
\hline \multirow[t]{2}{*}{12} & $2.35-2.29(\mathrm{~m})$ & $38.2 t$ & $\mathrm{H}-19$ & C-19, C-20, C-29 \\
\hline & $0.85-0.79(\mathrm{~m})$ & & & \\
\hline 13 & $1.62-1.52(\mathrm{~m})$ & $41.9 d$ & $\mathrm{H}-15, \mathrm{H}-18, \mathrm{H}-20$ & C-15, C-18 \\
\hline 14 & $2.80-2.70(\mathrm{~m})$ & $44.2 d$ & $\mathrm{H}-12, \mathrm{H}-19$ & C-11, C-15 \\
\hline 15 & $6.19-6.13(\mathrm{~m})$ & $145.8 d$ & $\mathrm{H}-20$ & \\
\hline 16 & $6.23-6.16(\mathrm{~m})$ & $134.7 d$ & $\mathrm{H}-23$ & C-23 \\
\hline 17 & $7.36-7.29(\mathrm{~m})$ & $143.9 d$ & $\mathrm{H}-22$ & \\
\hline 18 & $6.89(d, 15.5)$ & $120.7 d$ & $\mathrm{H}-23$ & C-22 \\
\hline \multicolumn{5}{|l|}{19} \\
\hline 20 & & $100.8 \mathrm{~s}$ & & \\
\hline 21 & & 176.3s & & \\
\hline \multicolumn{5}{|l|}{22} \\
\hline 23 & $3.93-3.88(\mathrm{~m})$ & $68.8 d$ & & C-1, C-3, C-4, C-27 \\
\hline 24 & & $192.9 \mathrm{~s}$ & & \\
\hline 25 & $3.95-3.89(\mathrm{~m})$ & $70.1 d$ & $\mathrm{H}-4$ & $C-5$ \\
\hline \multirow[t]{2}{*}{26} & $1.29-1.22(\mathrm{~m})$ & $33.1 \mathrm{t}$ & $\mathrm{H}-3, \mathrm{H}-5$ & C-3 \\
\hline & 0.93-0.85 (m) & & & \\
\hline \multirow[t]{2}{*}{27} & 3.59-3.53 (m) & $36.2 \mathrm{t}$ & $\mathrm{H}-4, \mathrm{H}-6$ & C-3, C-4, C-7 \\
\hline & $2.64-2.59(\mathrm{~m})$ & & & \\
\hline 28 & 7.96 (br s) & & $\mathrm{H}-5$ & C-7 \\
\hline 29 & & 209.7s & & \\
\hline 30 & $2.14(\mathrm{~s})$ & $31.5 q$ & & C-16, C-30 \\
\hline 31 & $0.80(\mathrm{~d}, 7.2)$ & $19.1 q$ & $\mathrm{H}-17$ & C-16, C-17, C-18 \\
\hline
\end{tabular}




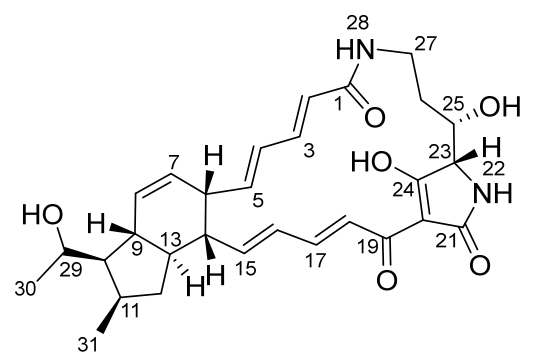

clifednamide J (9)

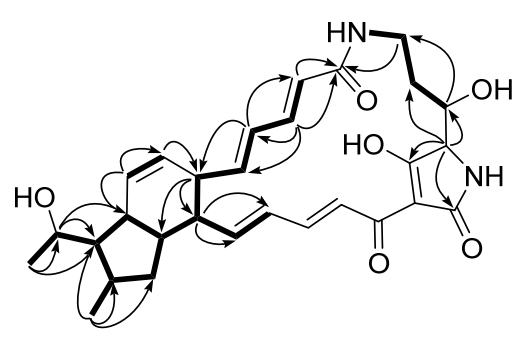

$\curvearrowright \mathrm{HMBC}$

- ${ }^{1} \mathrm{H}-{ }^{1} \mathrm{H} \cos Y$

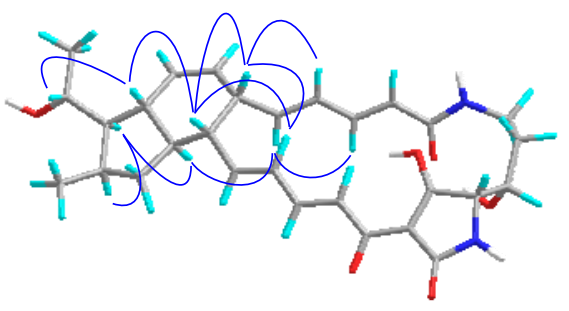

NOESY

Figure S10. The key HMBC, ${ }^{1} \mathrm{H}-{ }^{1} \mathrm{H}$ COSY and NOESY correlations of 9.

Table S10. The NMR date of 9 in pyridine- $d_{5}$ (at $600 \mathrm{MHz}, \delta$ in ppm, $J$ in $\mathrm{Hz}$ ).

\begin{tabular}{|c|c|c|c|c|}
\hline No. & ${ }^{1} \mathrm{H}$ & ${ }^{13} \mathrm{C}$ & ${ }^{1} \mathrm{H}-{ }^{1} \mathrm{H}$ COSY & HMBC \\
\hline 1 & & $167.6 s$ & & \\
\hline 2 & $6.43(d, 15.1)$ & $126.5 d$ & $\mathrm{H}-9$ & C-7, C-10 \\
\hline 3 & $7.63-7.60(\mathrm{~m})$ & $140.5 d$ & $\mathrm{H}-8, \mathrm{H}-10$ & C-7, C-10, C-11 \\
\hline 4 & $6.23-6.18(\mathrm{~m})$ & $132.4 d$ & $\mathrm{H}-9, \mathrm{H}-11$ & C-8, C-9, C-12 \\
\hline 5 & $5.61(\mathrm{dd}, 13.1,6.4)$ & $142.9 \mathrm{~d}$ & $\mathrm{H}-10, \mathrm{H}-12$ & C-9 \\
\hline 6 & 3.36-3.31 (m) & $46.9 d$ & $\mathrm{H}-11, \mathrm{H}-20$ & C-10, C-11, C-13, C-14, C-19, C-20 \\
\hline 7 & $5.55-5.51(\mathrm{~m})$ & $129.0 \mathrm{~d}$ & $\mathrm{H}-14$ & C-12, C-15 \\
\hline 8 & $6.78(\mathrm{~d}, 10.0)$ & $135.0 d$ & $\mathrm{H}-13$ & C-12, C-13, C-15, C-16 \\
\hline 9 & $2.43(t, 11.3)$ & $46.8 \mathrm{~d}$ & $\mathrm{H}-16, \mathrm{H}-19$ & C-13, C-14, C-16, C-19, C-30 \\
\hline 10 & $1.75-1.72(\mathrm{~m})$ & $53.0 \mathrm{~d}$ & $\mathrm{H}-15, \mathrm{H}-17, \mathrm{H}-30$ & C-14, C-15, C-17, C-29, C-30, C-31 \\
\hline 11 & $2.27-2.22(\mathrm{~m})$ & $35.1 d$ & $\mathrm{H}-16, \mathrm{H}-18, \mathrm{H}-29$ & C-15, C-16, C-18, C-29 \\
\hline 12 & $\begin{array}{l}2.15-2.12(\mathrm{~m}) \\
0.94-0.91(\mathrm{~m})\end{array}$ & $39.4 \mathrm{t}$ & $\mathrm{H}-17, \mathrm{H}-19$ & C-15, C-16, C-19, C-29 \\
\hline 13 & $1.62-1.55(\mathrm{~m})$ & $44.5 \mathrm{~d}$ & $\mathrm{H}-15, \mathrm{H}-18, \mathrm{H}-20$ & C-18 \\
\hline 14 & $2.66(\mathrm{br} \mathrm{s})$ & $46.2 d$ & $\mathrm{H}-12, \mathrm{H}-19$ & C-12, C-15, C-21, C-22 \\
\hline 15 & $7.61-7.52(\mathrm{~m})$ & $143.4 d$ & $\mathrm{H}-22$ & \\
\hline 16 & $6.23-6.18(\mathrm{~m})$ & $135.7 d$ & $\mathrm{H}-21$ & C-12, C-20 \\
\hline \multicolumn{5}{|l|}{17} \\
\hline \multicolumn{5}{|l|}{18} \\
\hline \multicolumn{5}{|l|}{$\begin{array}{l}19 \\
20\end{array}$} \\
\hline \multicolumn{5}{|l|}{20} \\
\hline 21 & & $179.1 \mathrm{~s}$ & & \\
\hline \multicolumn{5}{|l|}{22} \\
\hline 23 & $4.56(\mathrm{~s})$ & $70.3 d$ & & C-1, C-3, C-4, C-27 \\
\hline 24 & & $195.4 \mathrm{~s}$ & & \\
\hline 25 & 4.89 (s) & $72.4 d$ & $\mathrm{H}-4$ & C-5 \\
\hline 26 & 1.99-1.95 (m) & $35.1 \mathrm{t}$ & $\mathrm{H}-3, \mathrm{H}-5$ & C-3, C-5 \\
\hline \multirow[t]{2}{*}{27} & $4.36-4.33(\mathrm{~m})$ & $38.3 \mathrm{t}$ & $\mathrm{H}-4, \mathrm{H}-6$ & C-3, C-7 \\
\hline & $3.29-3.25$ (m) & & & \\
\hline 28 & $8.83(\mathrm{~s})$ & & $\mathrm{H}-5$ & \\
\hline 29 & $4.20-4.17(\mathrm{~m})$ & $68.9 \mathrm{~d}$ & $\mathrm{H}-16, \mathrm{H}-31$ & C-15, C-16, C-17, C-31 \\
\hline 30 & $1.43(\mathrm{~d}, 6.0)$ & $25.6 q$ & $\mathrm{H}-30$ & C-16, C-30 \\
\hline 31 & $1.09(\mathrm{~d}, 7.1)$ & $19.0 q$ & $\mathrm{H}-17$ & C-16, C-17, C-18 \\
\hline
\end{tabular}



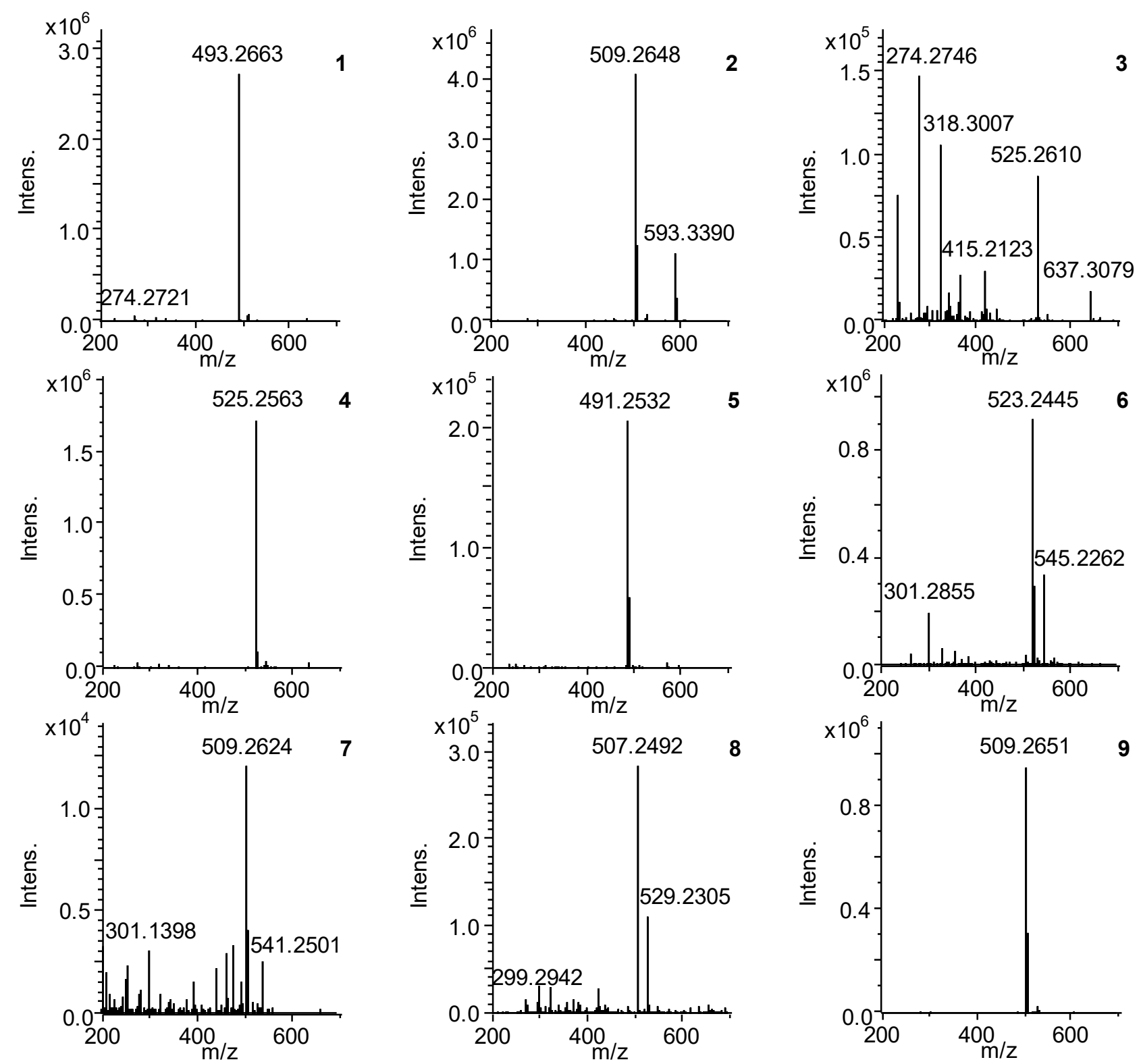

Figure S11. The HR ESIMS spectra of 1-9. 

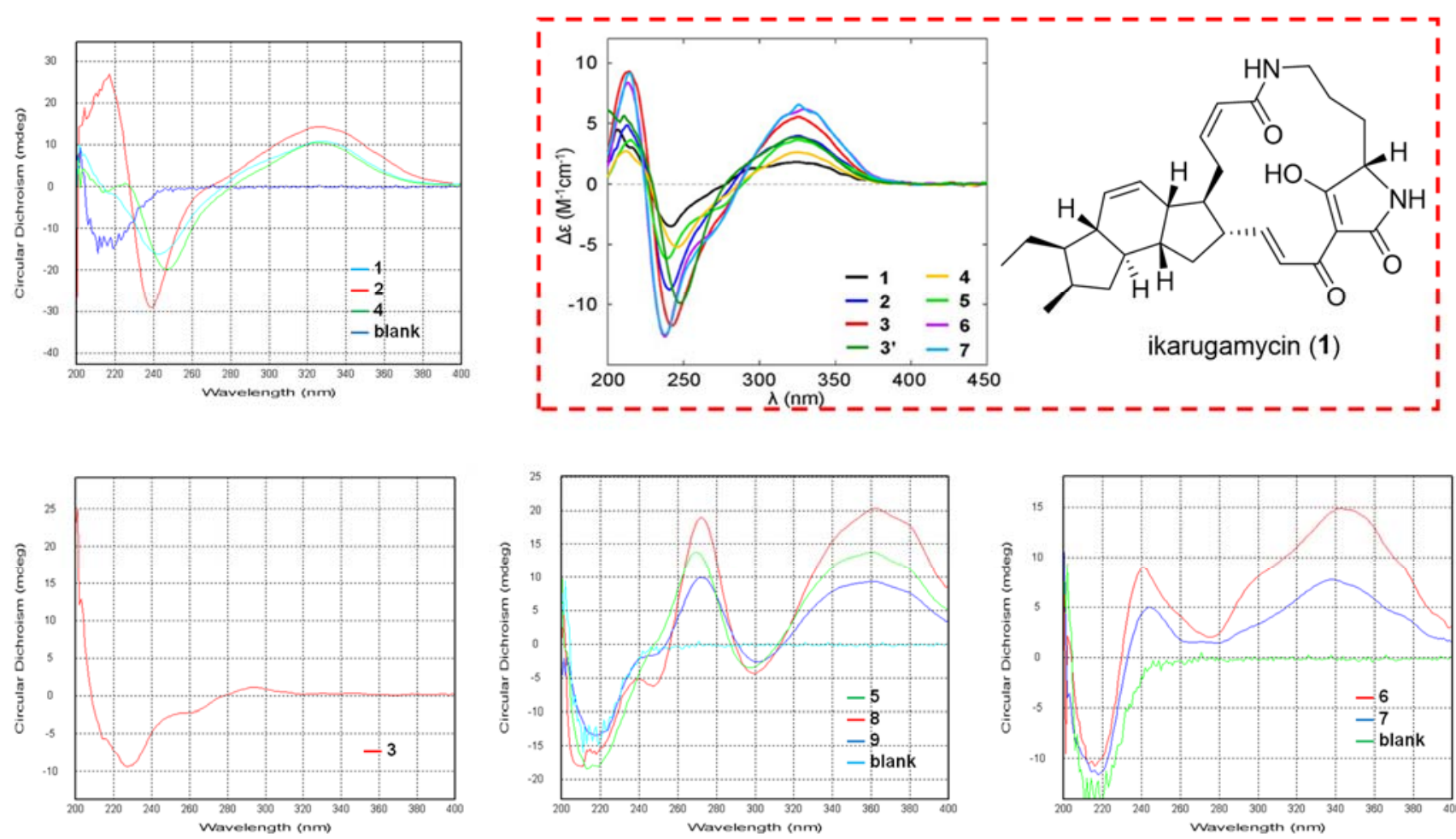

Figure S12. The ECD spectra of 1-9 and ikarugamycin. 
a)

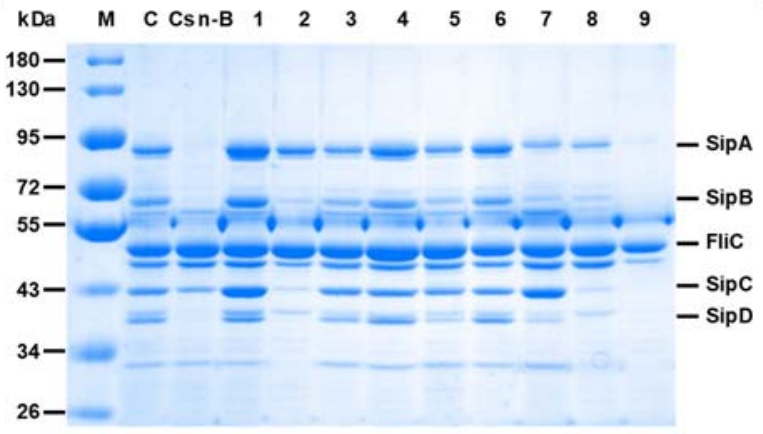

b)

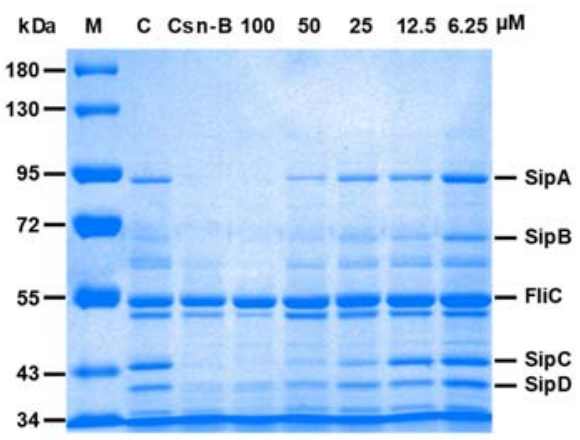

Figure S13. (a) Clifednamides A, B, D-J (1-9) inhibited secretion of SPI-1 effector proteins; (b) Compound 9 inhibited the secretion of SPI-1 effector proteins at a range of concentrations from 6.25 to $100 \mu \mathrm{M}$ under an SPI-1-induced condition in vitro. SipA/B/C/D, SPI-1 effector proteins; FliC, flagellar filament protein; M, marker; C, DMSO control. 


\section{NMR spectra for $1-9$}

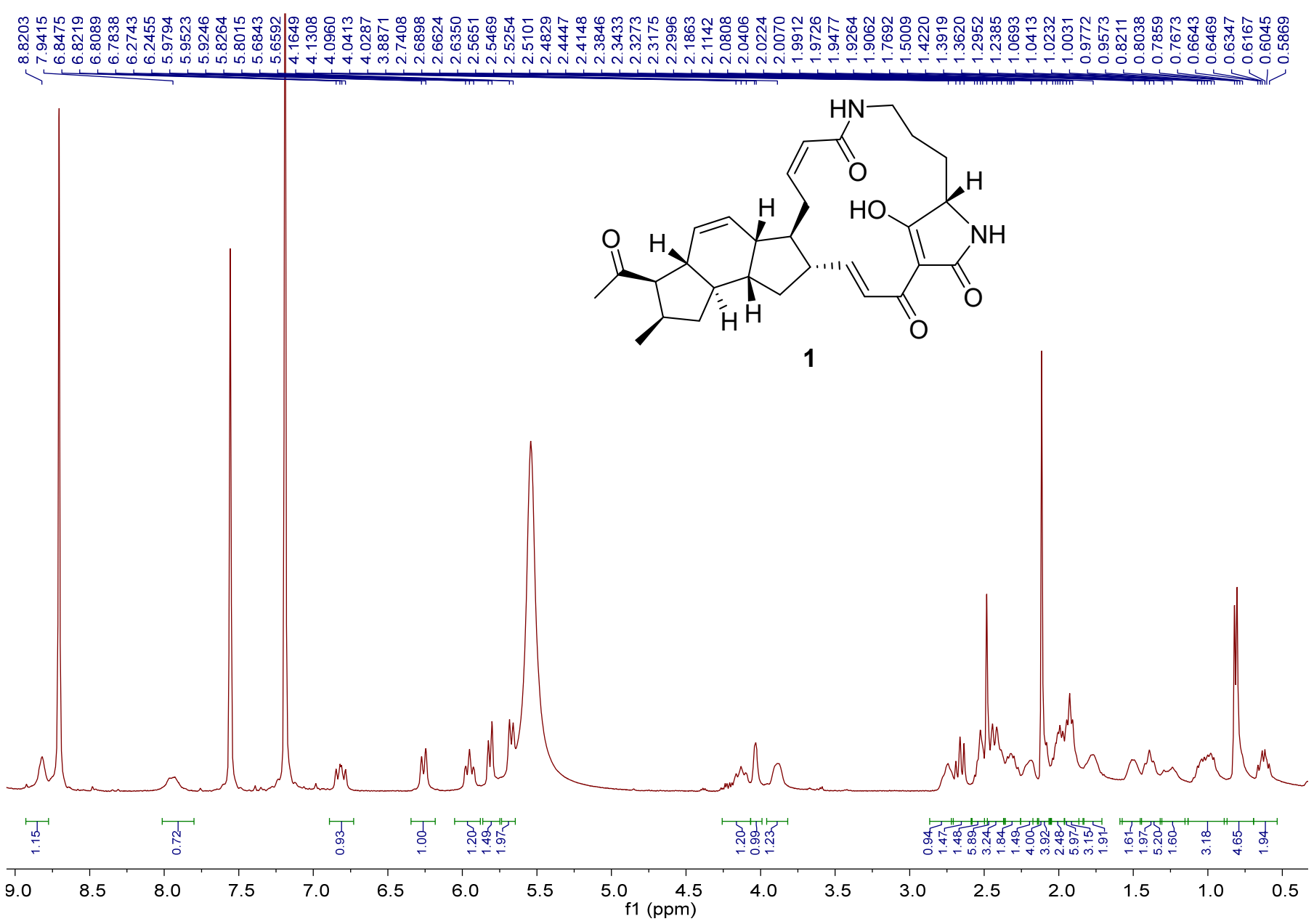

Figure S14. ${ }^{1} \mathrm{H}$ NMR spectrum of 1 in pyridine- $d_{5}$. 


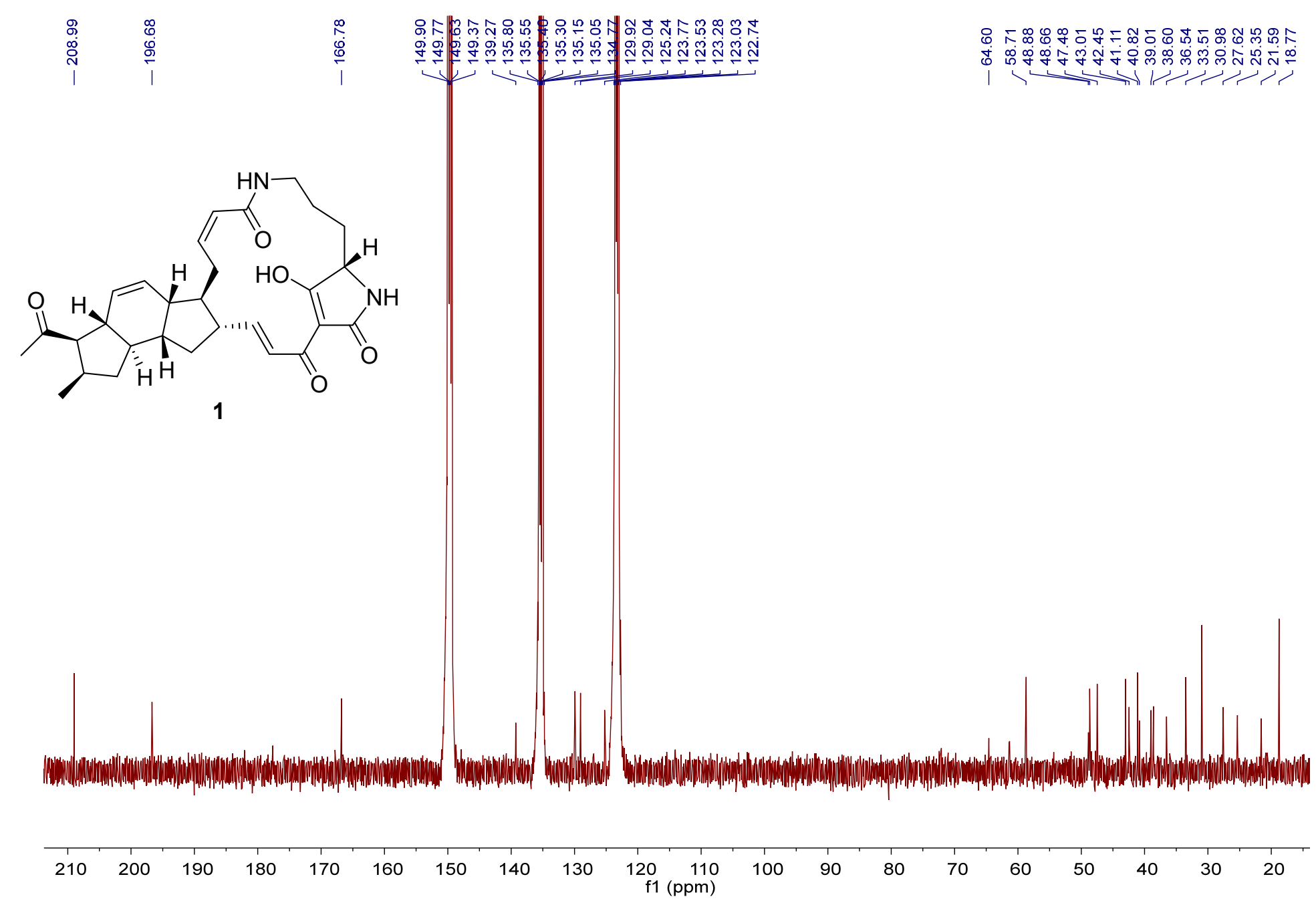

Figure S15. ${ }^{13} \mathrm{C}$ NMR spectrum of 1 in pyridine- $d_{5}$. 


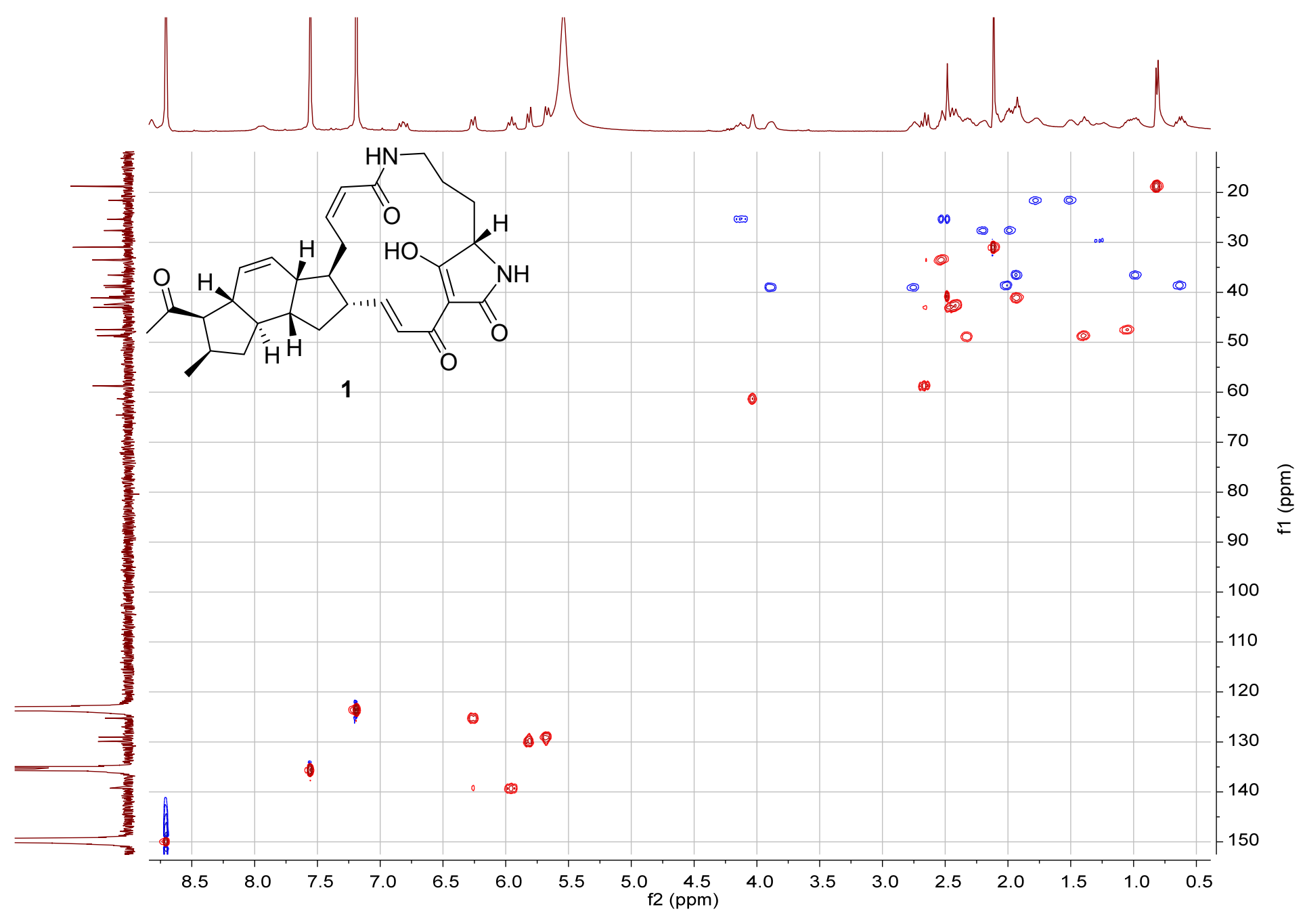

Figure S16. The HSQC spectrum of 1 in pyridine- $d_{5}$. 


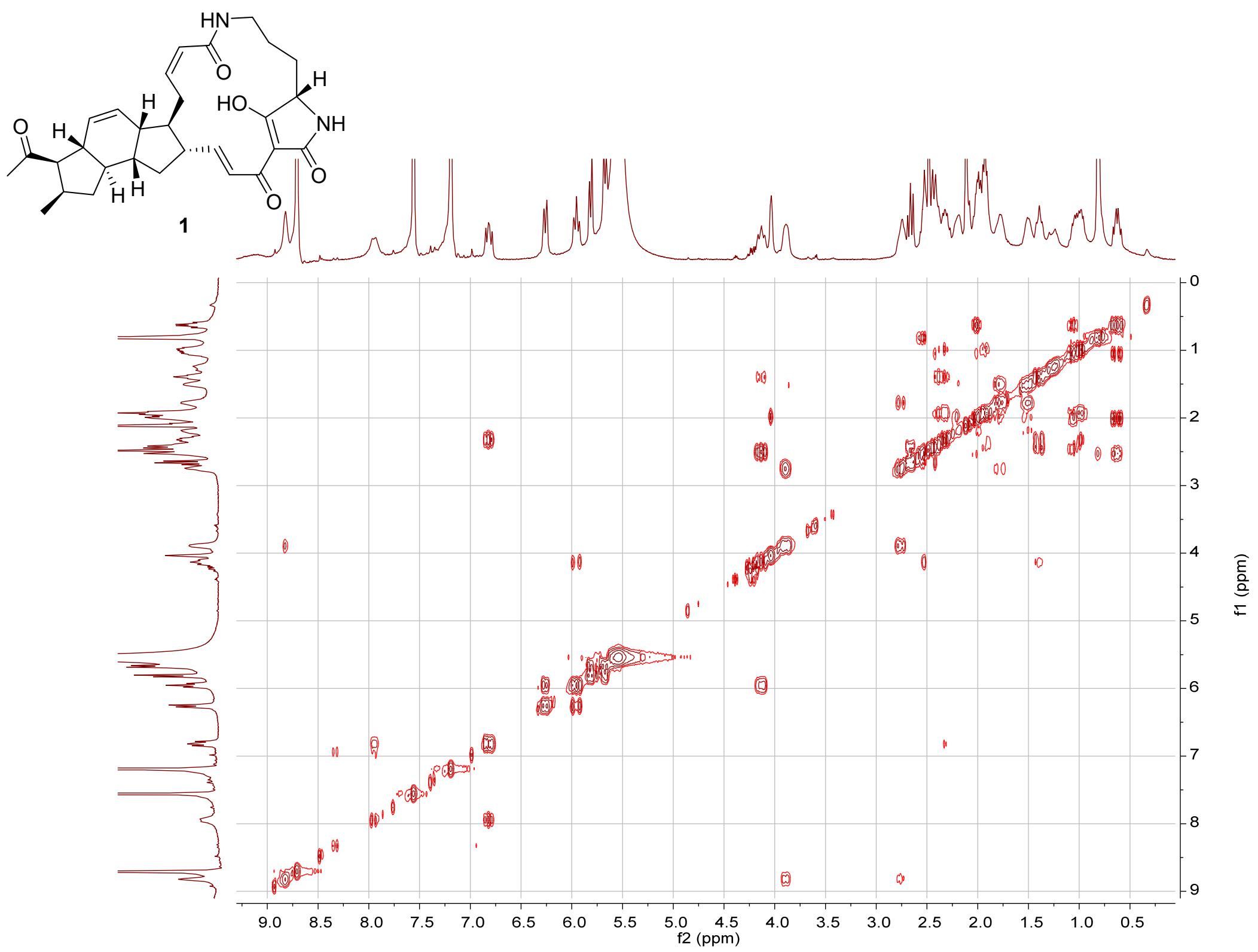

Figure S17. The ${ }^{1} \mathrm{H}-{ }^{1} \mathrm{H}$ COSY spectrum of 1 in pyridine- $d 5$. 


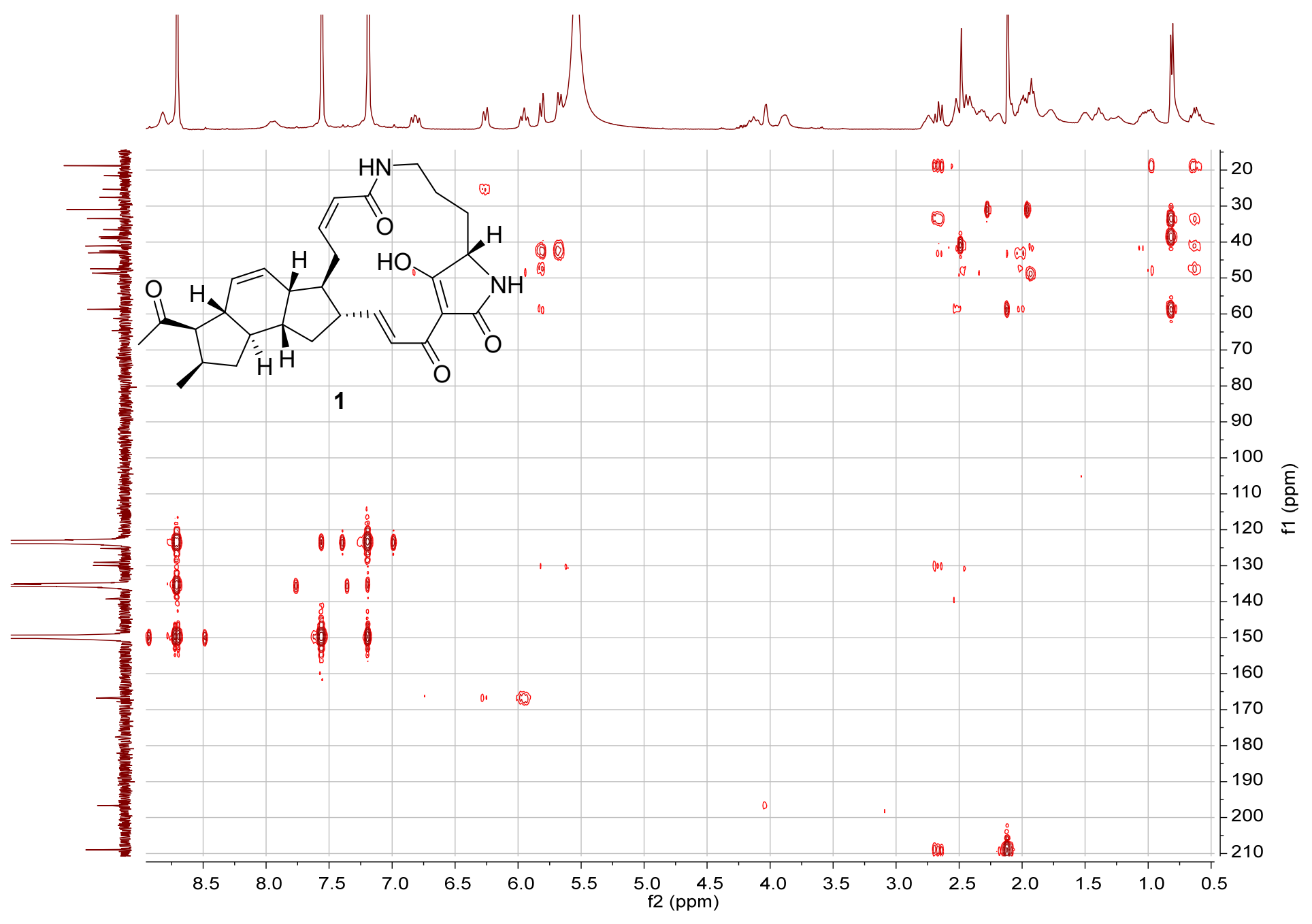

Figure S18. The HMBC spectrum of 1 in pyridine- $d_{5}$. 


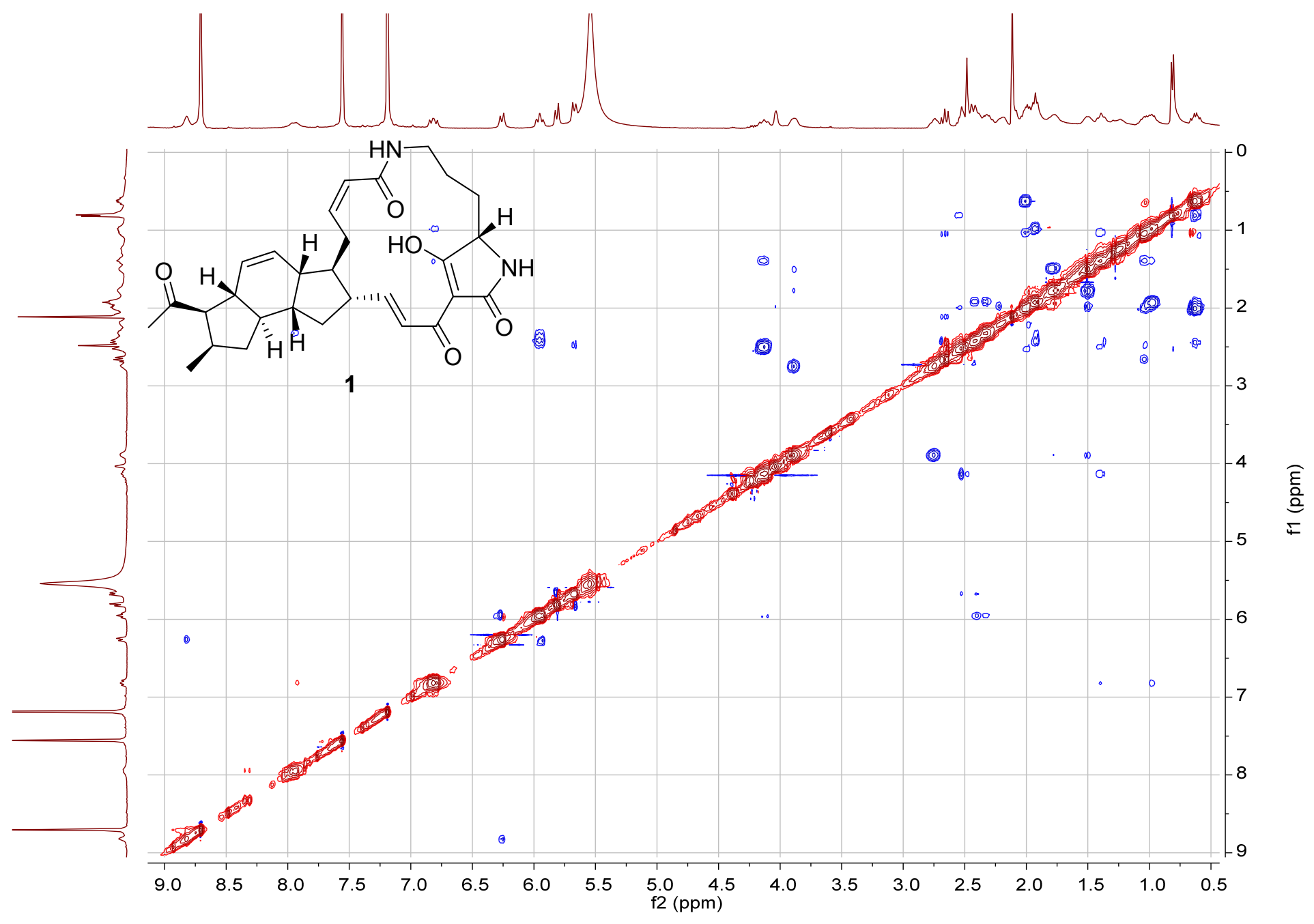

Figure S19. The NOESY spectrum of 1 in pyridine- $d_{5}$. 


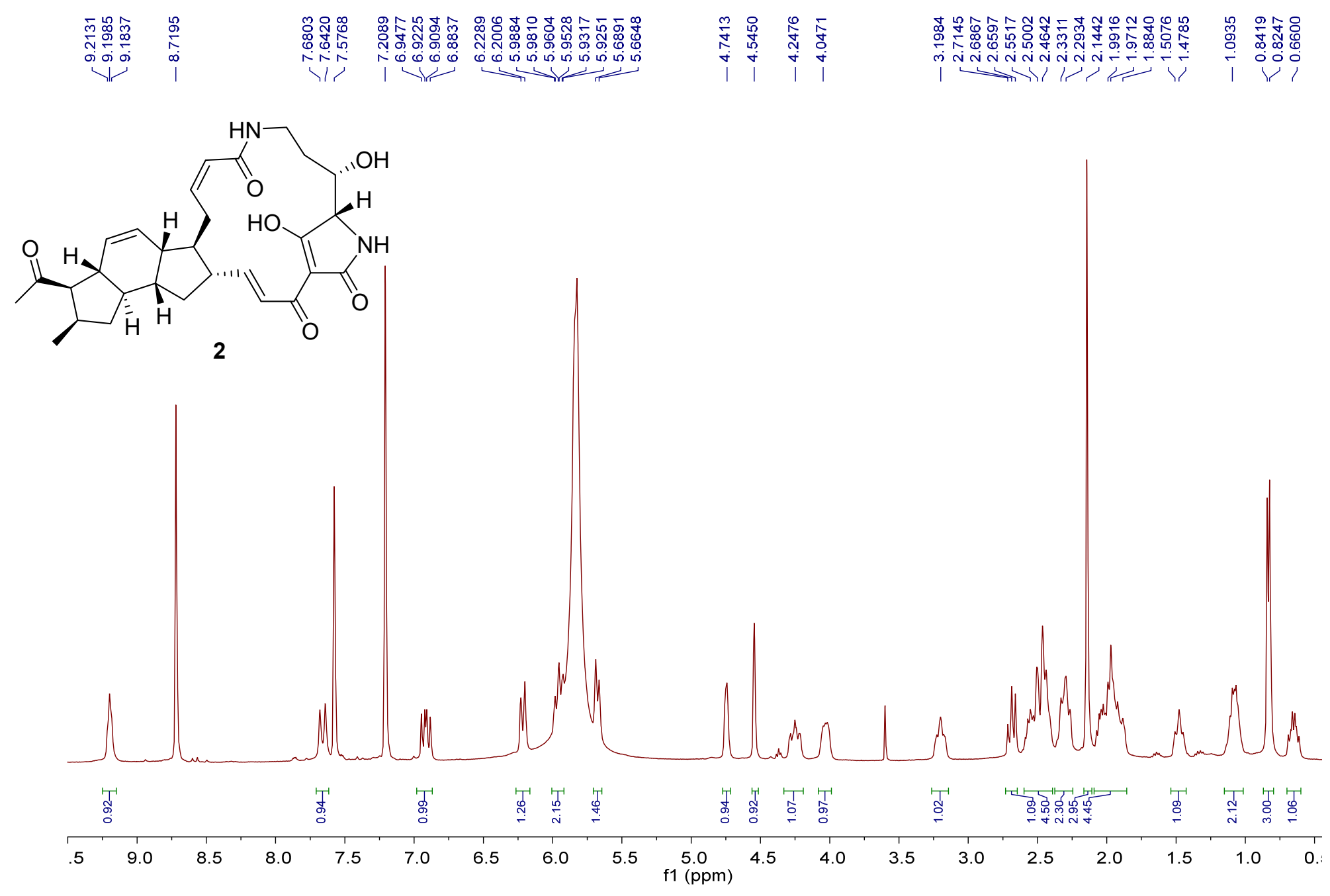

Figure S20. ${ }^{1} \mathrm{H}$ NMR spectrum of 2 in pyridine- $d_{5}$. 


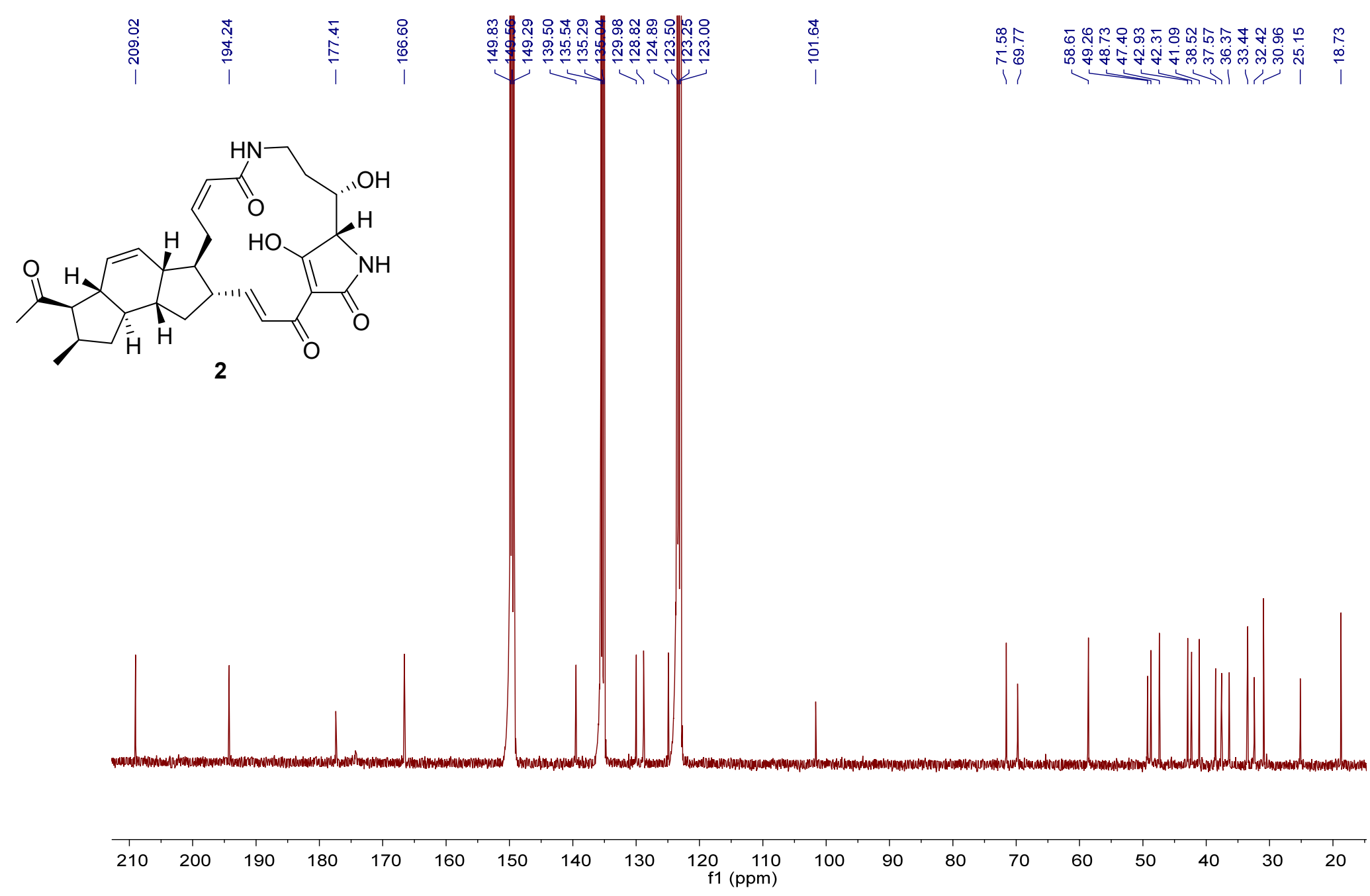

Figure S21. ${ }^{13} \mathrm{C}$ NMR spectrum of $\mathbf{2}$ in pyridine- $d_{5}$. 


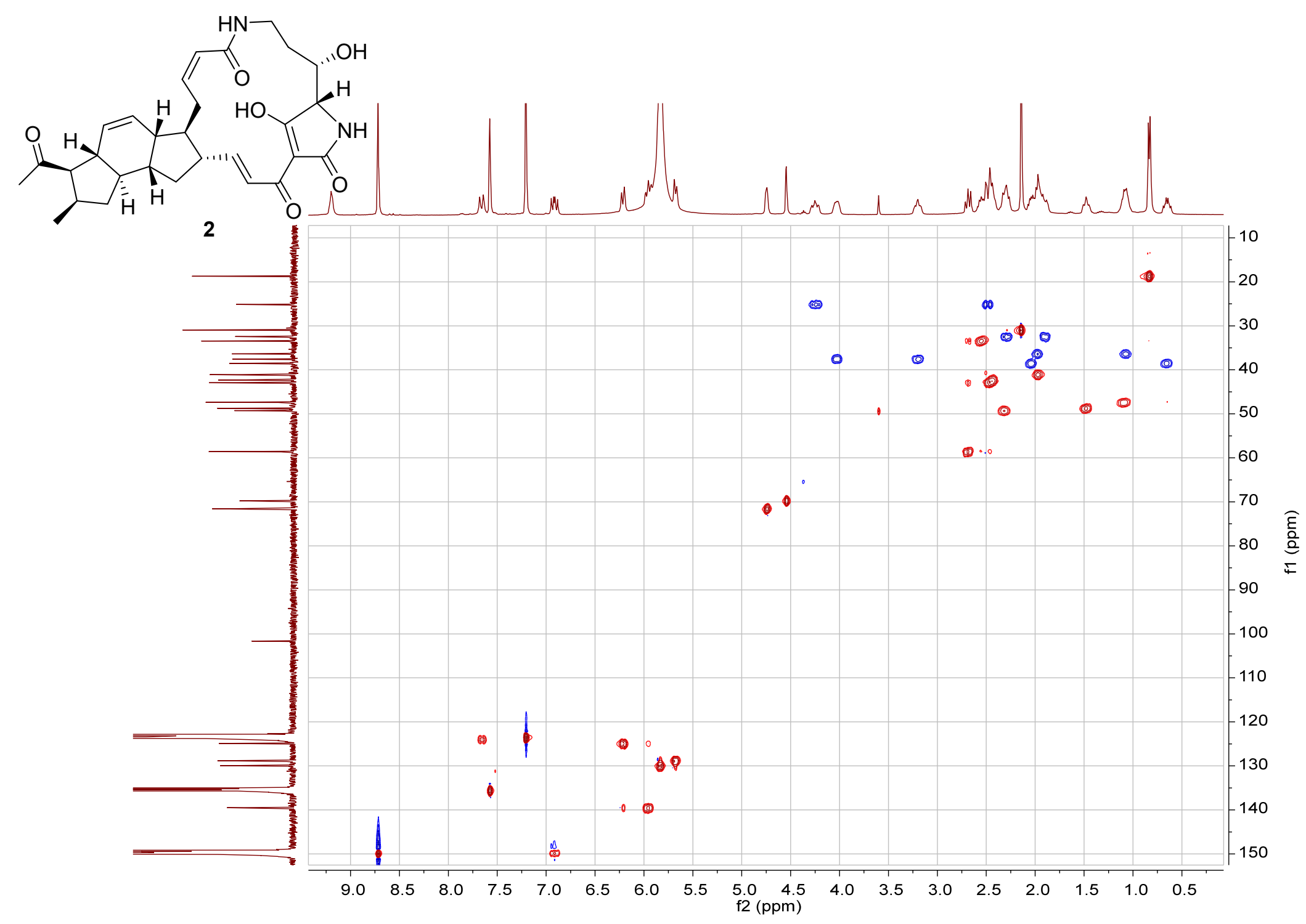

Figure S22. The HSQC spectrum of 2 in pyridine- $d_{5}$. 


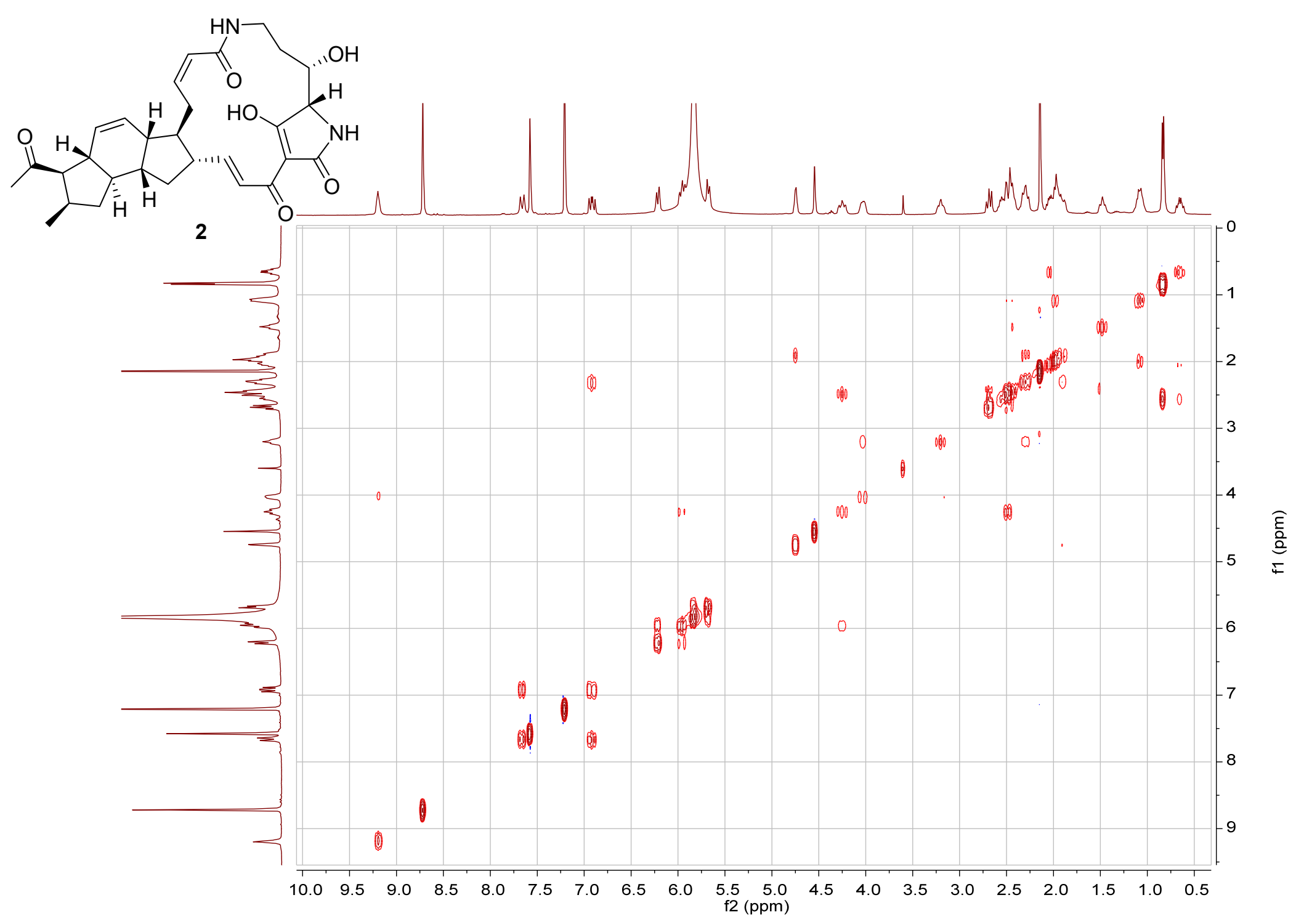

Figure S23. The ${ }^{1} \mathrm{H}-{ }^{1} \mathrm{H}$ COSY spectrum of 2 in pyridine- $d_{5}$. 


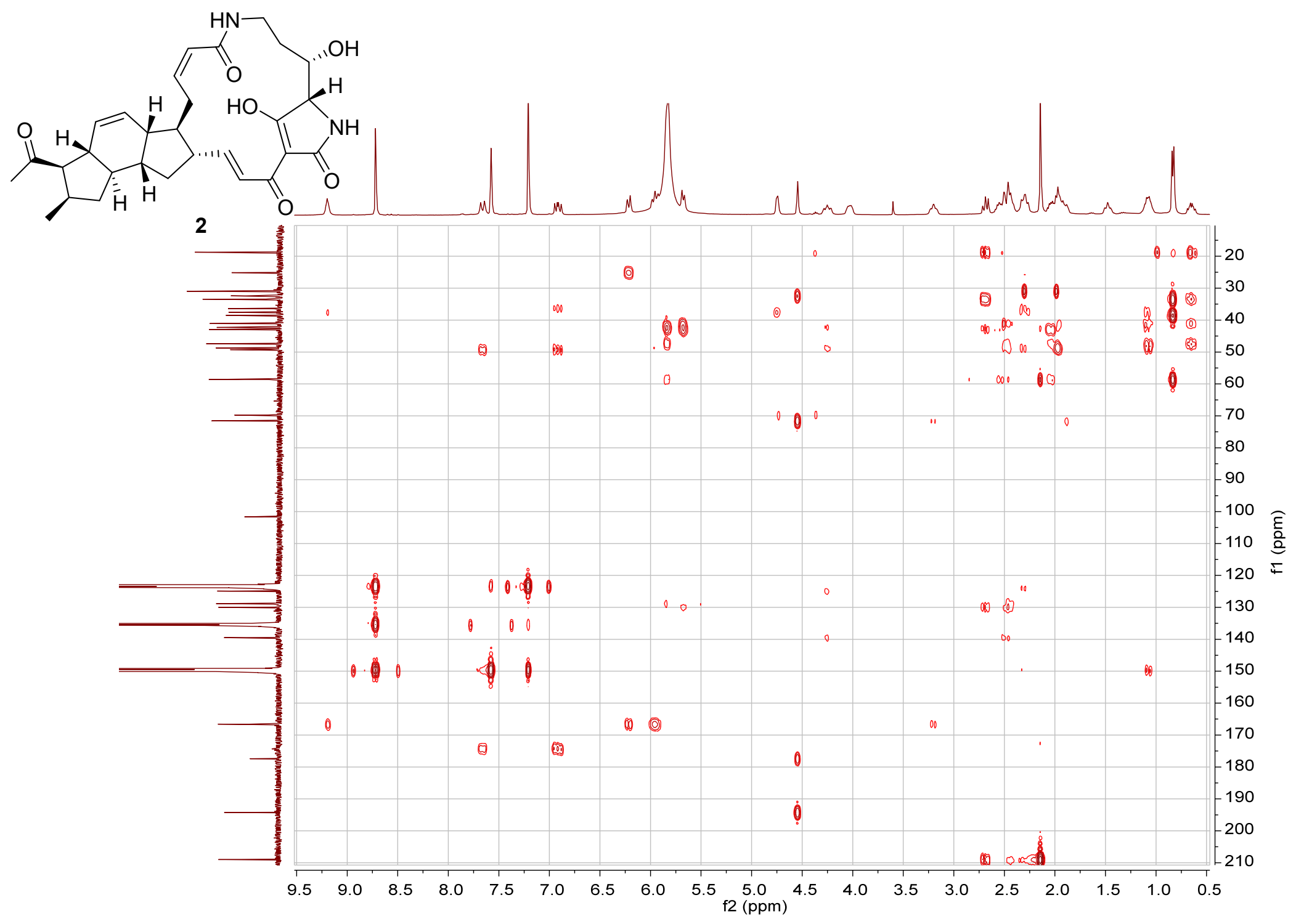

Figure S24. The HMBC spectrum of 2 in pyridine- $d_{5}$. 


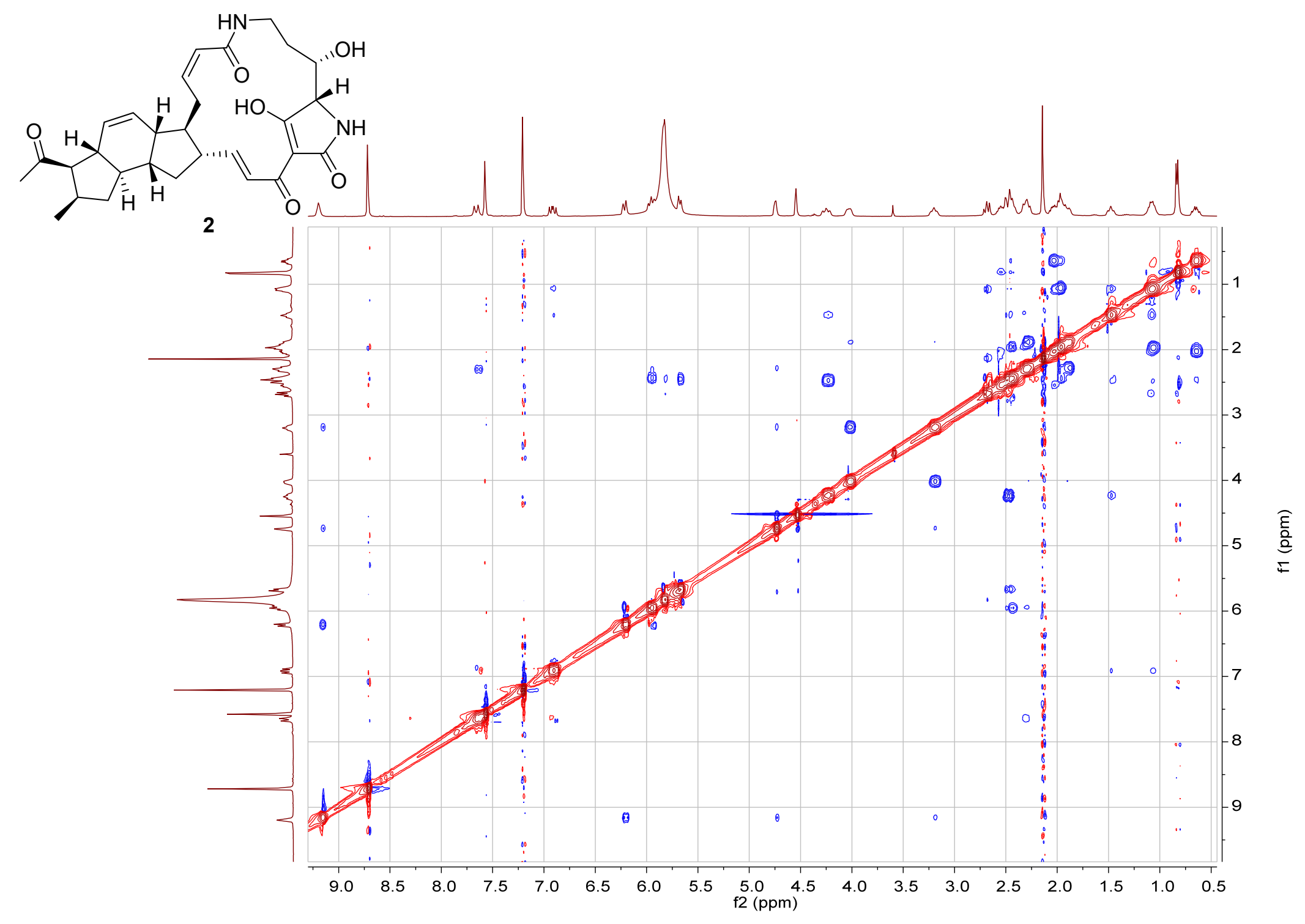

Figure S25. The NOESY spectrum of $\mathbf{2}$ in pyridine- $d_{5}$. 


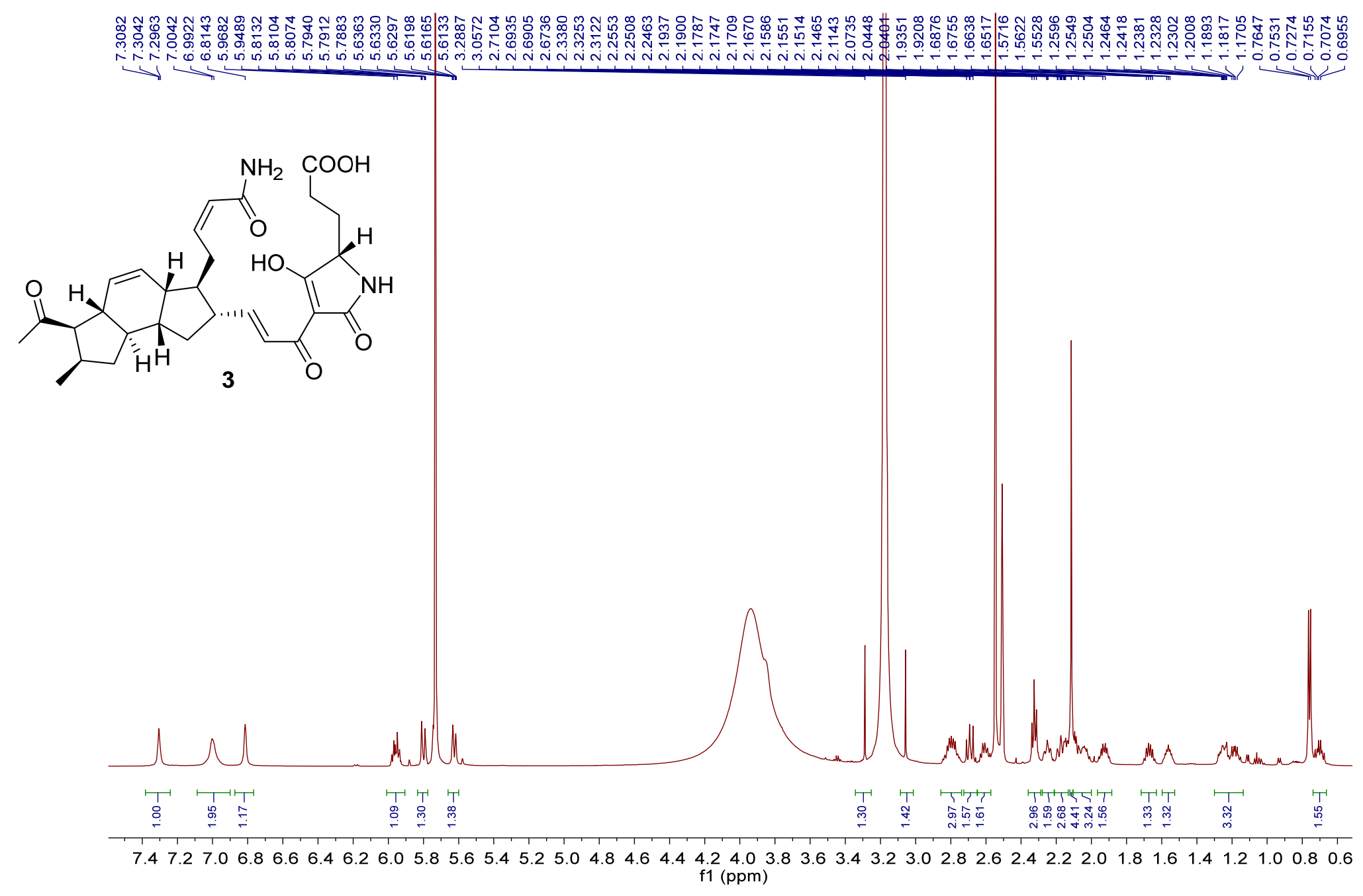

Figure S26. ${ }^{1} \mathrm{H}$ NMR spectrum of 3 in DMSO- $d_{6}$. 

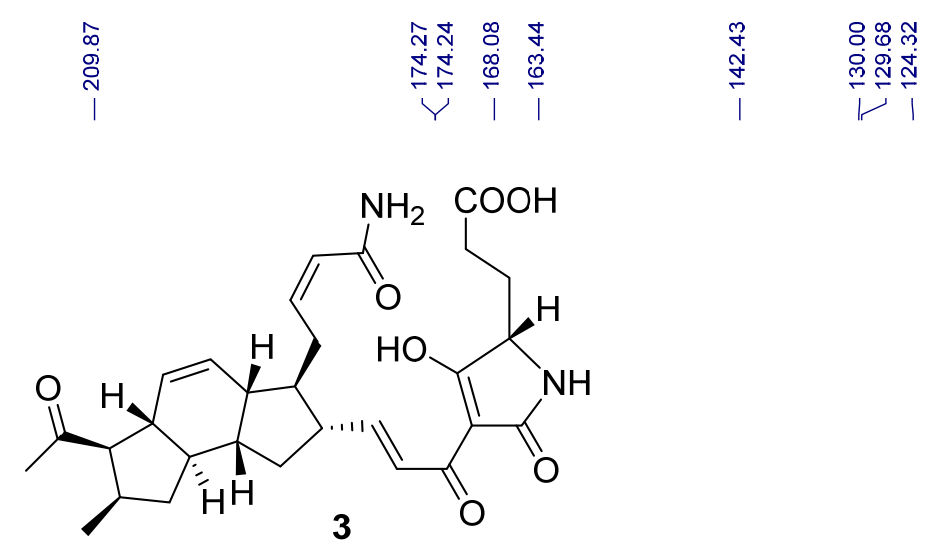

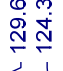

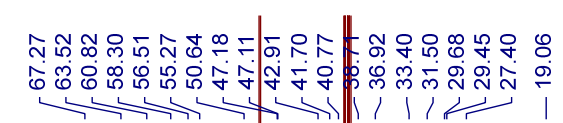

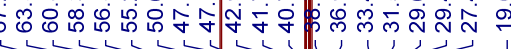
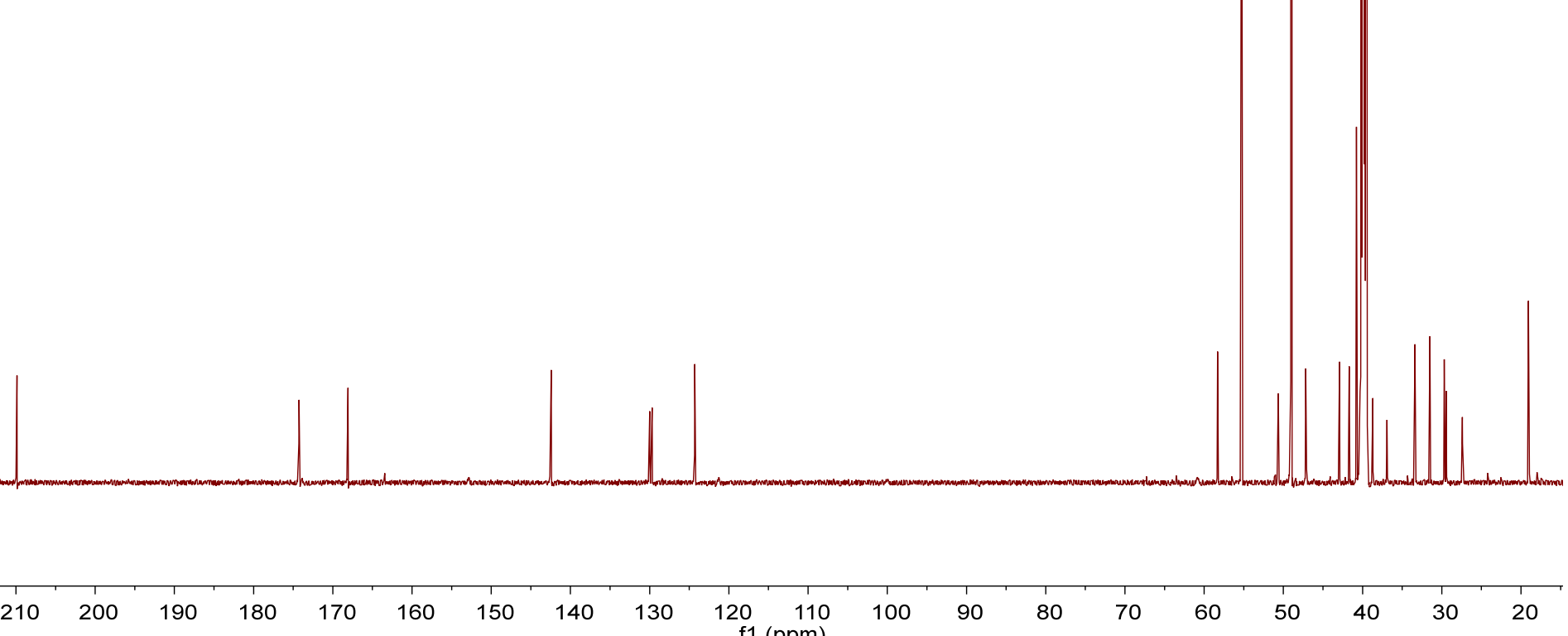

150

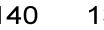

$\begin{array}{lr}120 & 110 \\ \mathrm{f} 1(\mathrm{ppm}) & 100\end{array}$
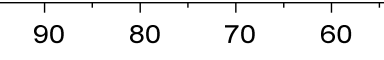

50

Figure S27. ${ }^{13} \mathrm{C}$ NMR spectrum of 3 in DMSO-d6. 


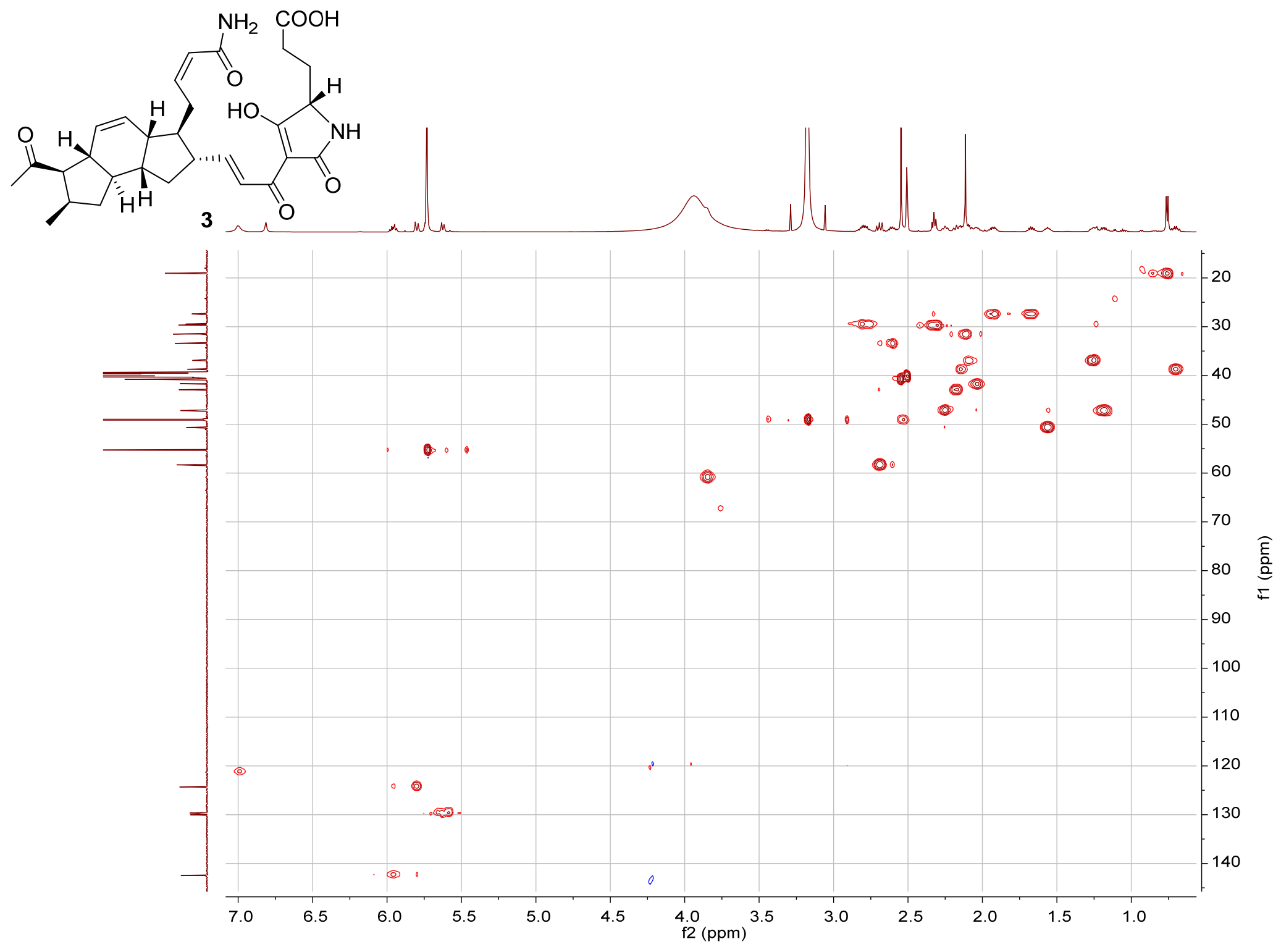

Figure S28. The HSQC spectrum of $\mathbf{3}$ in DMSO- $d_{6}$. 


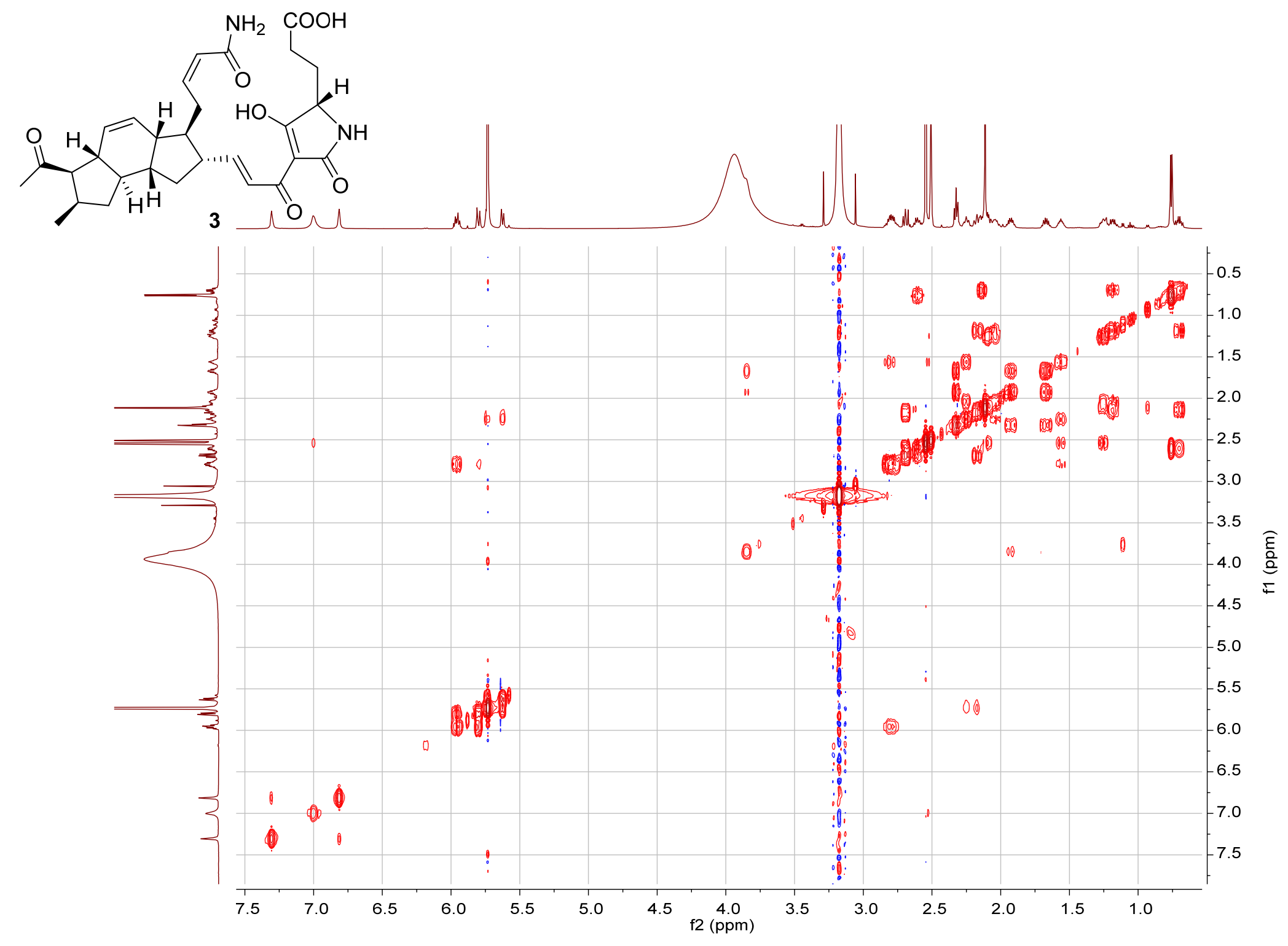

Figure S29. The ${ }^{1} \mathrm{H}-{ }^{-1} \mathrm{H}$ COSY spectrum of 3 in DMSO- $d_{6}$. 


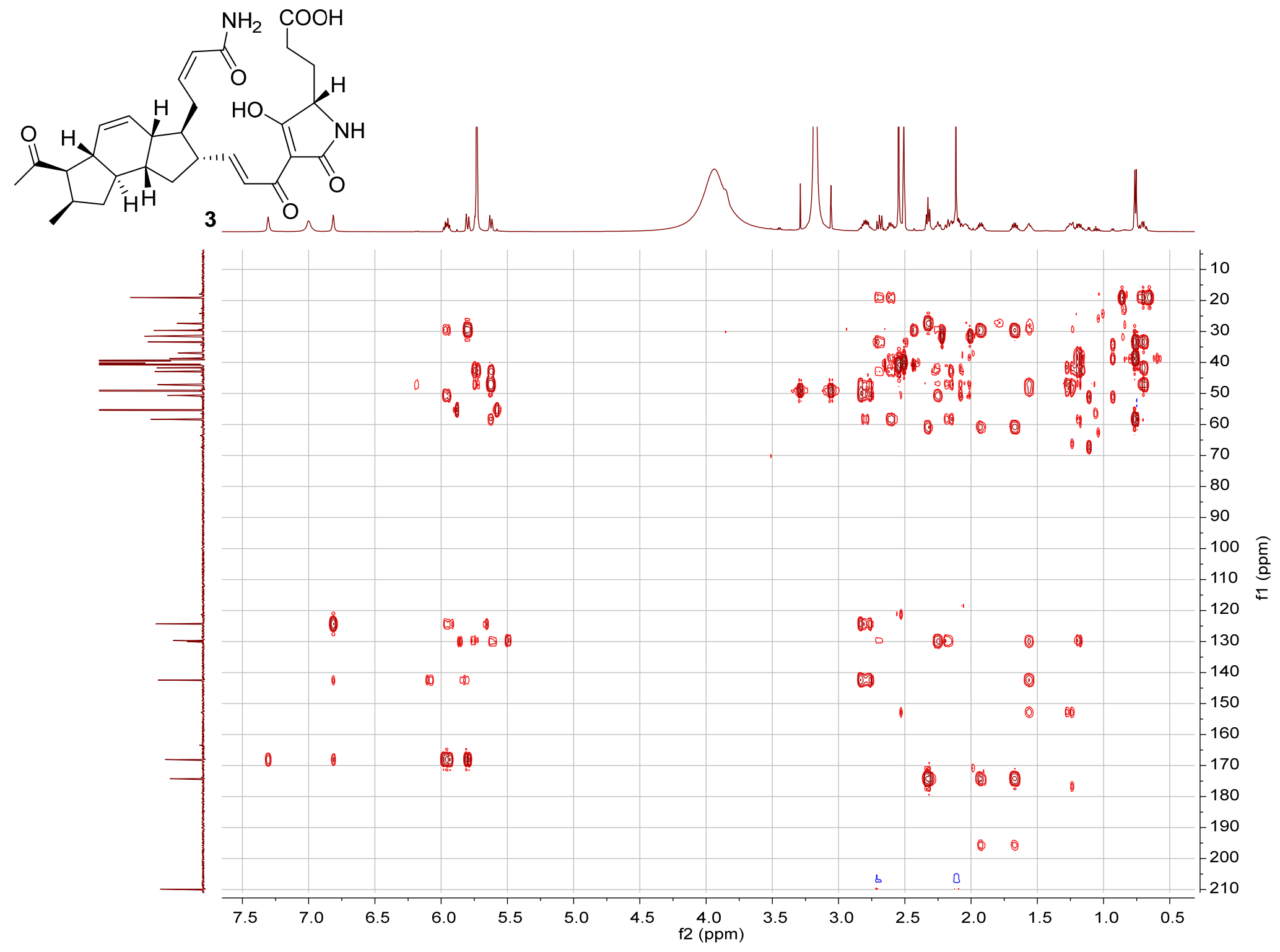

Figure S30. The HMBC spectrum of $\mathbf{3}$ in DMSO- $d_{6}$. 


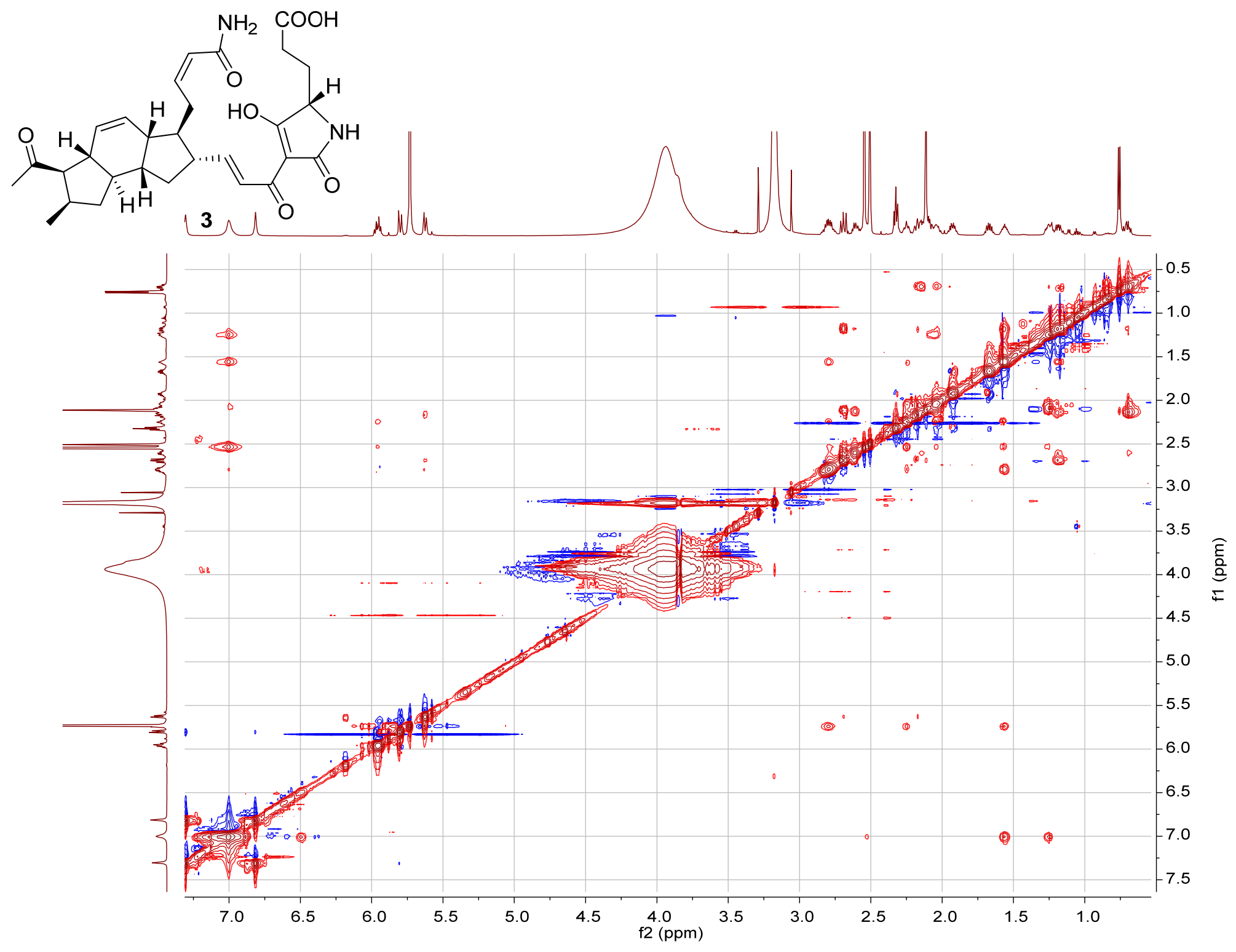

Figure S31. The NOESY spectrum of 3 in DMSO- $d_{6}$. 


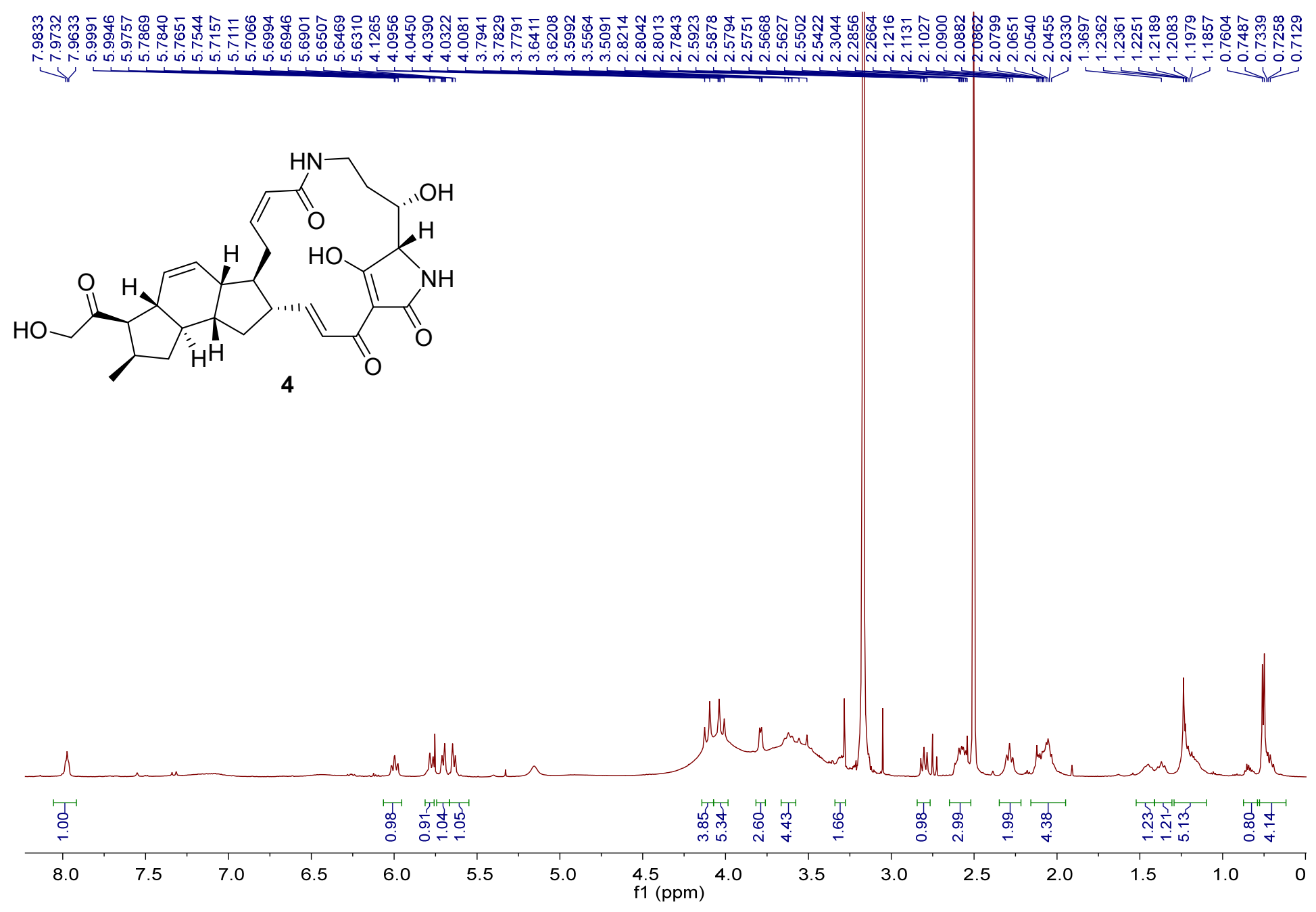

Figure S32. ${ }^{1} \mathrm{H}$ NMR spectrum of 4 in DMSO- $d_{6}$. 

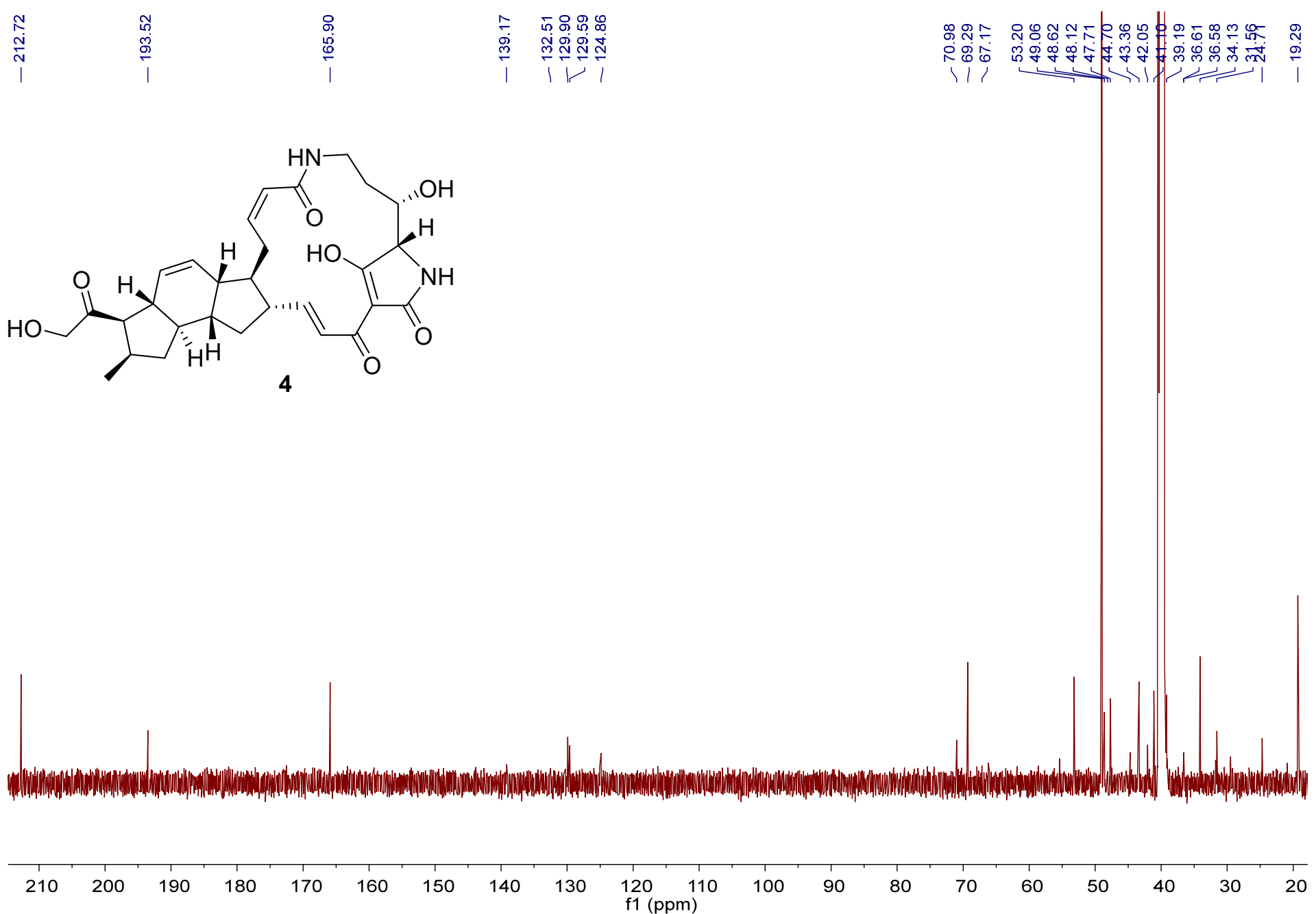

Figure S33. ${ }^{13} \mathrm{C}$ NMR spectrum of 4 in DMSO- $d_{6}$. 


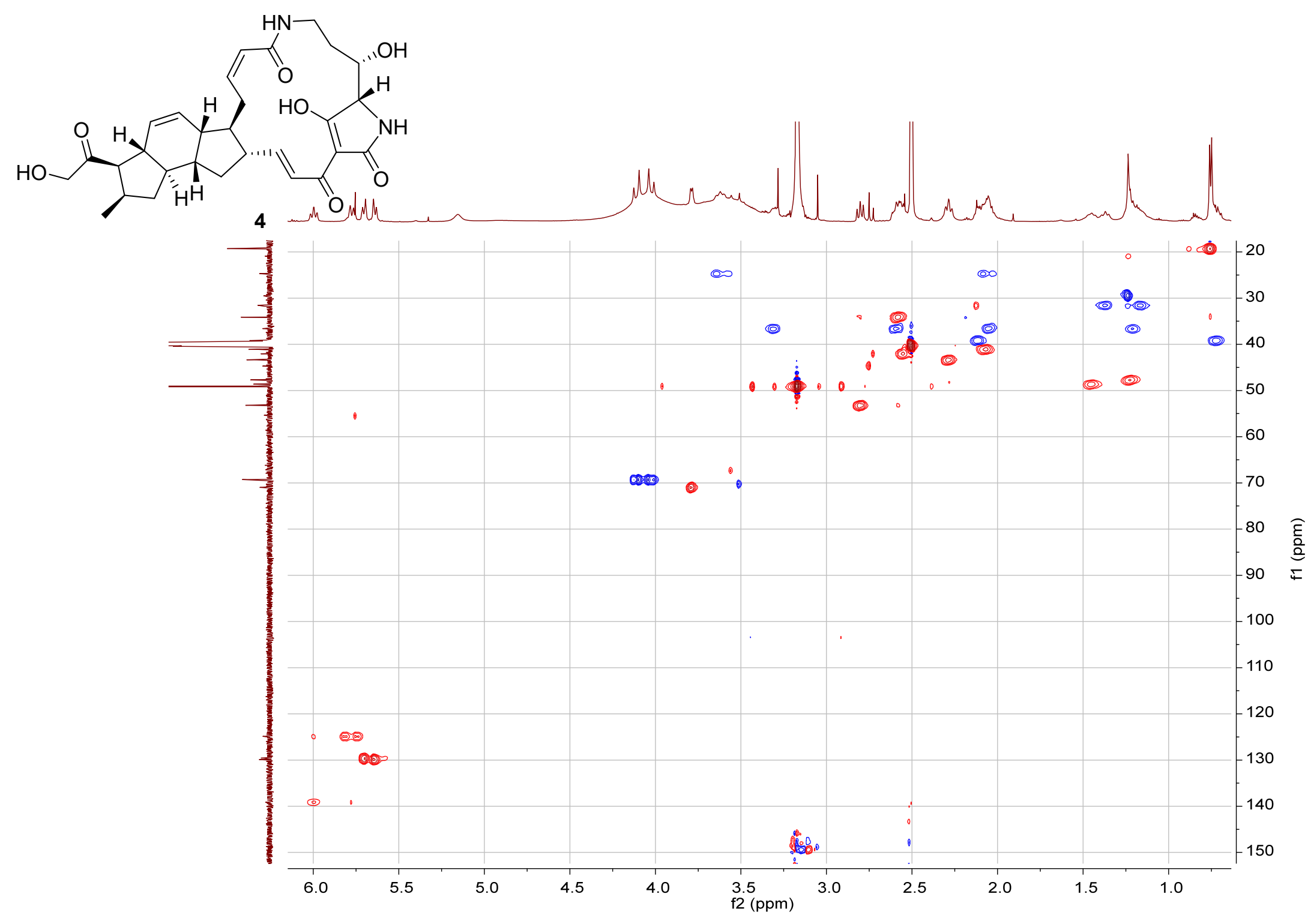

Figure S34. The HSQC spectrum of 4 in DMSO- $d_{6}$. 


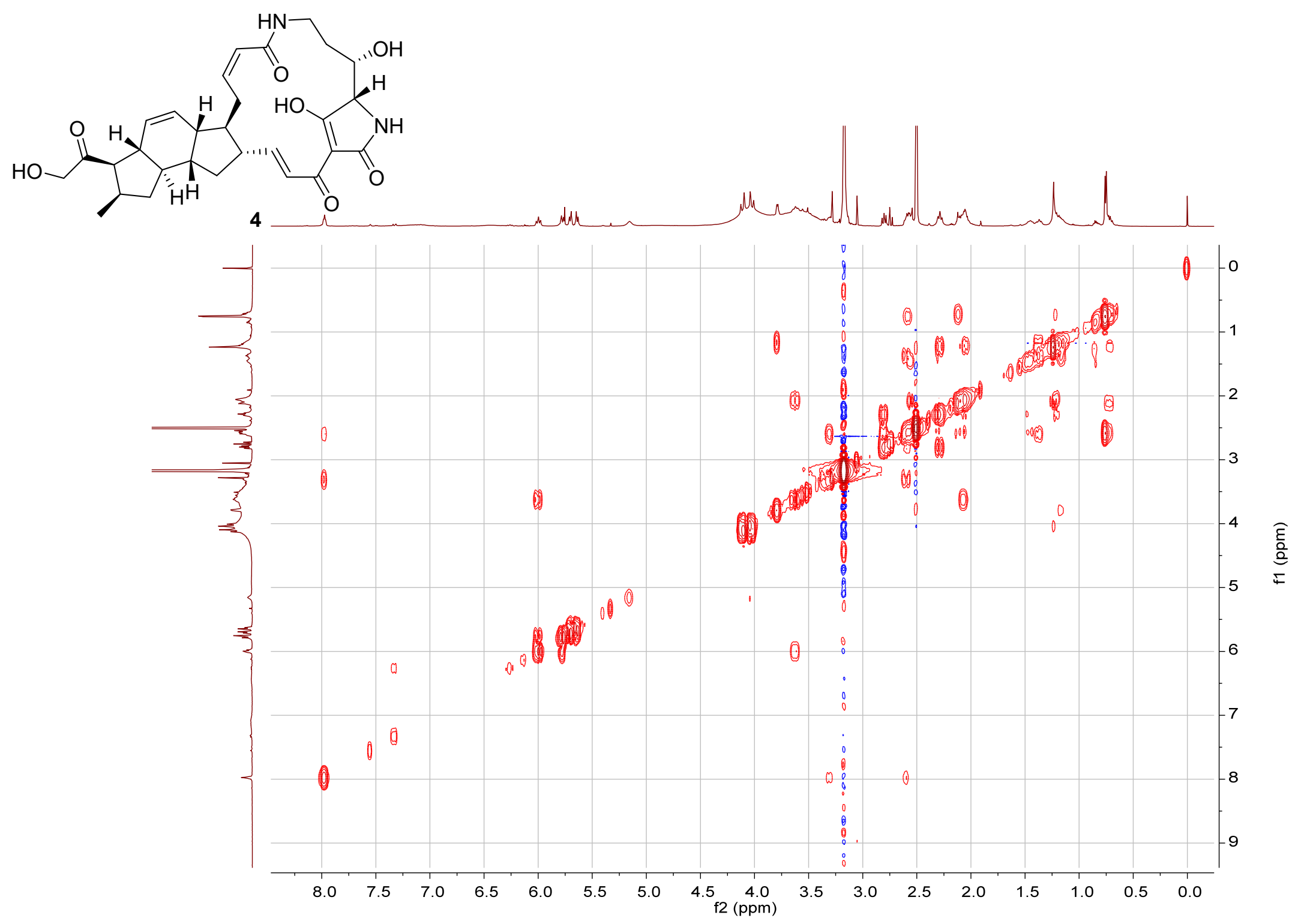

Figure S35. The ${ }^{1} \mathrm{H}-{ }^{1} \mathrm{H}$ COSY spectrum of 4 in DMSO- $d 6$. 


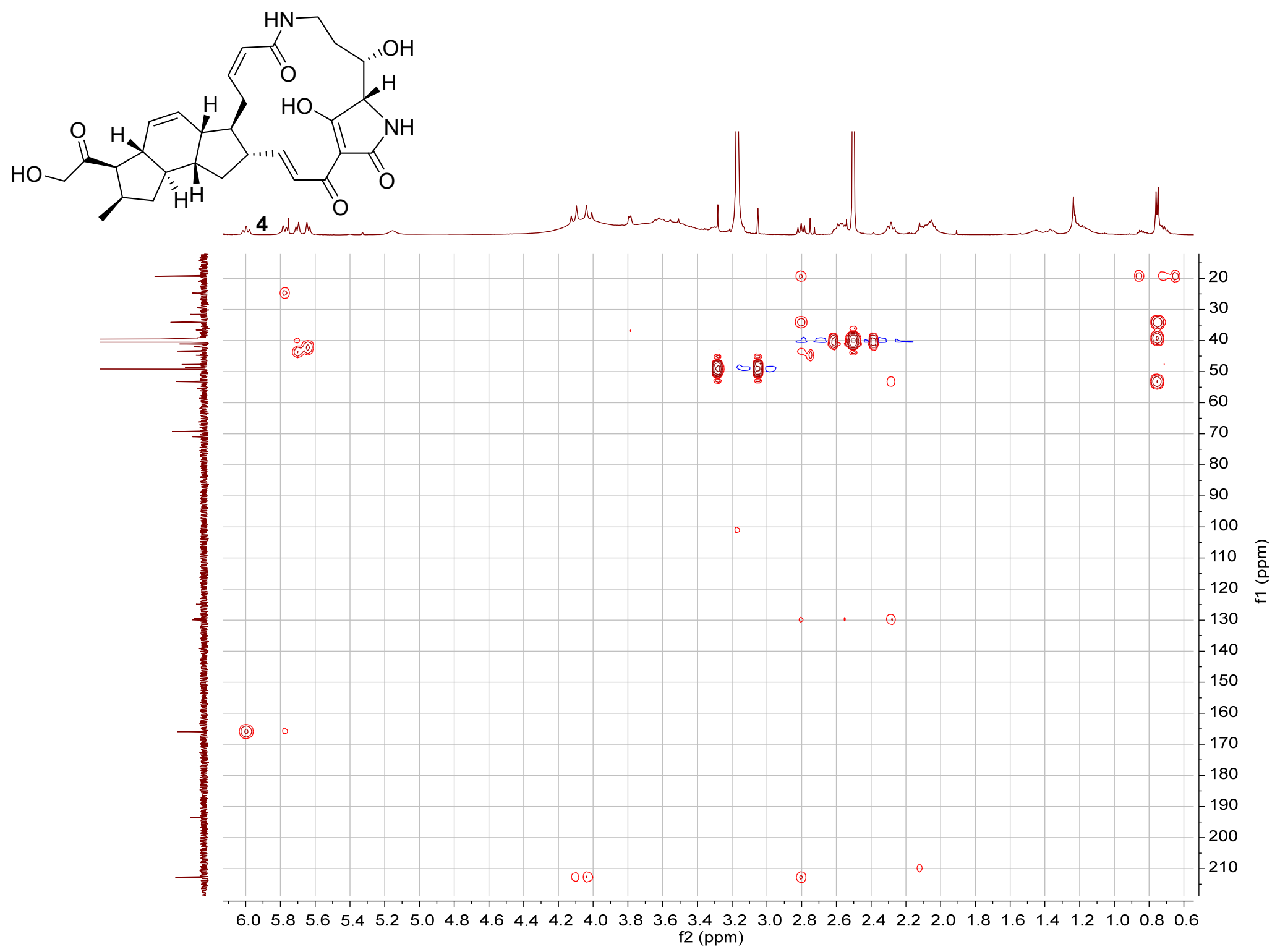

Figure S36. The HMBC spectrum of $\mathbf{4}$ in DMSO-d6. 


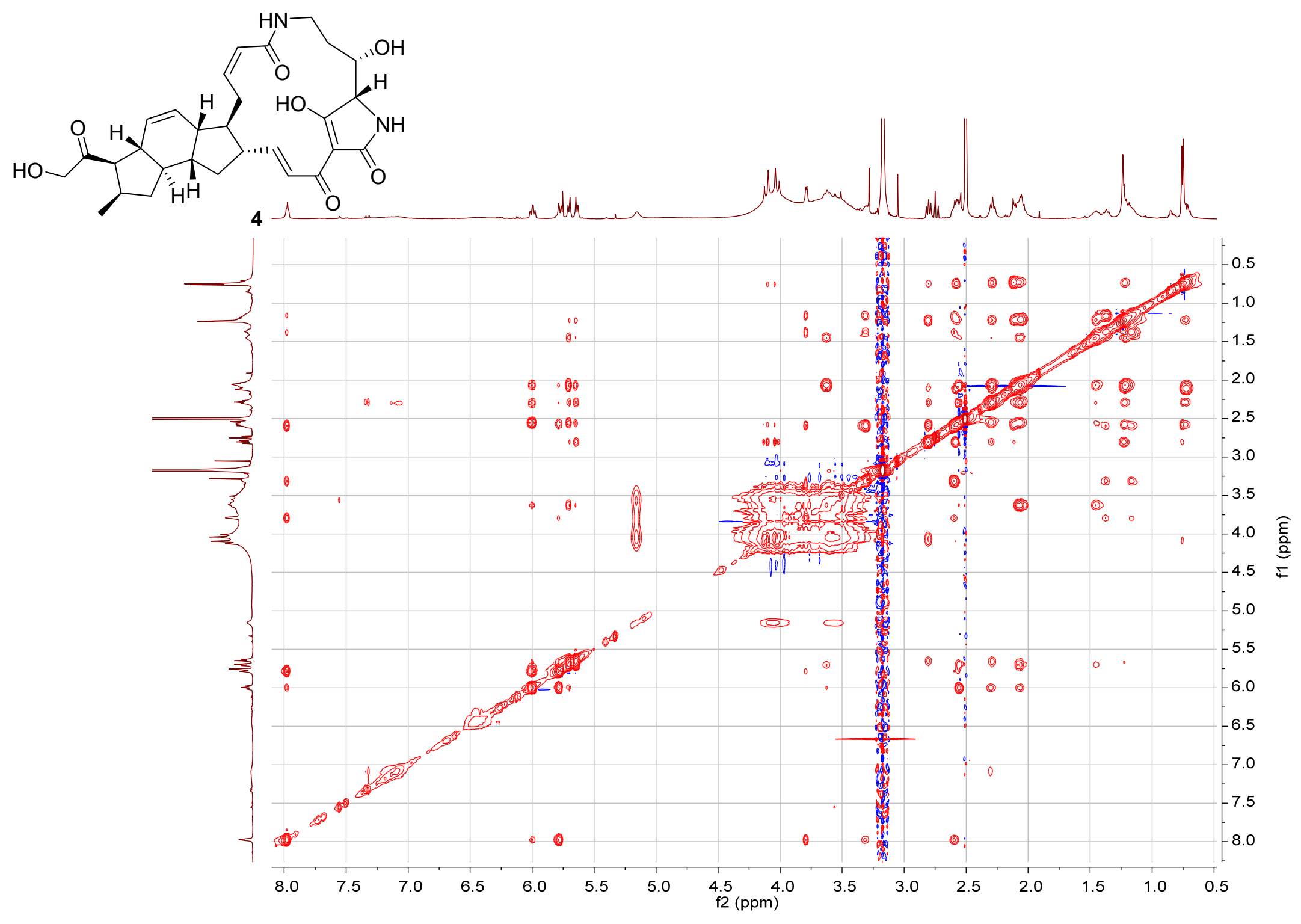

Figure S37. The NOESY spectrum of 4 in DMSO- $d_{6}$. 


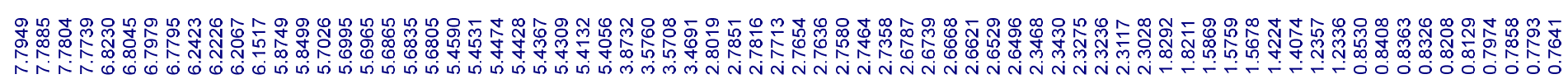<smiles></smiles>

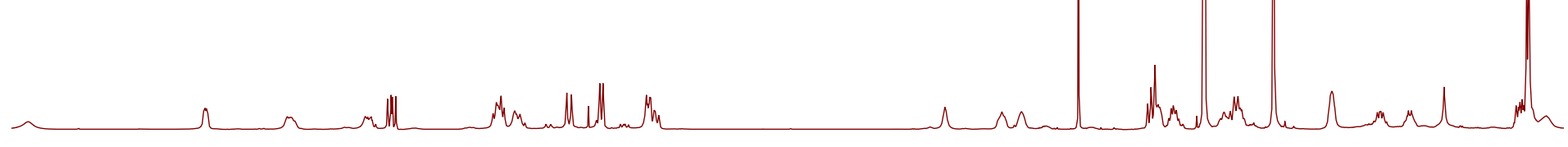

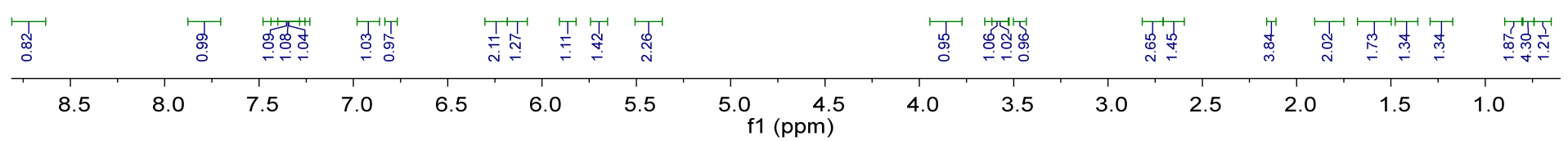

Figure S38. ${ }^{1} \mathrm{H}$ NMR spectrum of 5 in DMSO- $d_{6}$. 


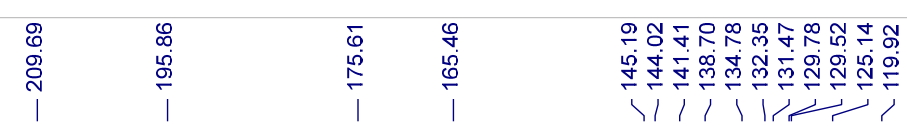

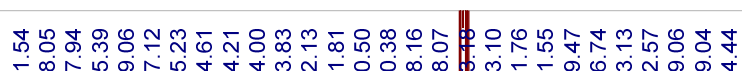

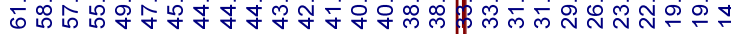
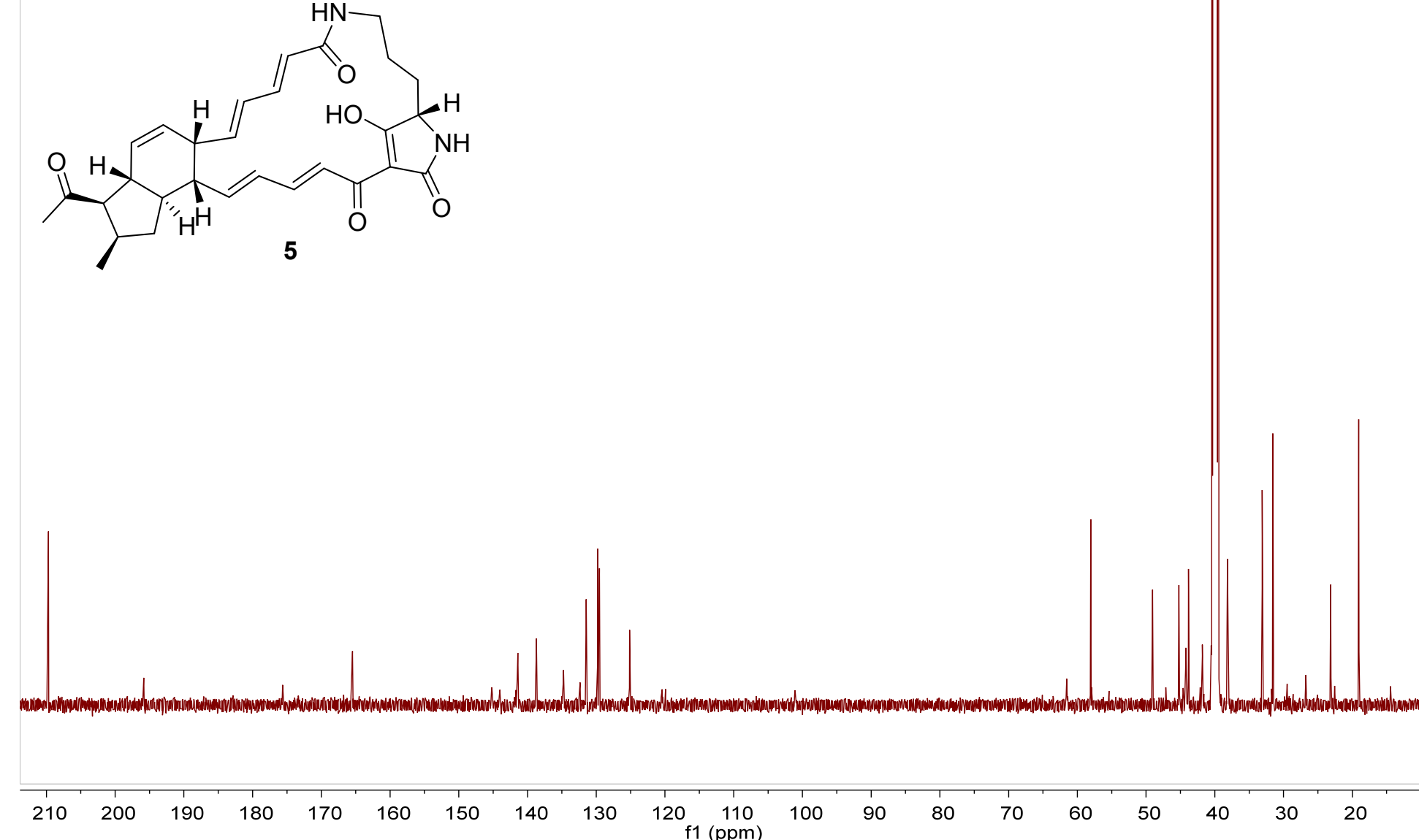

Figure S39. ${ }^{13} \mathrm{C}$ NMR spectrum of 5 in DMSO-d6. 


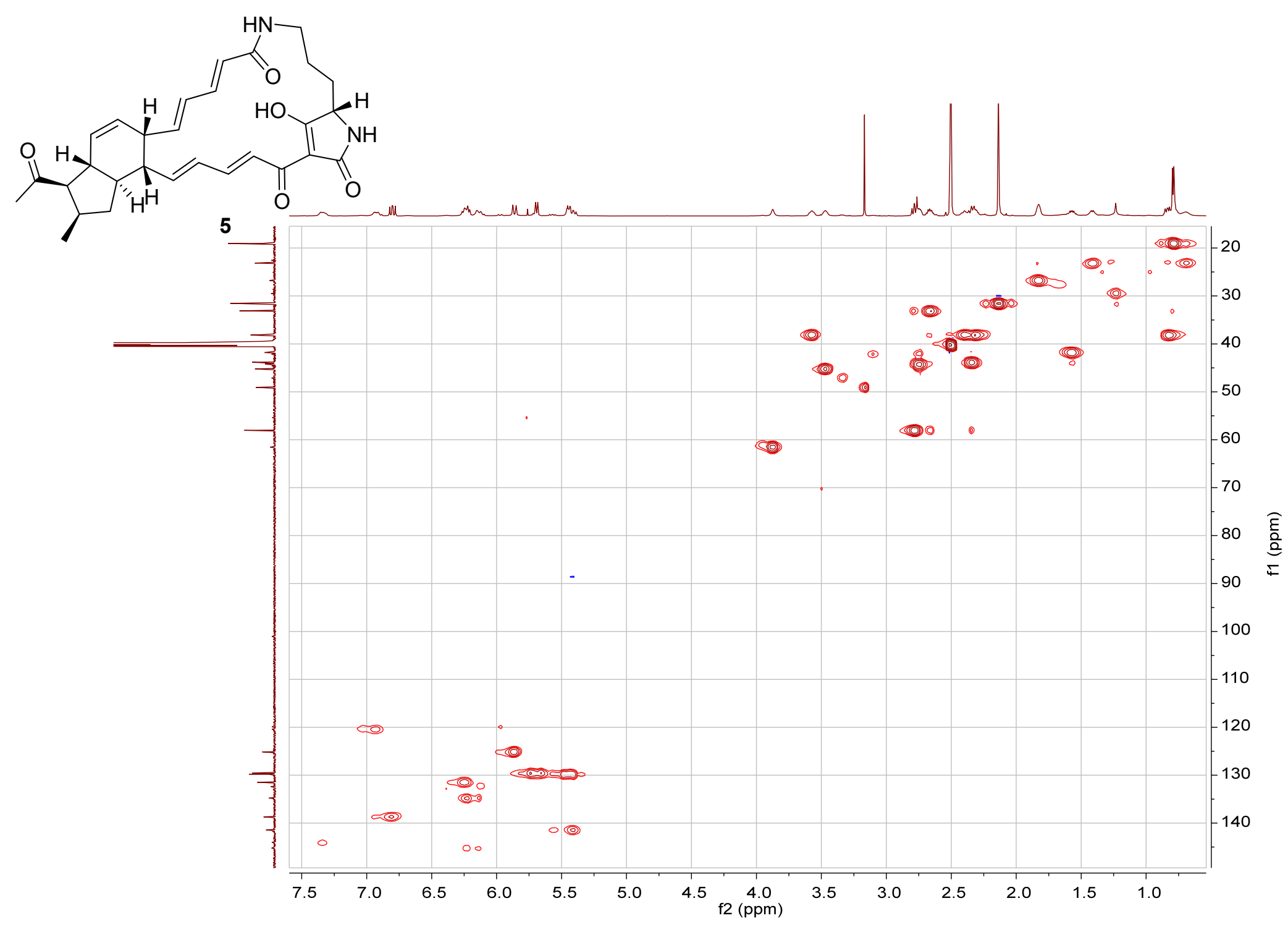

Figure S40. The HSQC spectrum of 5 in DMSO- $d_{6}$. 


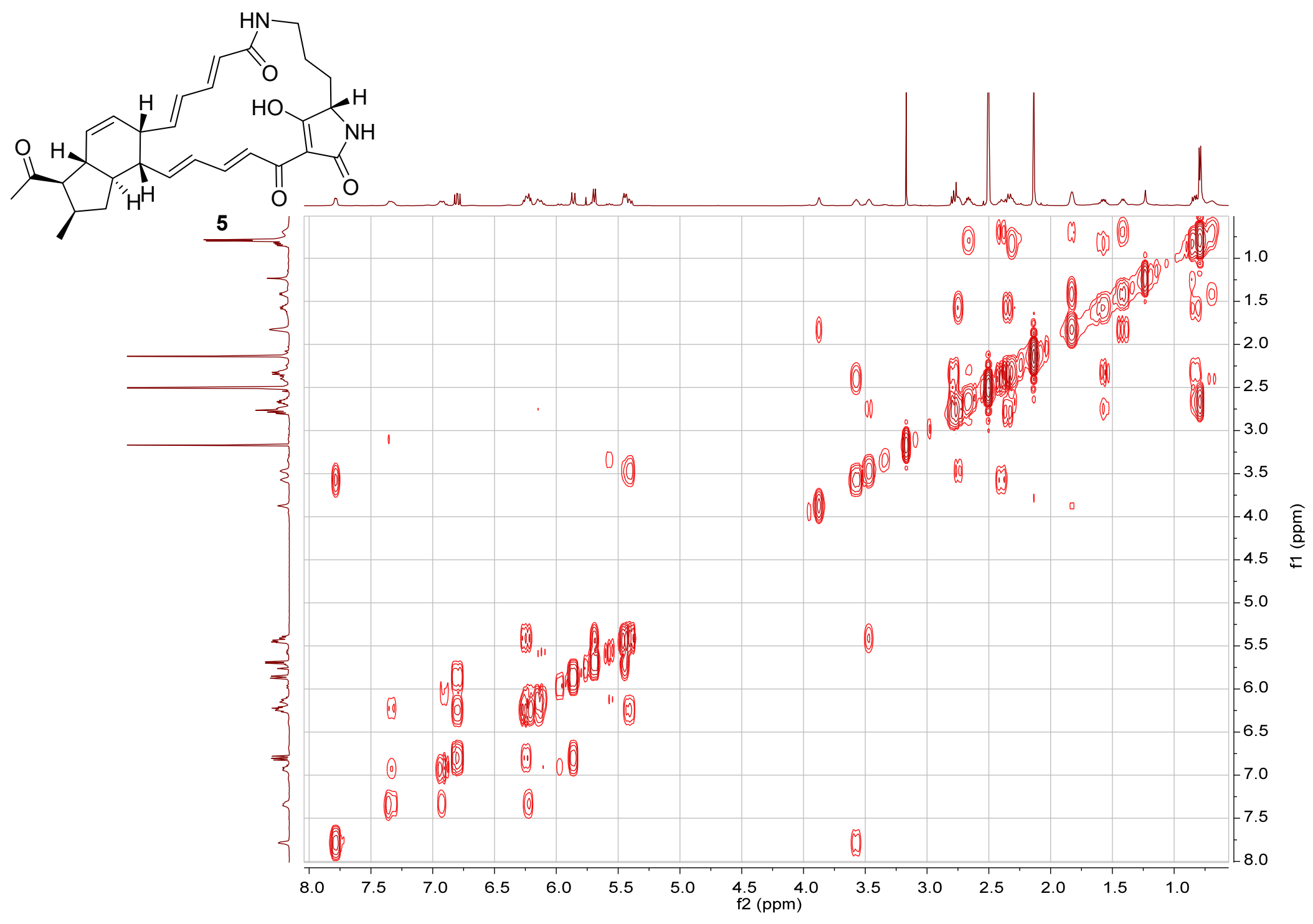

Figure S41. The ${ }^{1} \mathrm{H}-{ }^{-1} \mathrm{H}$ COSY spectrum of 5 in DMSO- $d_{6}$. 


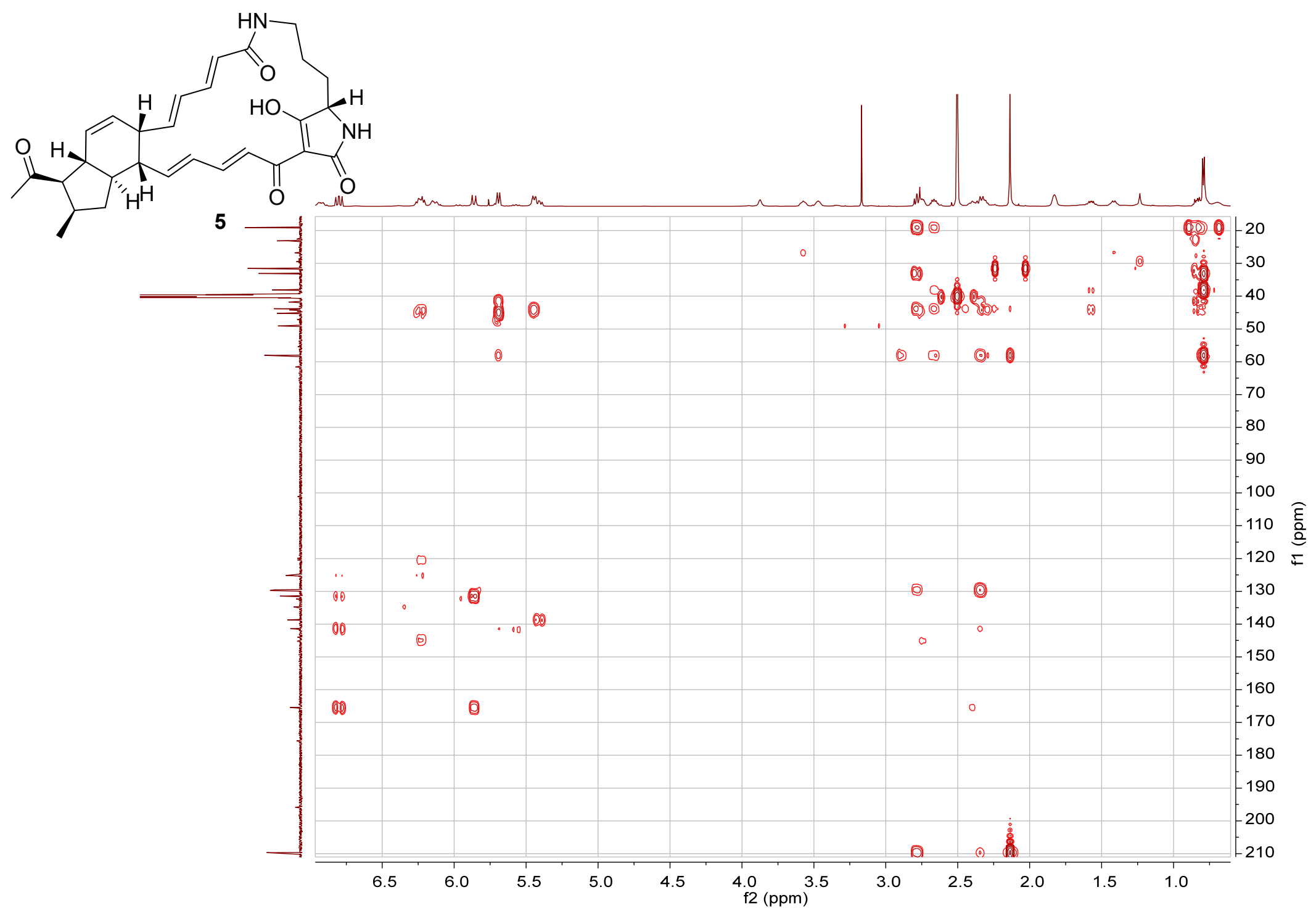

Figure S42. The HMBC spectrum of $\mathbf{5}$ in DMSO- $d_{6}$. 


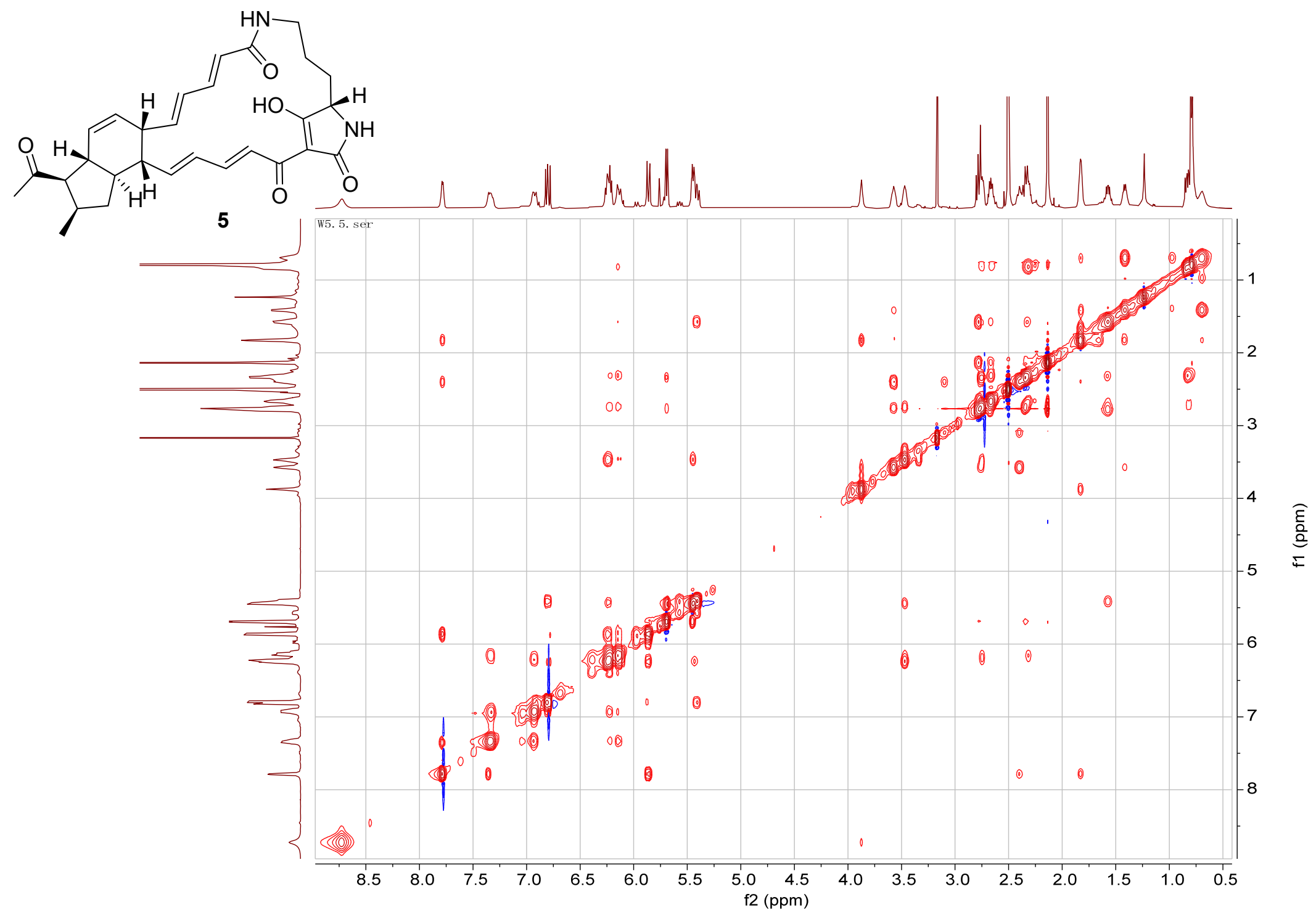

Figure S43. The NOESY spectrum of 5 in DMSO- $d_{6}$. 


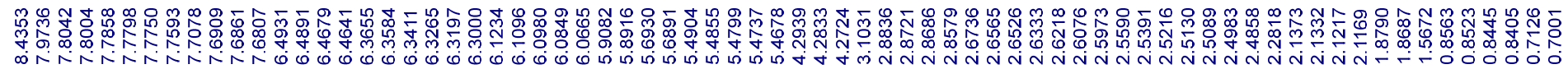

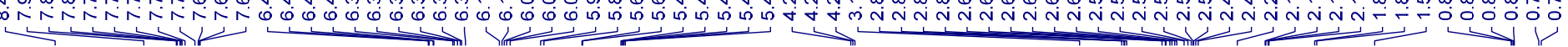<smiles>CC(=O)C1C(C)CC2C(/C=C/C=C/C(=O)C3=C(O)[C@@H](CC(=O)O)NC3=O)C=CC21</smiles>

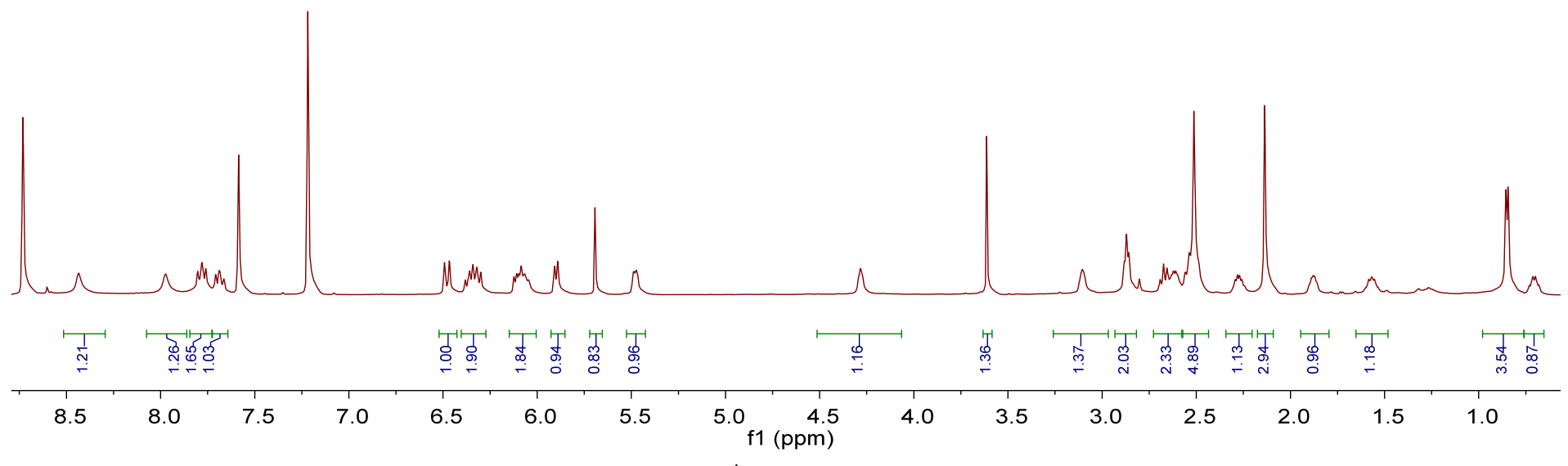

Figure S44. ${ }^{1} \mathrm{H}$ NMR spectrum of 6 in pyridine- $d_{5}$. 


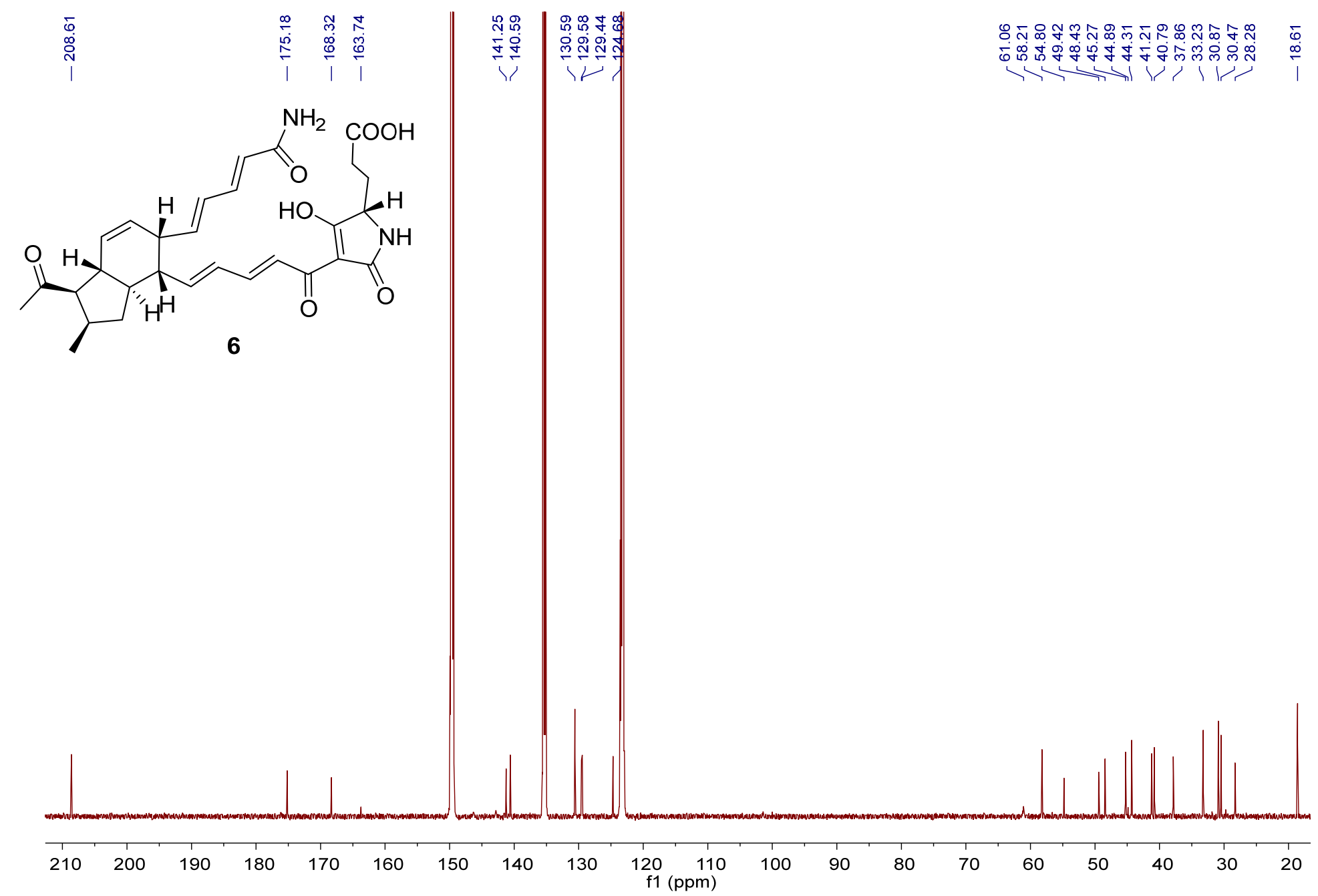

Figure S45. ${ }^{13} \mathrm{C}$ NMR spectrum of 6 in pyridine- $d_{5}$. 


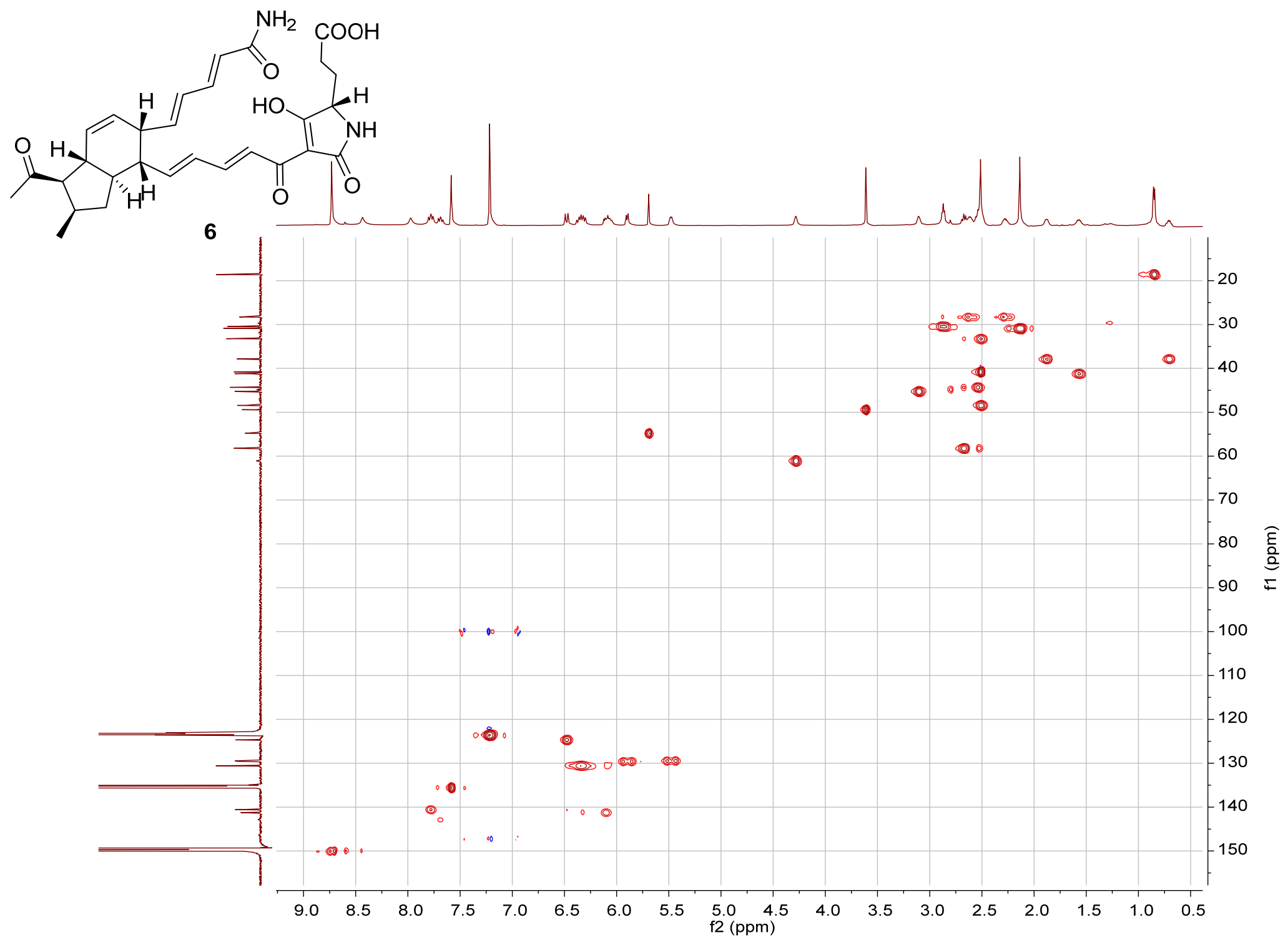

Figure S46. The HSQC spectrum of 6 in pyridine- $d_{5}$. 


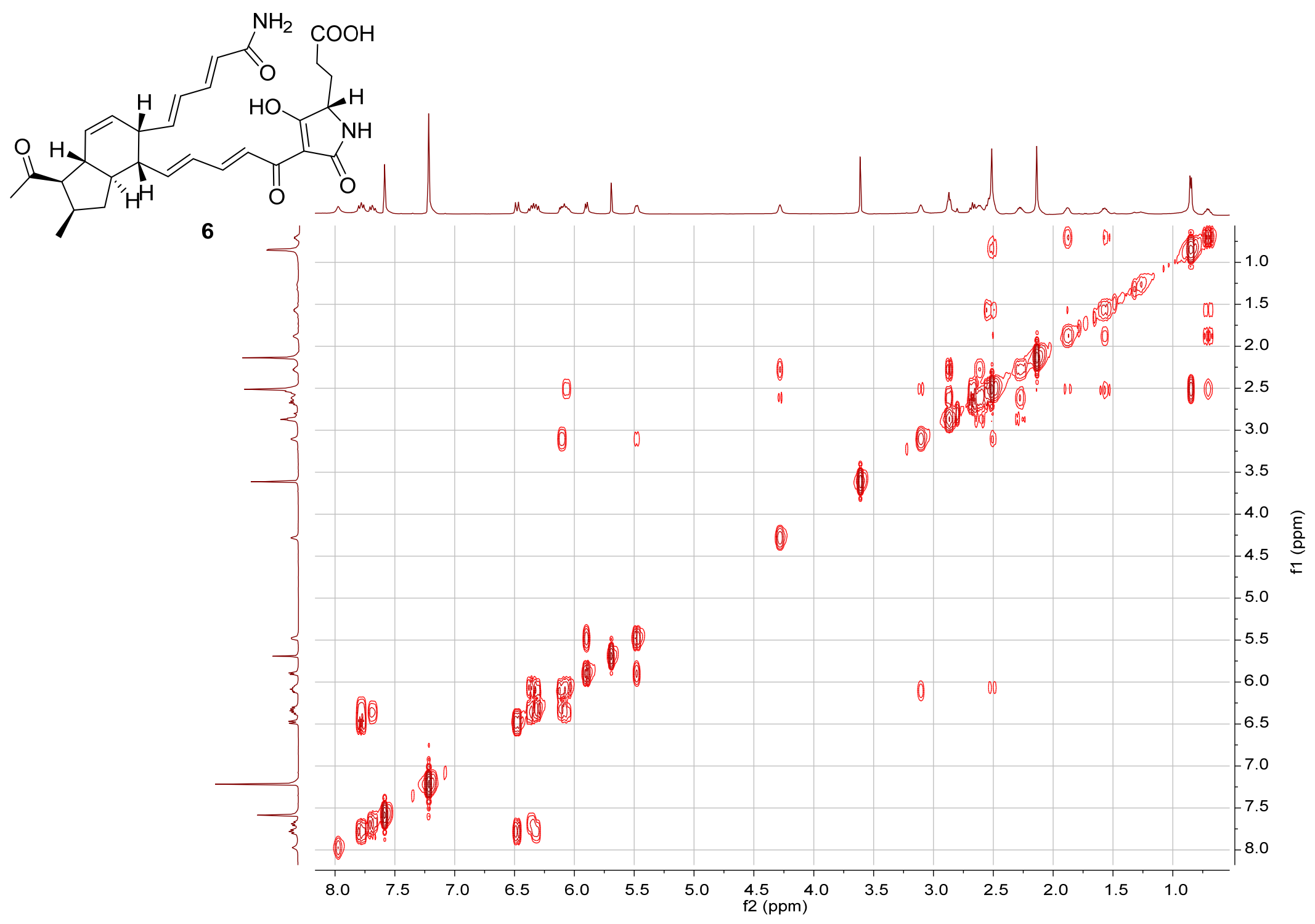

Figure S47. The ${ }^{1} \mathrm{H}-{ }^{1} \mathrm{H}$ COSY spectrum of 6 in pyridine- $d_{5}$. 


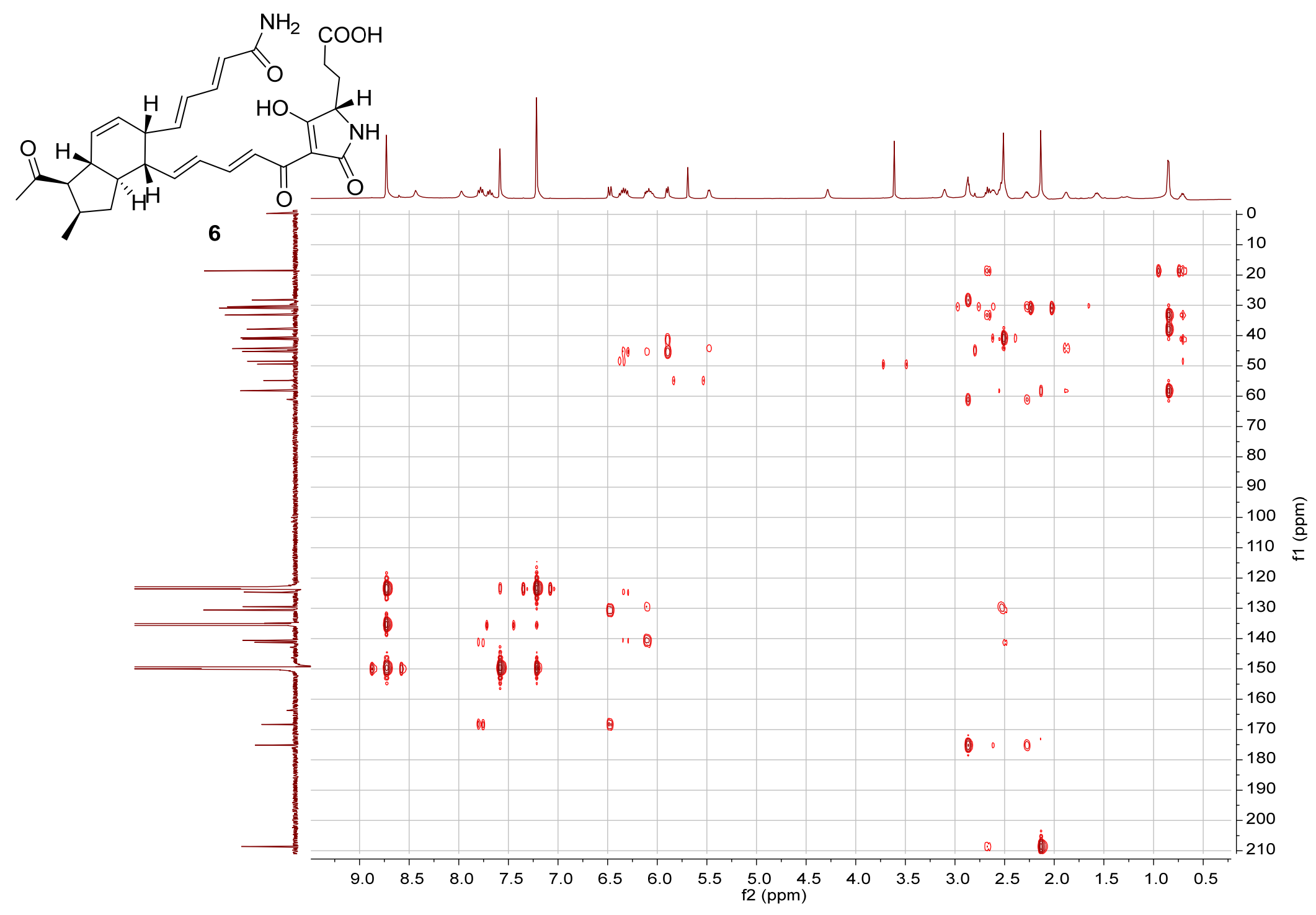

Figure S48. The HMBC spectrum of 6 in pyridine- $d_{5}$. 


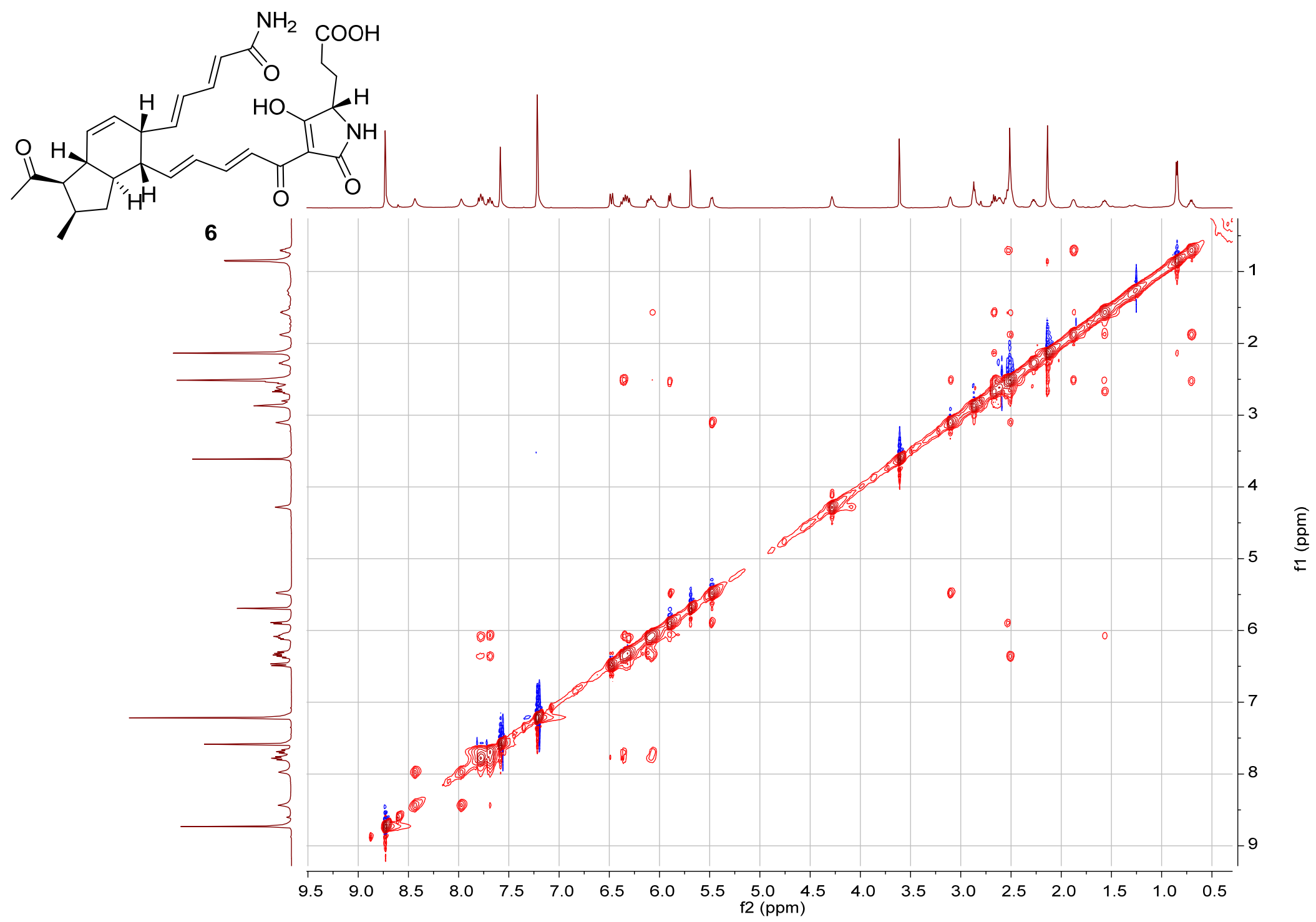

Figure S49. The NOESY spectrum of 6 in pyridine- $d_{5}$.

S51 


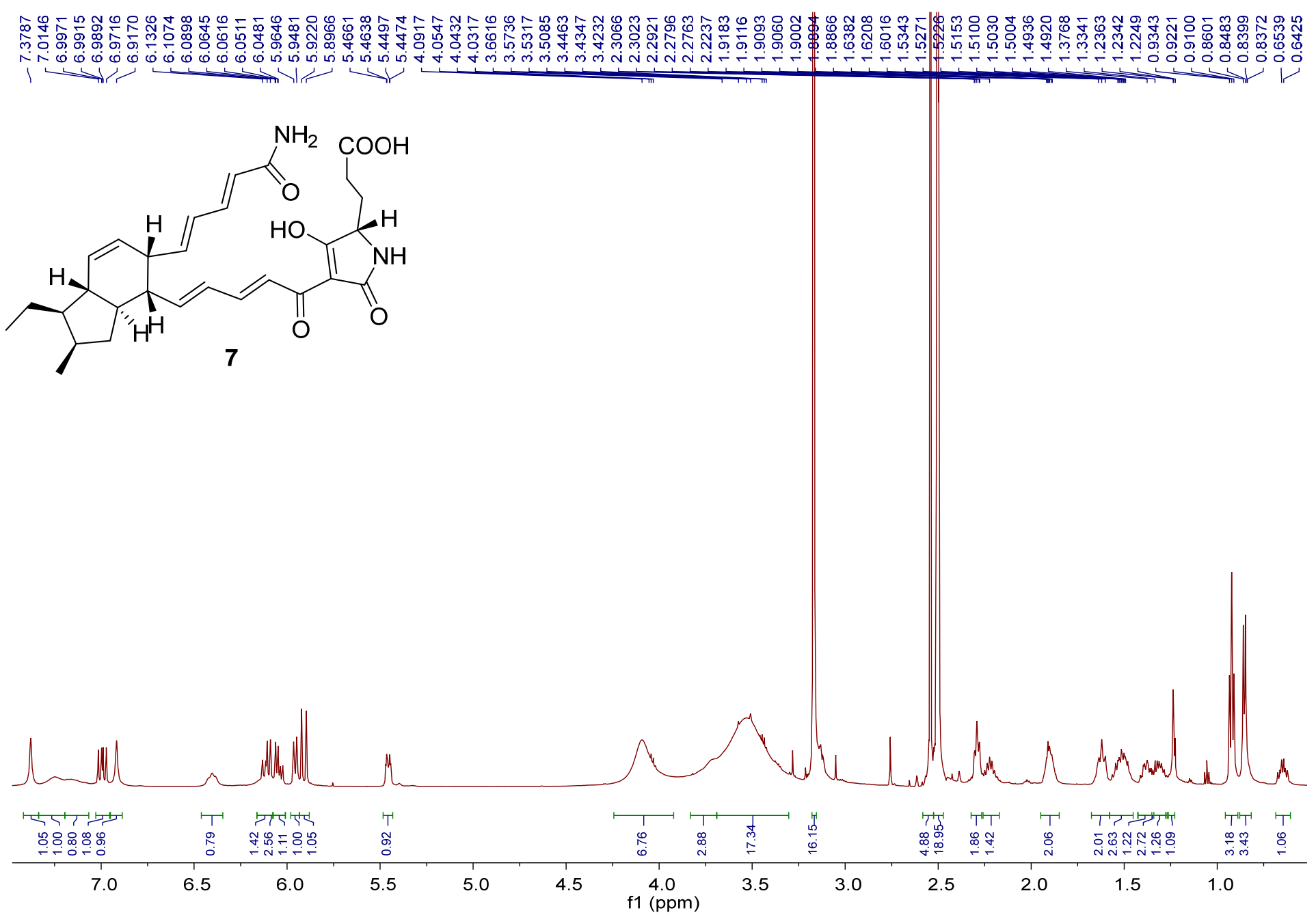

Figure S50. ${ }^{1} \mathrm{H}$ NMR spectrum of 7 in DMSO- $d_{6}$. 

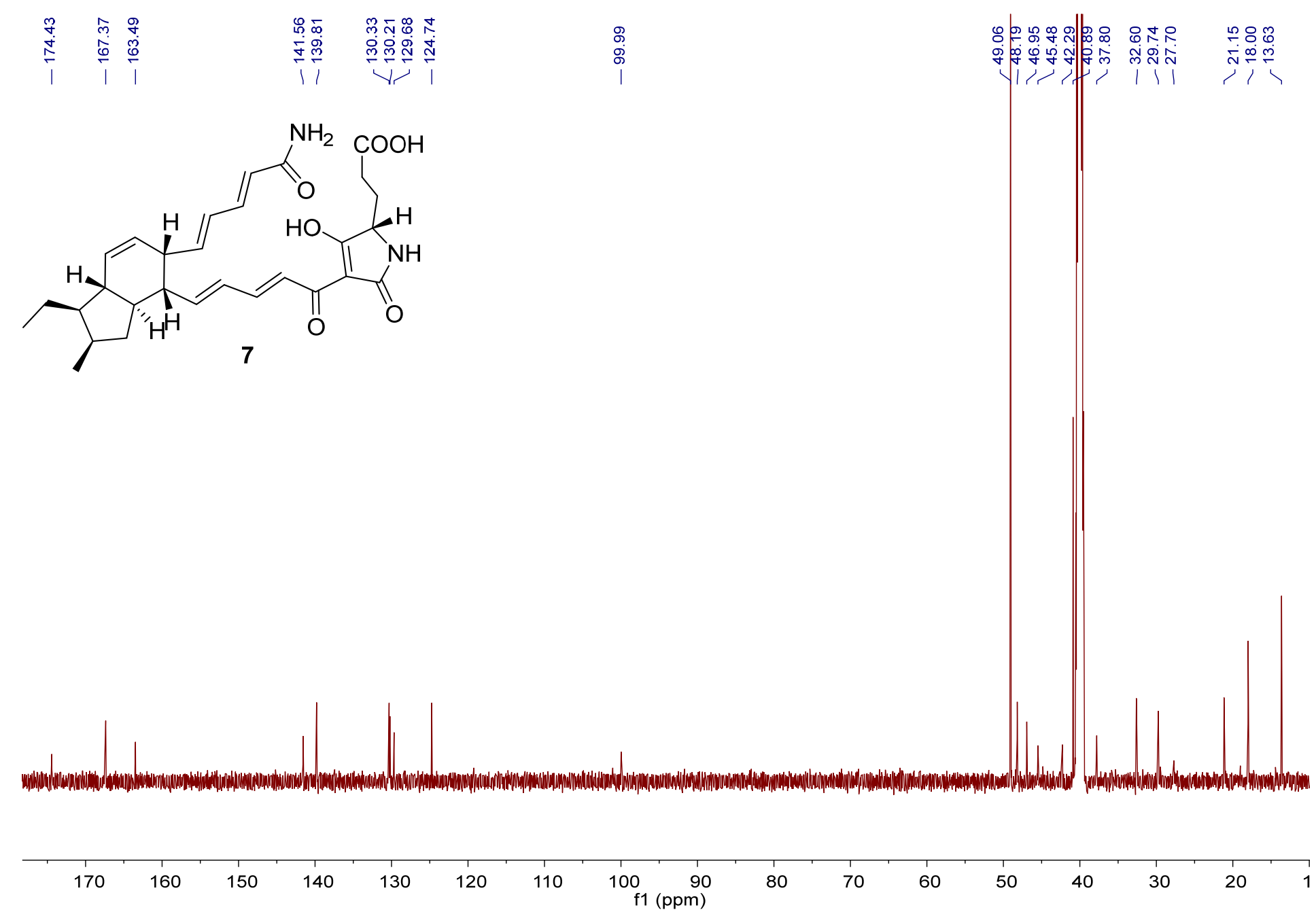

Figure S51. ${ }^{13} \mathrm{C}$ NMR spectrum of 7 in DMSO- $d_{6}$. 


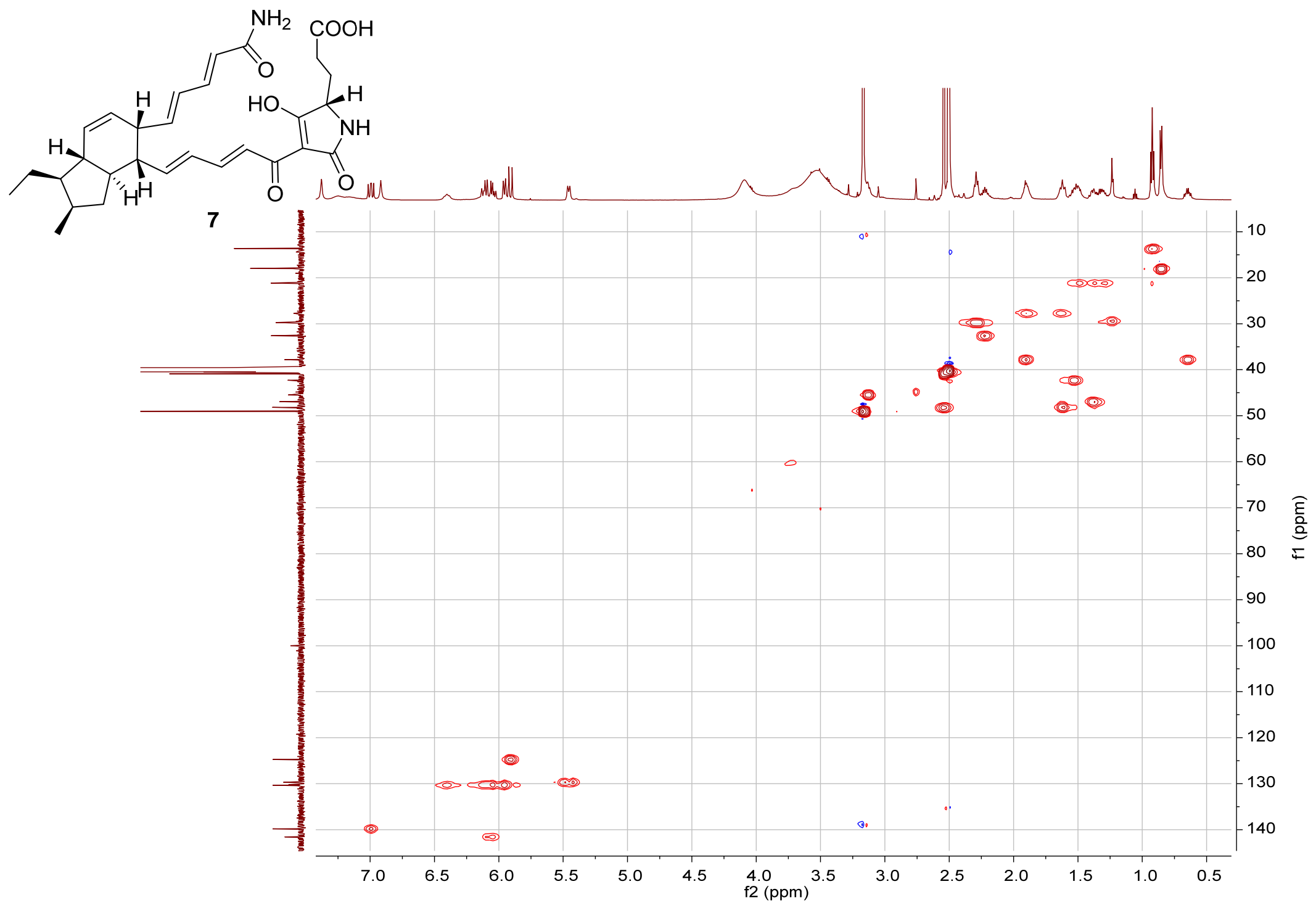

Figure S52. The HSQC spectrum of 7 in DMSO- $d_{6}$. 


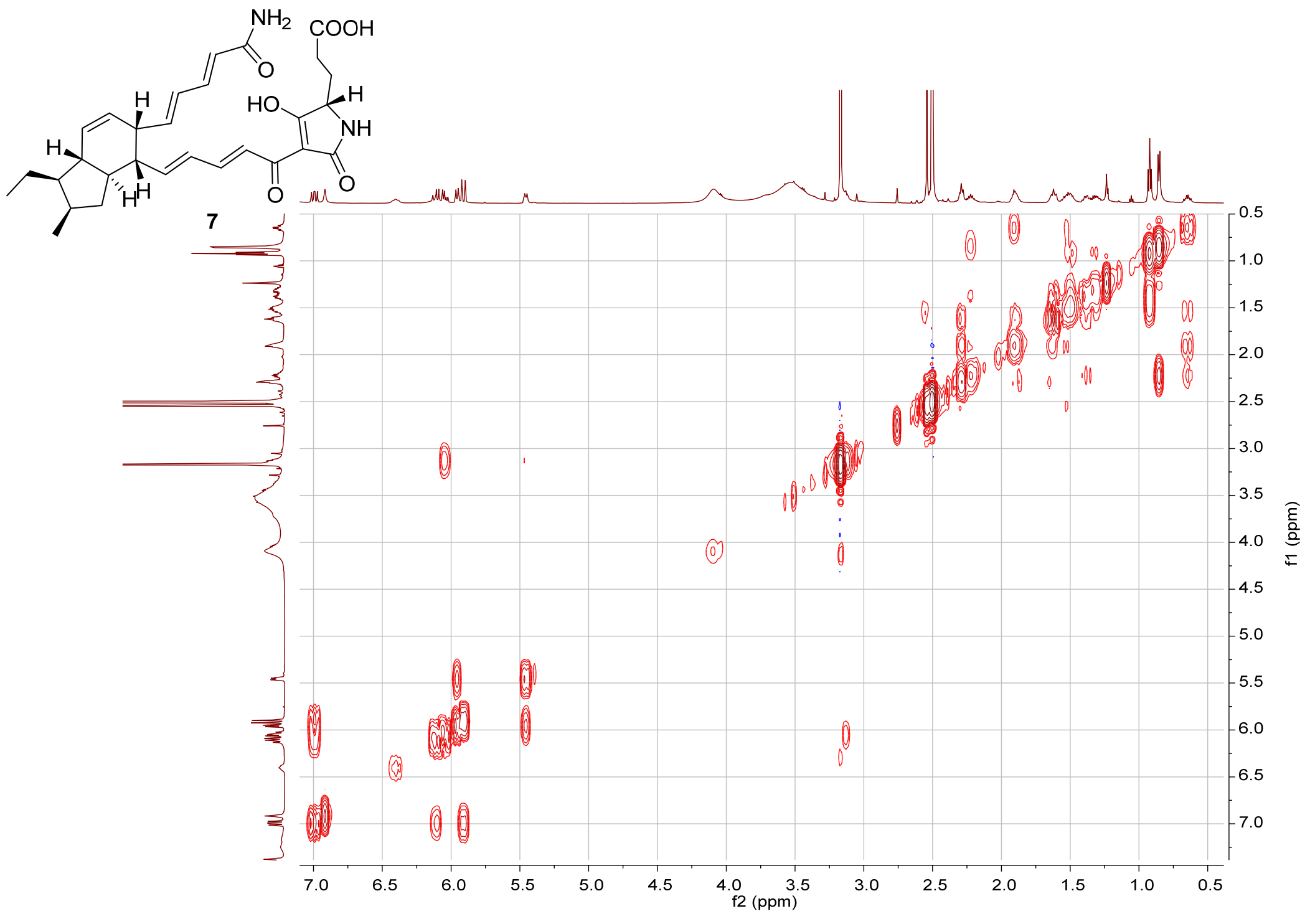

Figure S53. The ${ }^{1} \mathrm{H}-{ }^{-1} \mathrm{H}$ COSY spectrum of 7 in DMSO- $d_{6}$. 


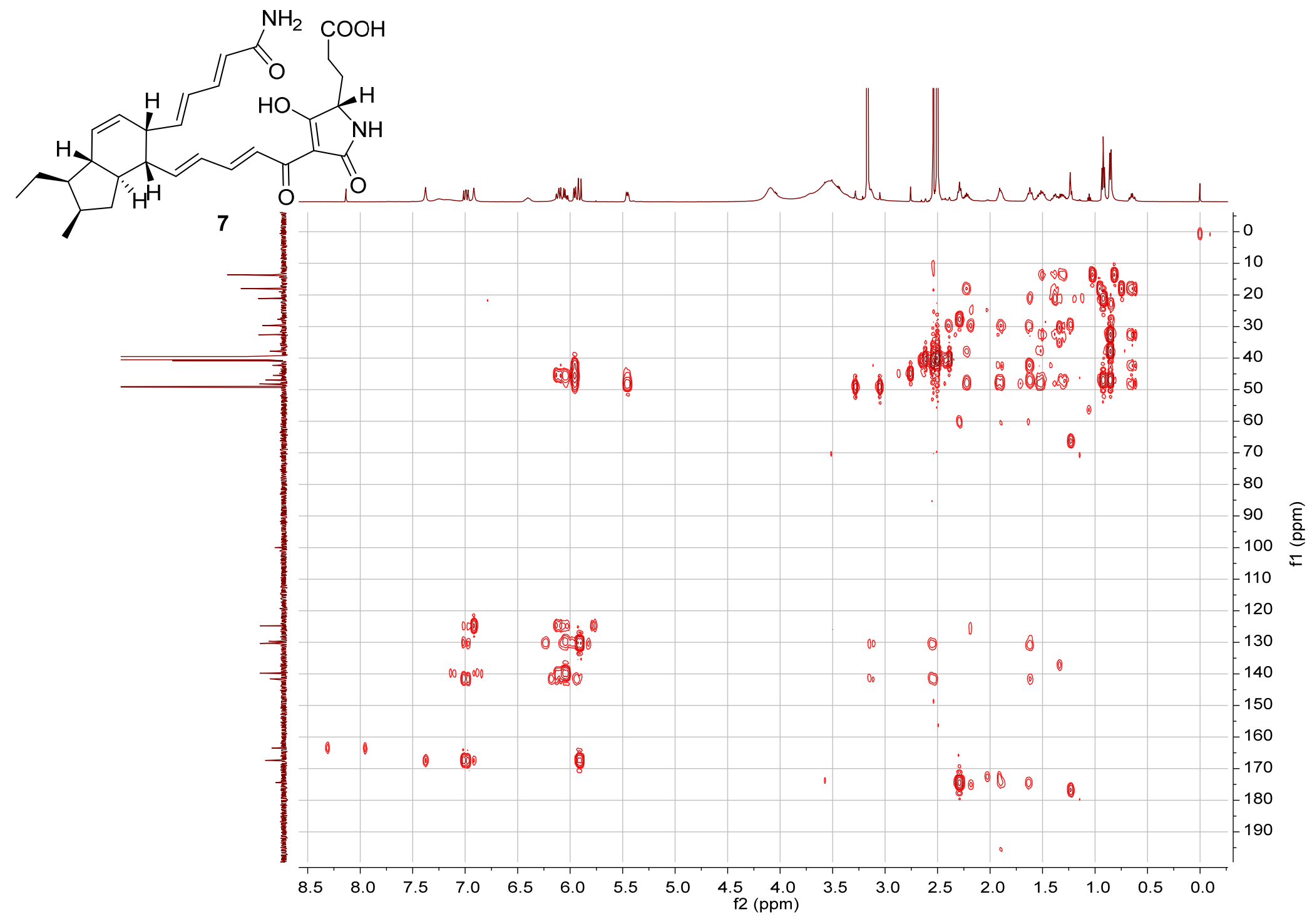

Figure S54. The HMBC spectrum of 7 in DMSO-d6. 


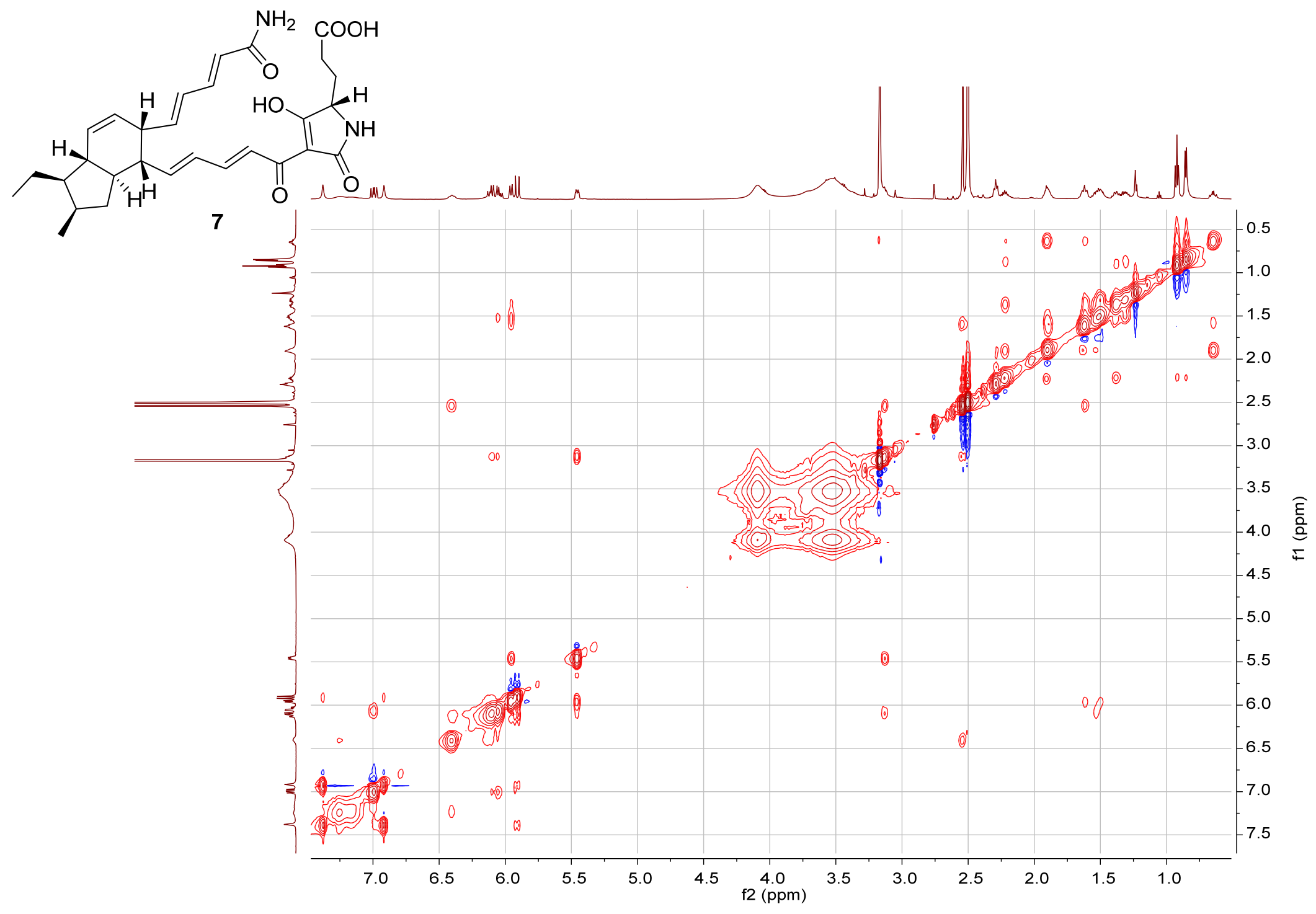

Figure S55. The NOESY spectrum of 7 in DMSO- $d_{6}$. 

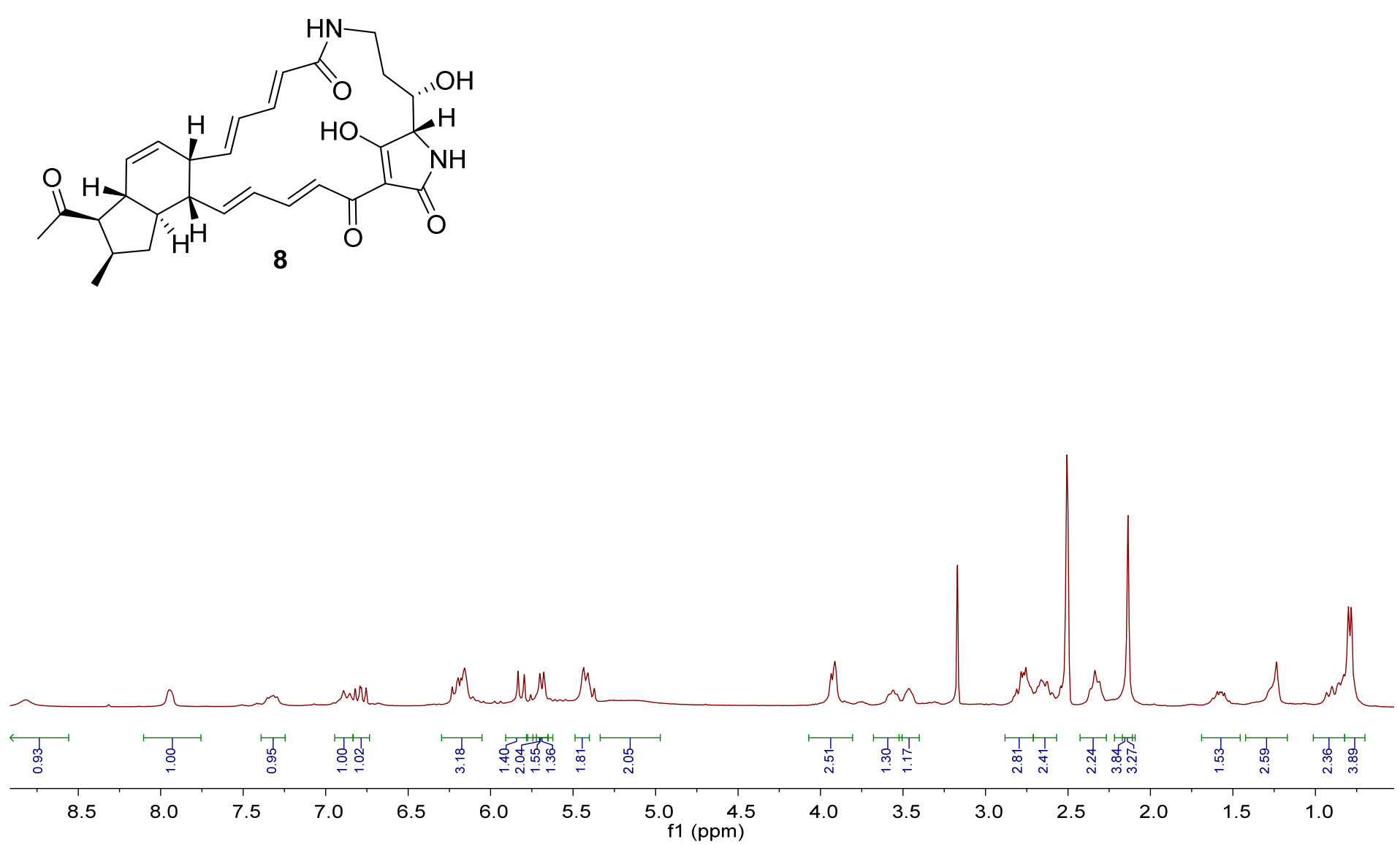

Figure S56. ${ }^{1} \mathrm{H}$ NMR spectrum of 8 in DMSO- $d_{6}$. 


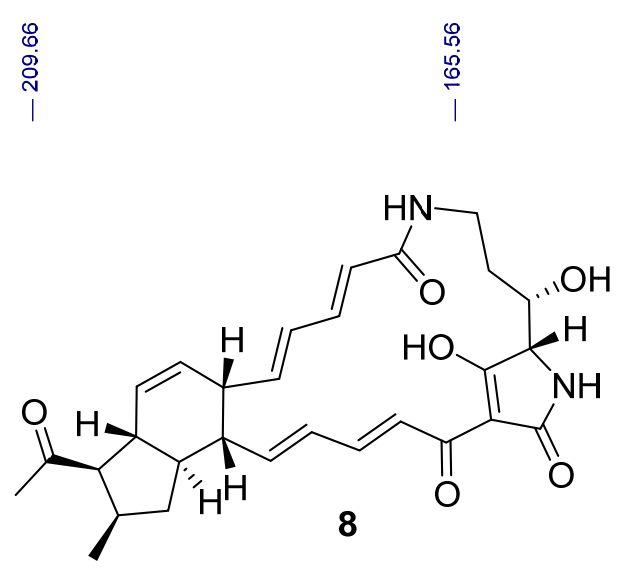

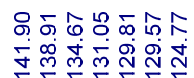

11 |रे।

$=\quad 8 \quad 8000$.

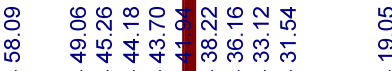

$1 \quad 1 \quad \sqrt{0}$
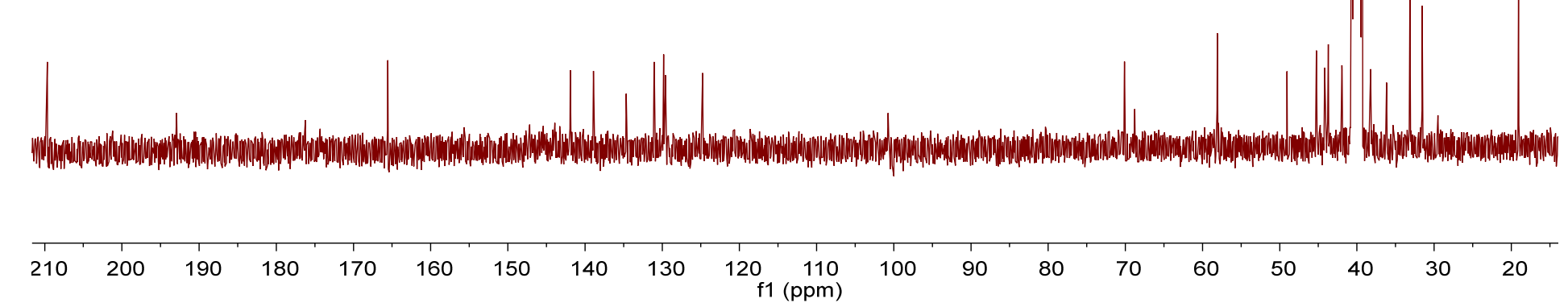

Figure S57. ${ }^{13} \mathrm{C}$ NMR spectrum of 8 in DMSO-d 6 . 


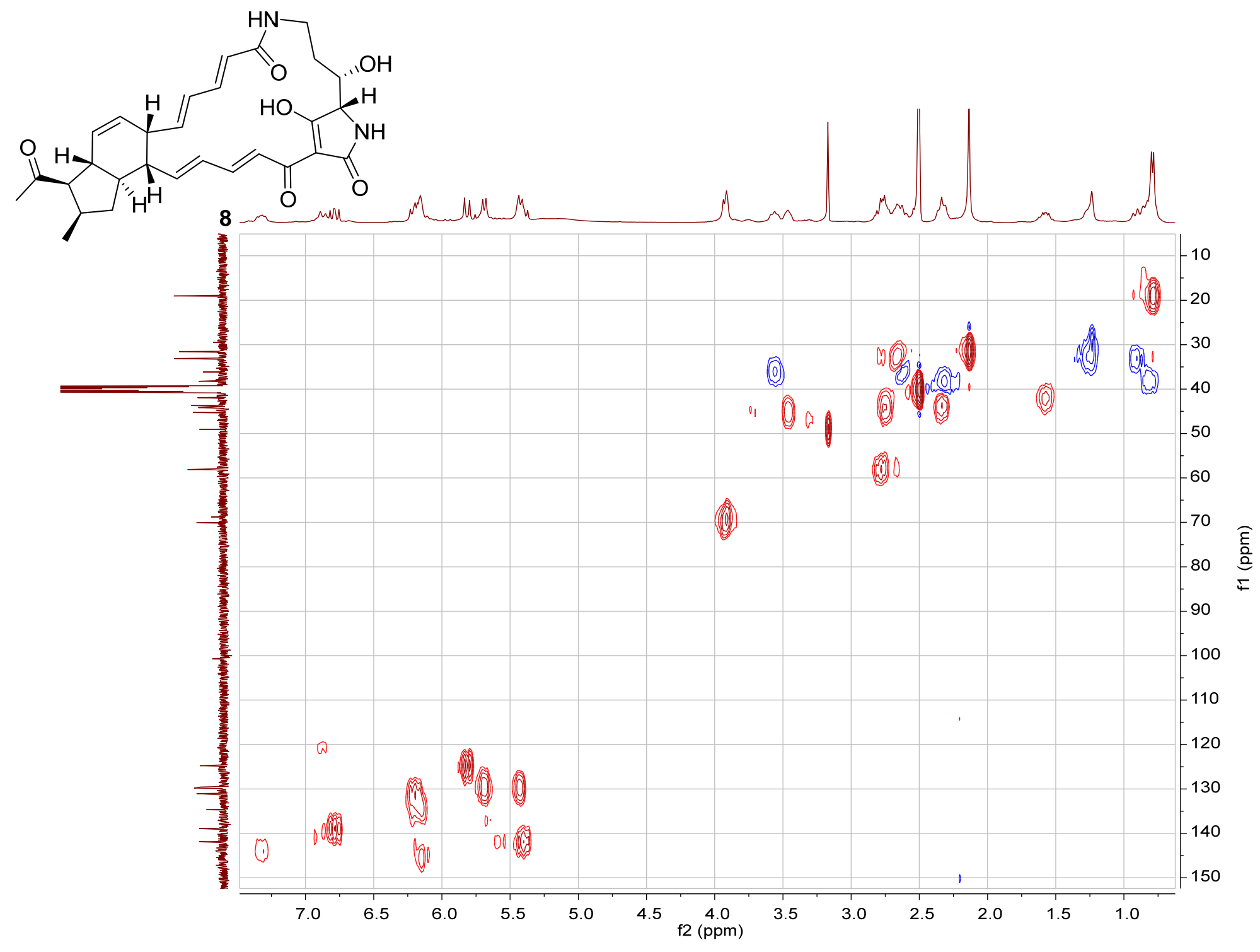

Figure S58. The HSQC spectrum of 8 in DMSO- $d_{6}$. 


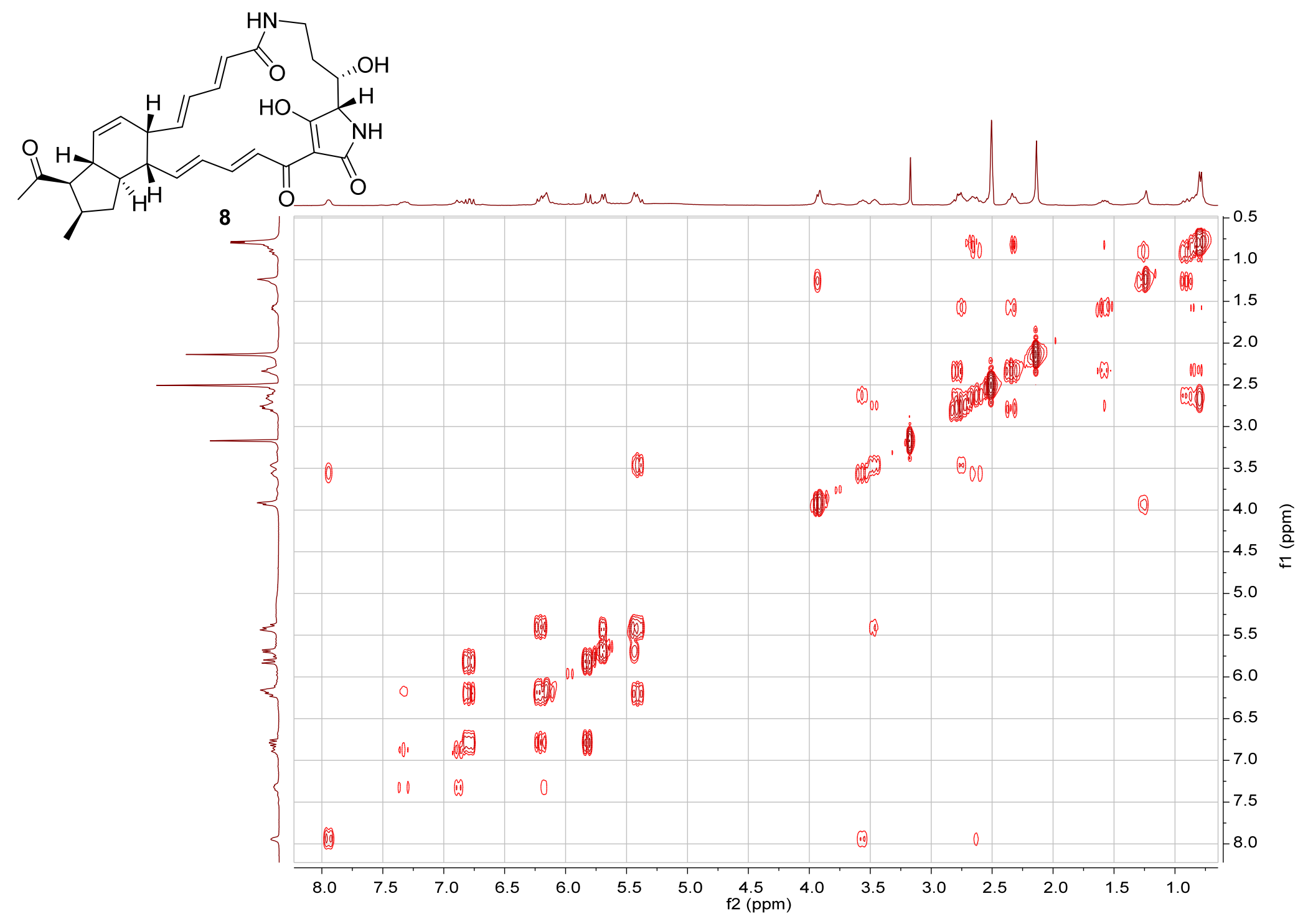

Figure S59. The ${ }^{1} \mathrm{H}-{ }^{-1} \mathrm{H}$ COSY spectrum of 8 in DMSO- $d_{6}$. 


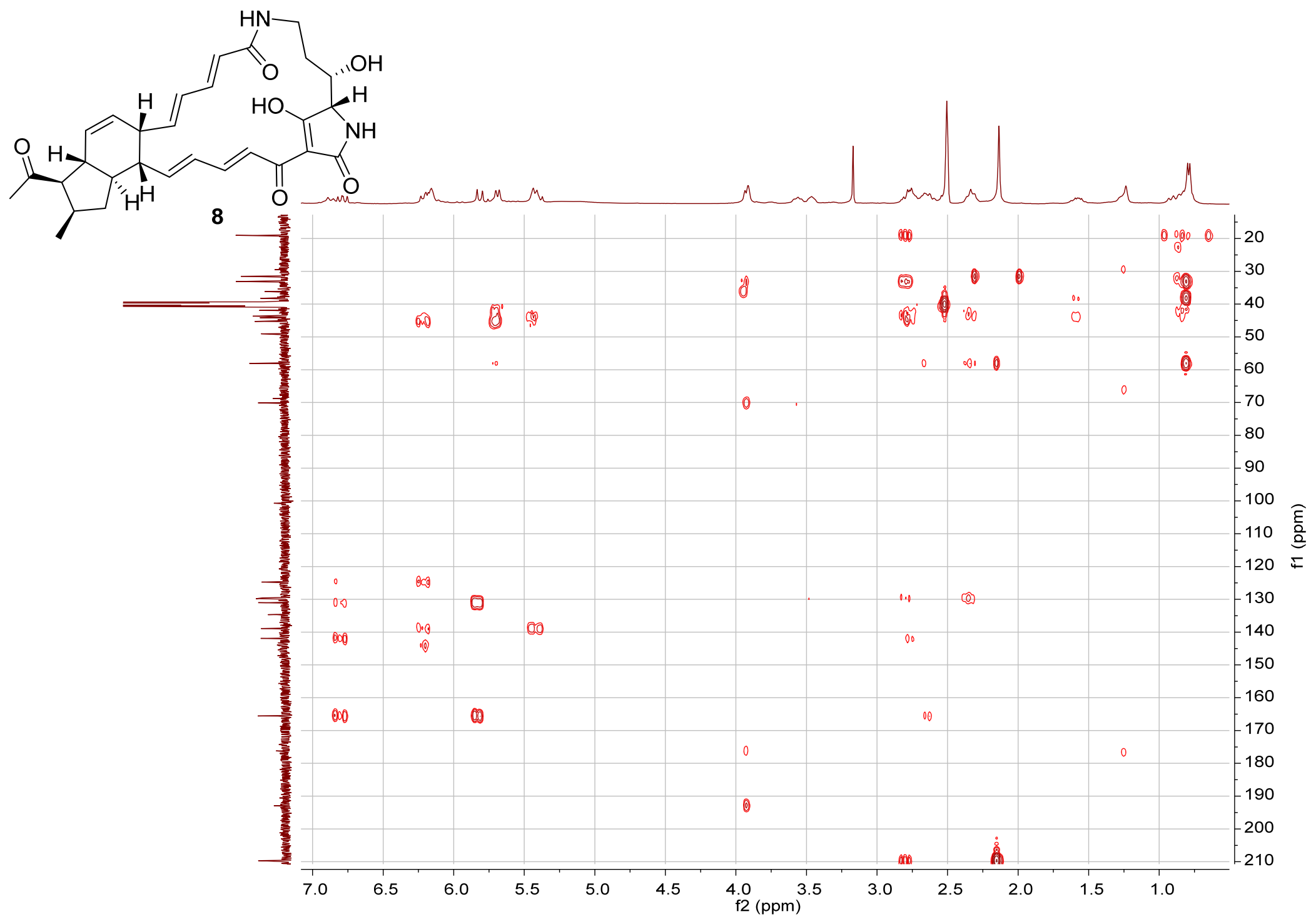

Figure $\mathbf{5 6 0}$. The HMBC spectrum of $\mathbf{8}$ in DMSO- $d_{6}$. 


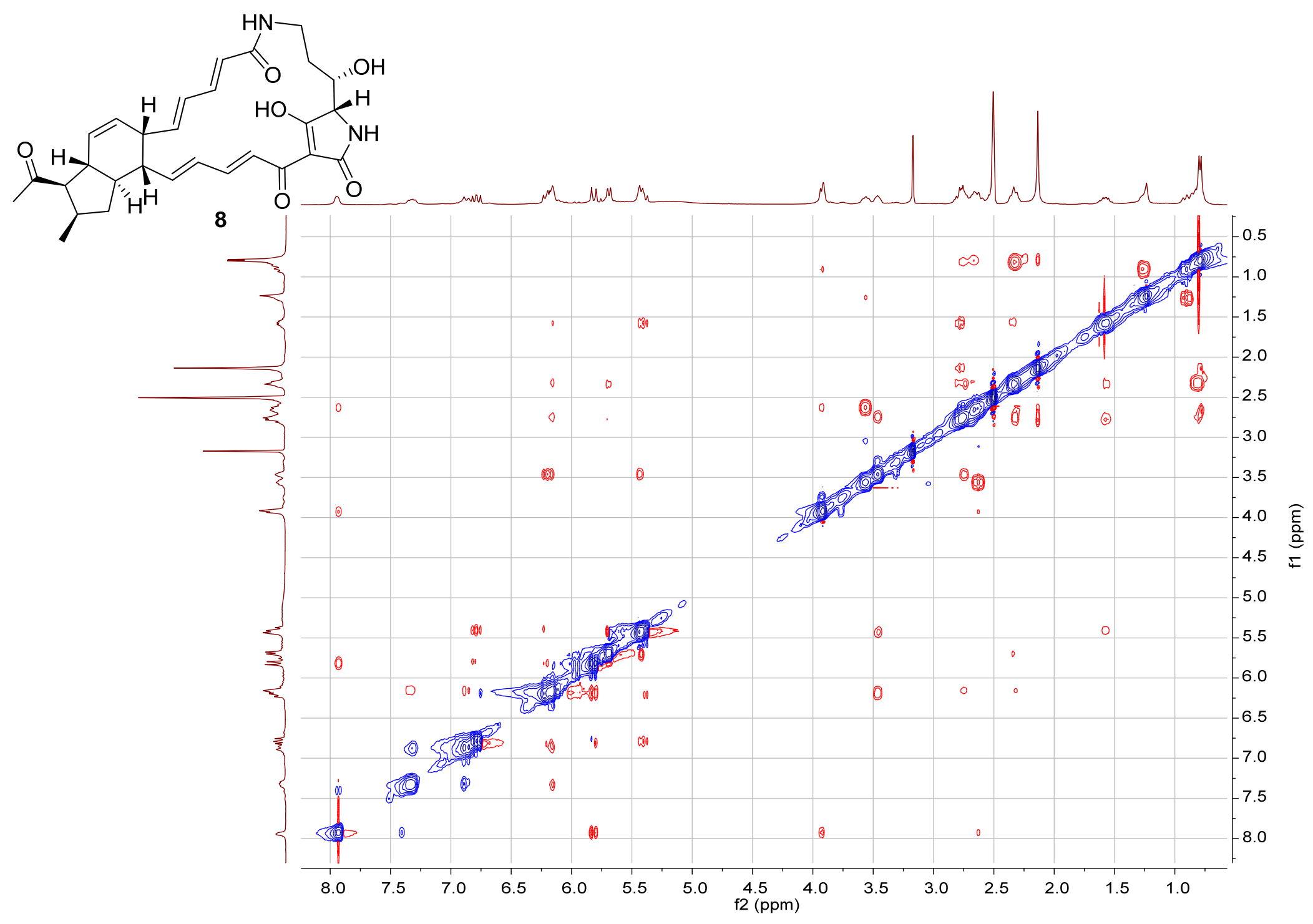

Figure S61. The NOESY spectrum of 8 in DMSO- $d_{6}$. 


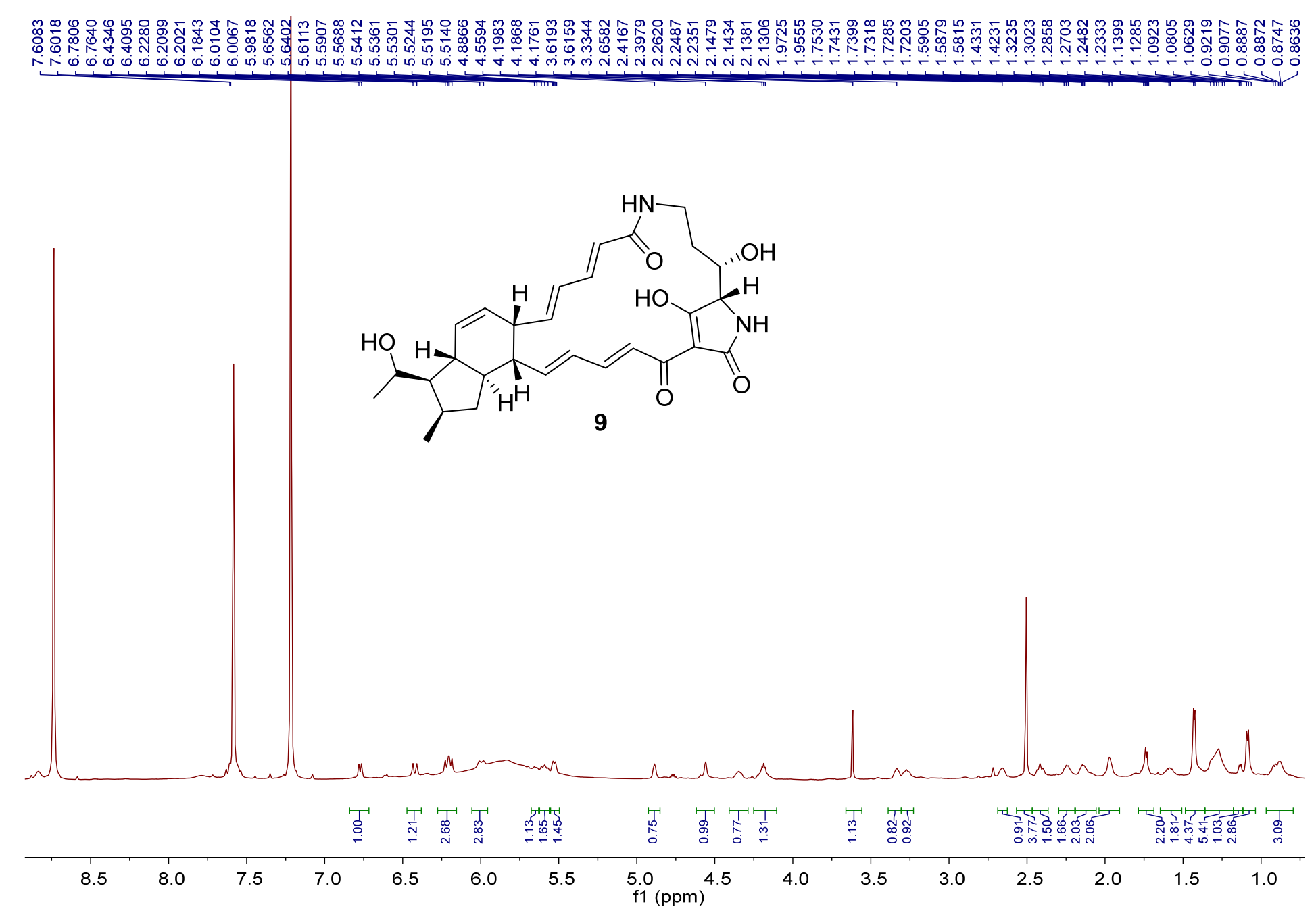

Figure S62. ${ }^{1} \mathrm{H}$ NMR spectrum of 9 in pyridine- $d_{5}$. 

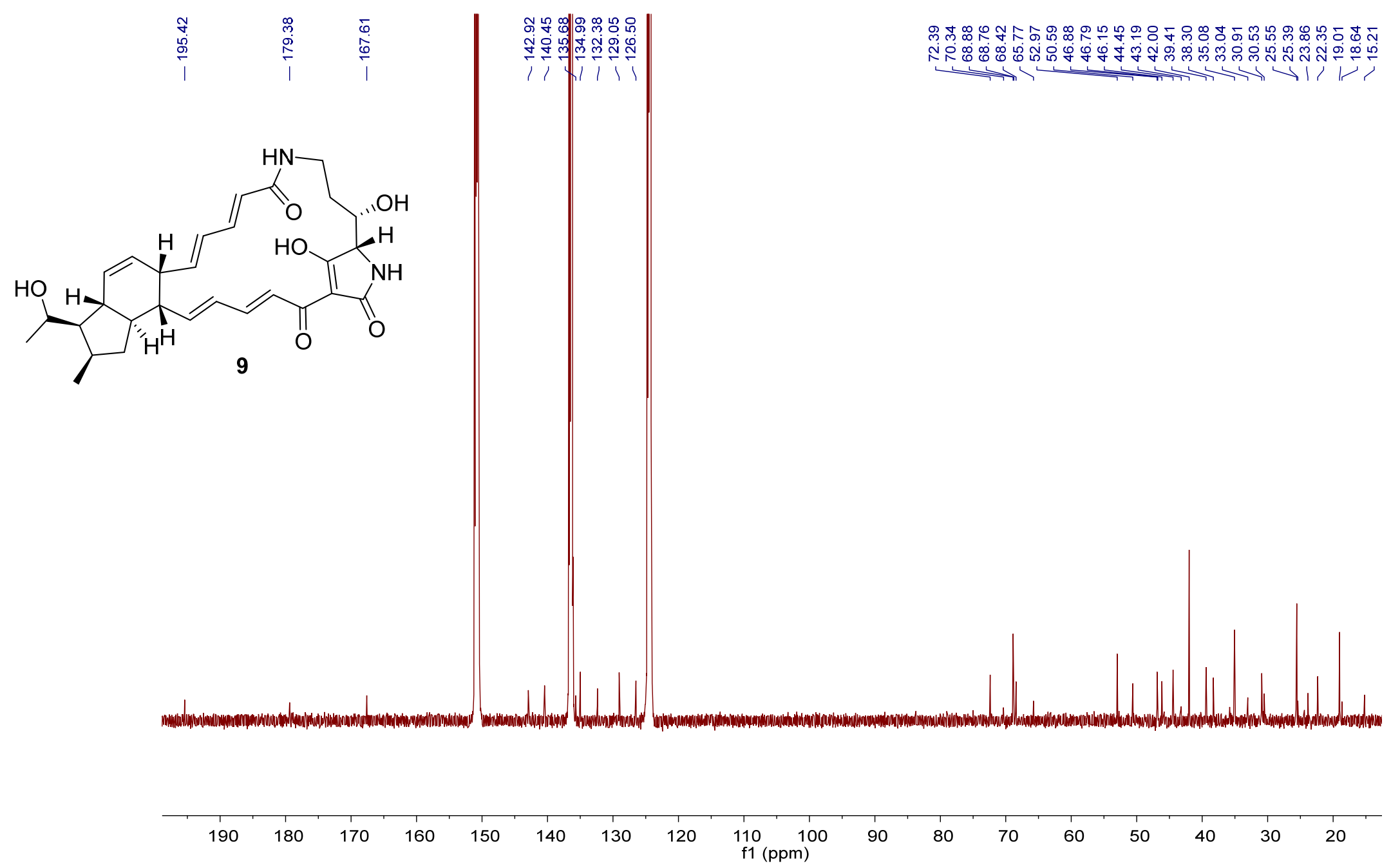

Figure S63. ${ }^{13} \mathrm{C}$ NMR spectrum of 9 in pyridine- $d_{5}$. 


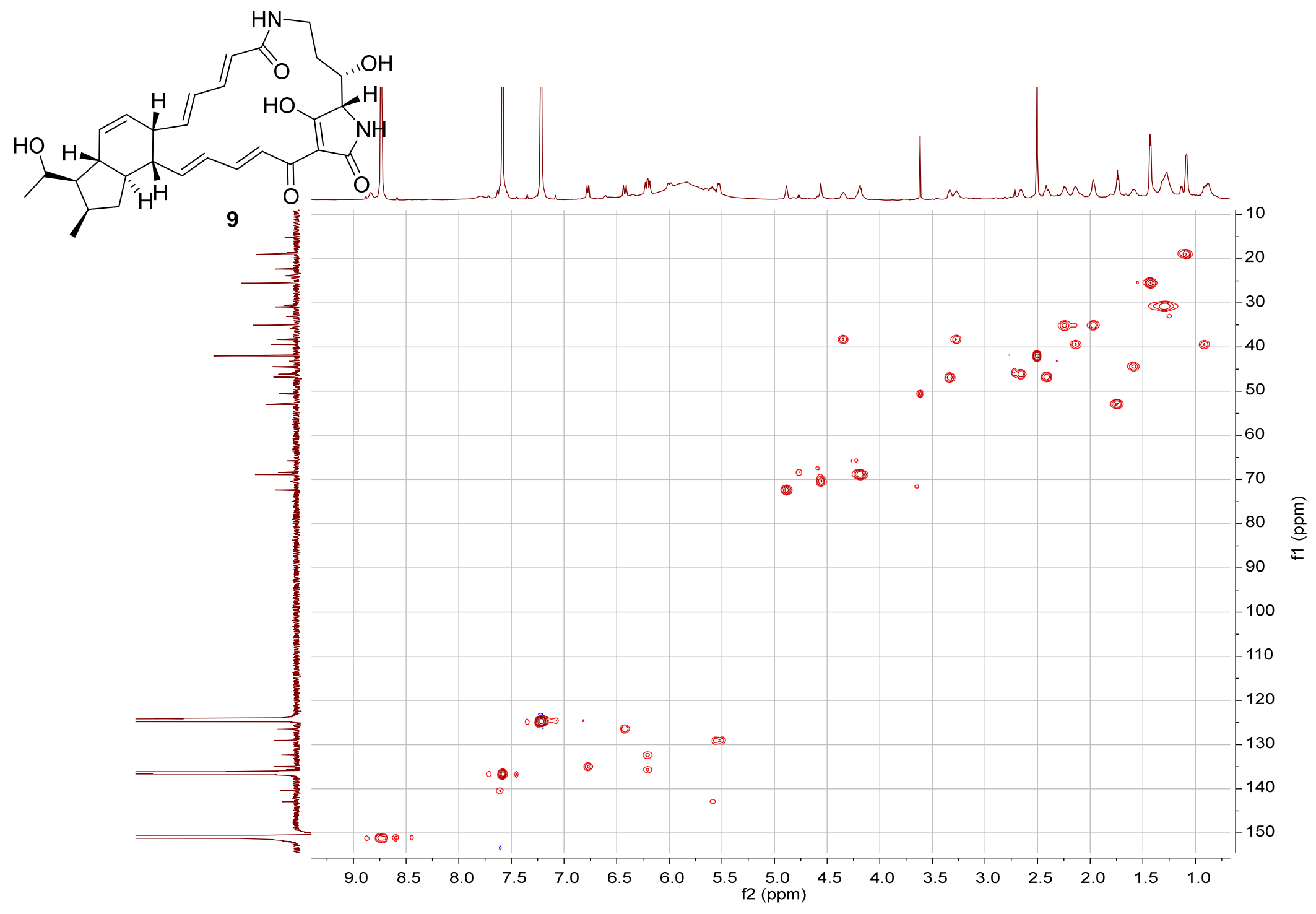

Figure S64. The HSQC spectrum of 9 in pyridine- $d_{5}$. 


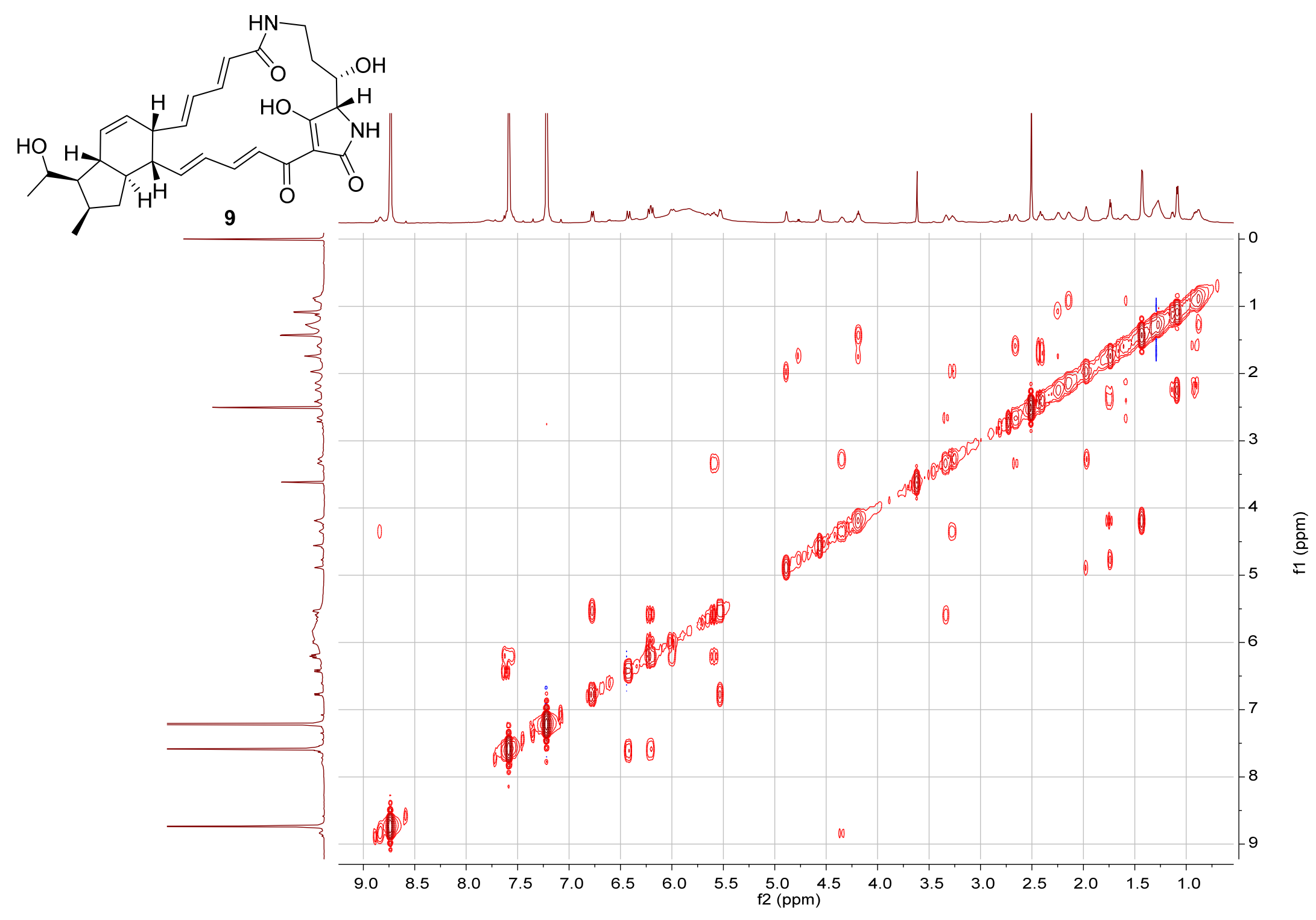

Figure S65. The ${ }^{1} \mathrm{H}-{ }^{1} \mathrm{H}$ COSY spectrum of 9 in pyridine- $d_{5}$. 


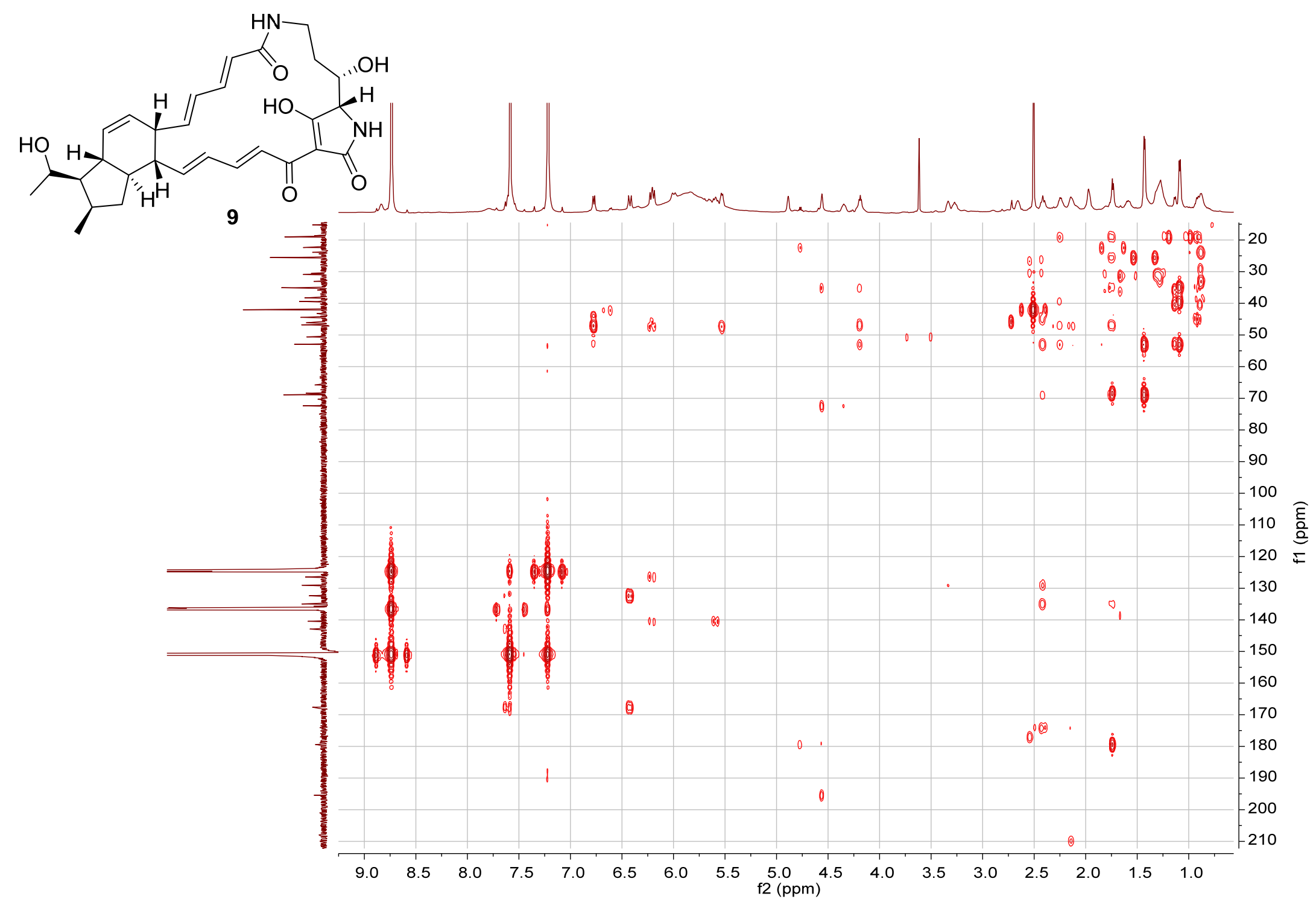

Figure S66. The HMBC spectrum of 9 in pyridine- $d_{5}$. 


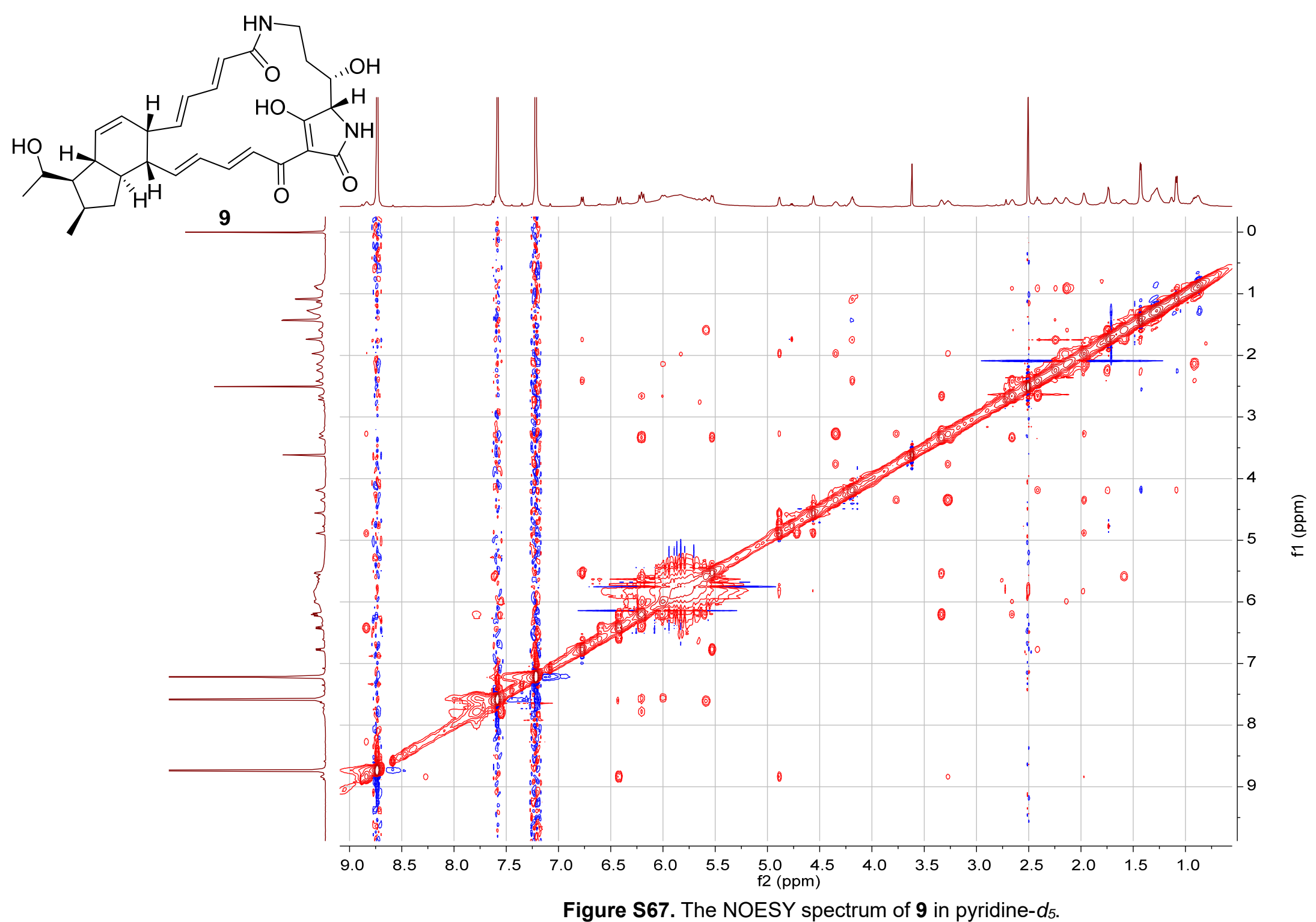

